JULIANA CRISTINA DE LIMA

\title{
EVIDÊNCIAS DE PROJECCÕES INDIRETAS DA SUBSTÂNCIA NEGRA COMPACTA PARA O NÚCLEO RETROTRAPEZÓIDE POR MEIO DA SUBSTÂNCIA CINZENTA PERIAQUEDUTAL E AS ALTERAÇÕES RESPIRATÓRIAS OBSERVADAS NESTA VIA EM UM MODELO DA DOENÇA DE PARKINSON
}

Tese apresentada ao Programa de PósGraduação em Farmacologia do Instituto de Ciências Biomédicas da Universidade de São Paulo, para obtenção do título de Doutora em farmacologia.

São Paulo 
JULIANA CRISTINA DE LIMA

\section{EVIDÊNCIAS DE PROJECÕES INDIRETAS DA SUBSTÂNCIA NEGRA COMPACTA PARA O NÚCLEO RETROTRAPEZÓIDE POR MEIO DA SUBSTÂNCIA CINZENTA PERIAQUEDUTAL E AS ALTERAÇÕES RESPIRATÓRIAS OBSERVADAS NESTA VIA EM UM MODELO DA DOENÇA DE PARKINSON}

Tese apresentada ao Programa de PósGraduação em Farmacologia do Instituto de Ciências Biomédicas da Universidade de São Paulo, para obtenção do título de Doutora em farmacologia.

Área de concentração: Farmacologia

Orientador: Prof(a) $\operatorname{Dr}(\mathrm{a})$. Ana Carolina Takakura

Versão original.

São Paulo

2017 


\section{CATALOGAÇÃO NA PUBLICAÇÃO (CIP) \\ Serviço de Biblioteca e informação Biomédica \\ do Instituto de Ciências Biomédicas da Universidade de São Paulo}

Ficha Catalográfica elaborada pelo(a) autor(a)

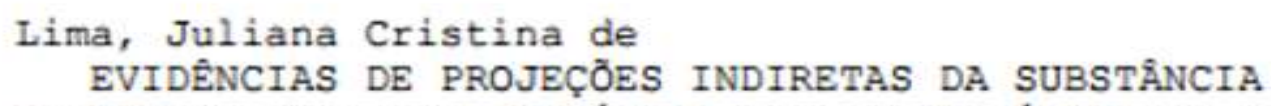

1. doença de Parkinson. 2. núcleo retrotrapezóide. 3. respiraçăo. 4. substância negra. 5. substância cinzenta periaquedutal. I. Takakura, Ana Carolina, orientador. II. Titulo. 
Candidato(a): Juliana Cristina de Lima

Título da Dissertação/Tese: Evidências de projeções indiretas da substância negra compacta para o núcleo retrotrapezóide por meio da substância cinzenta periaquedutal e as alterações respiratórias observadas nesta via em um modelo da doença de Parkinson.

Orientador: $\operatorname{Prof}(a) \operatorname{Dr}(a)$. Ana Carolina Takakura

A Comissão Julgadora dos trabalhos de Defesa da Dissertação de Mestrado/Tese de Doutorado, em sessão pública realizada a ............................., considerou o(a) candidato(a):

\section{( ) Aprovado(a) ( ) Reprovado(a)}

Examinador(a):

Assinatura:

Nome:

Instituição:

Examinador(a):

Assinatura:

Nome:

Instituição:

Examinador(a):

Assinatura:

Nome:

Instituição: 
Presidente:

Assinatura:

Nome:

Instituição: 


\section{Certificado}

Certificamos que o protocolo registrado sob n⿳ 99 nas fls. 22 do livto 03 para uso de animais em experimentaçă, sob a responsabilidade do Profia) Drial Ana Carolina Thomaz Takakura, Coondenador (a) da Linha de pesquisa "Propesóes anatomicas evistentes entre Substancia Negra e Nácleo Retrotrapezoide através da Substáncia Periaquedutal Cinzenta e participaçso da mesma no quimioreflexo central" do qual participam ois\} aluno(s\} Juliana Cristina de Lima, Pesquisador colaborador Thiago S. Moreira esta de acordo com os Principios Éticos de Experimentaçâo Animal adotado pela Soxiedade Brasileira de Ciencia de Animais de Laboratório (SBCAU e foi aprovado pela COMISSẢO DE ÉTICA NO USO DE. ANIMAIS (CEUA) em 28.08.2014, com validade de 4 anos.

Sto Paulo, 05 de setembro de 2014

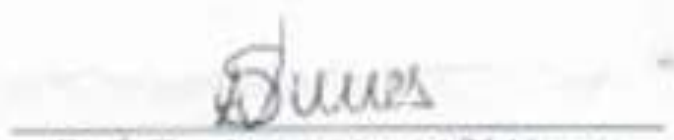

Prof. Dr. Andikson of SÁ Nunis Vice-Coordenador- CEUA-ICBNUSP

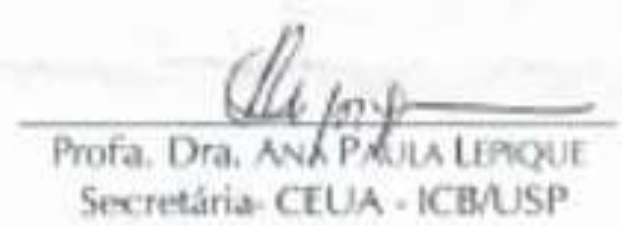


Dedico este trabalho à minha família, meus filhos Heitor e Pietro tudo que faço é por vocês, ao meu esposo Wellington, a minha amada mãe Ilma e ao meu pai Celso. 


\section{AGRADECIMENTOS}

Agradeço primeiramente a Deus por proteger a mim e aos que amo e direcionar os meus caminhos para que todos os passos deste projetos pudessem ser concluídos.

Grata à minha mãe Ilma Aparecida de São José a minha fortaleza, o meu porto seguro, sem você nada disso seria possível, obrigada por cuidar dos meus filhos na minha ausência, obrigada por acreditar em mim e no meu potencial e abdicar do seu sono e de suas tarefas para me ajudar a qualquer custo para que eu alcançasse o sucesso, você é a maior responsável por essa conquista, nunca poderei agradecer o suficiente.

Grata aos meus filhos Heitor e Pietro de Lima Silva, que são a razão do meu viver o meu bem maior, é por vocês que levanto todos os dias e enfrento o que for necessário, obrigada pela paciência nos momentos em que estive ausente e ocupada demais.

Grata ao meu esposo Wellington Silva pelo companheirismo, pelo incentivo e confiança na minha capacidade, por me dar todoo suporte necessário para que eu pudesse concluir esta etapa em minha vida.

Grata ao meu pai Celso Serafim de Lima por sempre acreditar em mim, por investir nos meus estudos sempre, me dando todo suporte financeiro e sentimental necessário para que eu evoluísse como profissional e como pessoa.

Serei eternamente grata à Profa. Dra. Ana Carolina Takakura, minha orientadora, que sempre foi um exemplo de competência e disciplina, que me mostrou que orientar um aluno vai muito além de ensinar conceitos teóricos e práticos, mas que engloba ser humano e afetuoso com o próximo, uma excelente profissional mas acima de tudo é uma excelente pessoa, compreensiva e muito justa, uma orientadora impecável, muito obrigada Ana!

Grata ao Prof. Dr. Thiago dos Santos Moreira, um profissional idôneo e competente naquilo que faz. Meus sinceros agradecimentos.

Grata aos minhas amigas Prof $^{a}$ Dr $^{a}$ Bárbara Falquetto e $\operatorname{Dr}^{\mathrm{a}}$ Talita de Mello que fizeram esta minha jornada muito mais leve e feliz, alegravam meus dias, me ajudavam e apoiavam nas fases mais difíceis deste projeto, e de forma especial quero agradecer ao meu amigo Luiz 
Marcelo de Oliveira que colaborou de forma muito importante no desenvolvimento deste projeto, obrigada Luiz!

Grata aos professores, técnicos e funcionários do Departamento de Farmacologia. Em especial: Fabiane, Mônica e Camila.

Grata aos animais, que foram essenciais para a execução deste trabalho, eles são a base de diversos avanços na ciência, à eles todo meu respeito.

Grata à Universidade de São Paulo, ao Instituto de Ciências Biomédicas e ao Departamento de Farmacologia por cederem o espaço para que este trabalho fosse realizado. Não há palavras que descrevam o quanto foi importante pra mim, ter a oportunidade de estar aqui, colaborando com o avanço da ciência e poder progredir cientificamente. 


\section{AGRADECIMENTOS}

Agradeço em especial às agências de fomento FAPESP, CAPES e CNPq pelo suporte financeiro que viabilizou a execução deste estudo. 
"Você nunca alcança o sucesso verdadeiro a menos que você goste do que está fazendo.

Dale Carnegie 


\section{RESUMO}

LIMA, J. C. Evidências de projeções indiretas da substância negra compacta para o núcleo retrotrapezóide por meio da substância cinzenta periaquedutal e as alterações observadas nesta via em um modelo da Doença de Parkinson. 2017. 85 f. Dissertação (Doutorado em Farmacologia) - Instituto de Ciências Biomédicas, Universidade de São Paulo, São Paulo, 2017.

A doença de Parkinson (DP) é uma desordem neurodegenerativa caracterizada clinicamente por tremor, rigidez, acinesia (ou bradicinesia) e instabilidade postural. Patofisiologicamente, a DP é classificada como uma sinucleinopatia associada à perda de neurônios dopaminérgicos na substância negra (SN), mas outros neurônios do tronco encefálico podem estar degenerados na DP, contribuindo não só para as alterações motoras, mas também não motoras observadas. Dentre as alterações não motoras, as alterações respiratórias estão presentes tais como obstrução das vias aéreas superiores, pneumonia e ainda a apnéia obstrutiva do sono uma das principais causas de morte na DP. Os mecanismos que levam à degeneração de neurônios envolvidos no controle respiratório ainda não estão bem esclarecidos, mas dados recentes do nosso laboratório mostraram que no modelo de DP induzido pela injeção no caudado-putâmen (CPu) de 6-hidroxidopamina (6-OHDA), um agente neurotóxico seletivo para células catecolaminérgicas, observou-se intensa redução na frequência respiratória e ventilação basais e induzidas pela ativação do quimiorreflexo central por hipercapnia. Além disso, observou-se também intensa redução do número de neurônios bulbares envolvidos no controle neural da respiração, como os neurônios Phox $2 b^{+}$da região do núcleo retrotrapezóide (RTN), que estão envolvidos com a inspiração e o quimiorreflexo central. Dessa forma, o objetivo do presente trabalho foi investigar se a existência de uma via entre os neurônios da SN e do RTN poderia ser responsável por essa neurodegeneração. Realizamos injeções de traçadores anterógrados e retrógrados na SN e no RTN de ratos para verificar a existência de projeções diretas entre essas regiões, entretanto observamos que não há projeções diretas entre a SN e o RTN, mas há projeções indiretas entre essas duas regiões, utilizando a Substância Cinzenta Periaquedutal (PAG) como região intermediária. Além disso, observamos que no modelo de DP induzido pela injeção bilateral de 6OHDA no CPu ocorre uma redução no número de varicosidades catecolaminérgicas na PAG e de neurônios que são ativados pelo quimiorreflexo central que se projetam da PAG para o RTN. Nossos experimentos eletrofisiológicos mostraram que a inibição bilateral da PAG pela injeção de muscimol não gera alterações respiratórias basais como ocorre no modelo da DP; entretanto, nesses animais, pudemos também observar, apesar de ser menor do que ocorre com animais submetidos ao modelo da DP, inibição de alterações respiratórias induzidas por hipercapnia. Nossos dados anatômicos mostraram que a comunicação entre os neurônios da SN e do RTN envolve neurônios da PAG e que essa via pode estar reduzida no modelo da DP, o que pode contribuir para a redução de neurônios do RTN; e que a redução neuronal desta via pode alterar as respostas respiratórias frente à ativação do quimiorreflexo central.

Palavras- Chave: Substância negra. Núcleo retrotrapezóide. Respiração. Substância cinzenta periaquedutal. Doença de Parkinson. 


\begin{abstract}
LIMA, J. C. Evidence of indirect projections of the substantia nigra to the retrotrapezoid nucleus through the periaqueductal gray matter and the changes observed in this pathway in a model of Parkinson's disease. 2017. 85 p. Dissertation (Doctorate in Pharmacology) - Instituto de Ciências Biomédicas, Universidade de São Paulo, São Paulo, 2017.

Parkinson's disease (PD) is a neurodegenerative disorder characterized clinically by tremor, rigidity, akinesia (or bradykinesia) and postural instability. Pathophysiologically, PD is classified as a synucleinopathy predominantly associated with loss of dopaminergic neurons in the substantia nigra (SN), but other brainstem neurons may also be degenerate in PD, contributing not only to the motor but also nonmotor alterations observed in this pathology. Among the non-motor changes observed respiratory changes are present and can be characterized as upper airway obstruction, pneumonia and obstructive sleep apnea are one of the main causes of death in PD. The mechanisms that lead to the degeneration of neurons involved in respiratory control are still not well understood but data in the literature have demonstrated the loss of receptors in a region considered to be the respiratory rate generator in postmortem brains of humans. In the model animal DP of 6-hydroxydopamine (6OHDA), a selective neurotoxic agent for catecholaminergic cells, there was an intense reduction in basal respiratory rate and ventilation, in addition to a intense reduction of neurons involved in neural control of breathing: Phox $2 b+$ neurons in the retrotrapezoid nucleus (RTN) region. Thus, the aim of the present study was to investigate whether the existence of a pathway between SN and RTN neurons could be responsible for this bulbar neurodegeneration. We performed experiments using the injection of anterograde and retrograde tracers in the SN and the RTN to verify the existence of direct projections between these regions in rats. However, our results showed that there are no direct projections between the SN and the RTN, but there are indirect projections between these two regions, using Periaquedutal Gray Substance (PAG) as the intermediate region. In addition, we observed that in the PD model induced by the bilateral injection of 6-OHDA in $\mathrm{CPu}$, a reduction of the projections PAG neurons for RTN and that are activated by the central chemoreflex. Our electrophysiological experiments have shown that in the 6-OHDA PD model there is a reduction of the cardiorespiratory responses induced by the activation of the central chemoreflex, since the bilateral inhibition of the PG of control animals does not alter these cardiorespiratory responses. Therefore, our anatomical results showed that the communication between SN and RTN neurons involves PAG neurons and that this pathway may be reduced in the PD model, which may contribute to the reduction of RTN neurons; and that the neuronal reduction of this pathway may alter respiratory responses to activation of the central chemoreflex.
\end{abstract}

Keywords: Substantia nigra. Retrotrapezoid nucleus. Respiration. Periaqueductal grey. Parkinson's disease. 


\section{LISTA DE ILUSTRAÇÕES}

Figura 1 - Fotomicrografia de um corte sagital de encéfalo de rato com representação esquemática da localização da coluna respiratória ventral e dorsal

Figura 2 - Esquema representativo dos efeitos da estimulação da PAG pela injeção de

DLH em neurônios pré-inspiratórios do pre-BötC.

Figura 3 - Fotomicrografias mostrando os efeitos da injeção bilateral de veículo ou 6OHDA $(24 \mu \mathrm{g} / \mu \mathrm{l})$ no $\mathrm{CPu}$

Figura 4 - Esquema representativo dos protocolos experimentais propostos. 32

Figura 5 - Esquema representativo de experimentos funcionais.

Figura 6 - Local das injeções na SN e RTN.

Figura 7 - Projeções da SN para a substância cinzenta periaquedutal (PAG): traçador anterógrado

Figura 8 - Projeções da SN para a substância cinzenta periaquedutal (PAG): traçador retrógrado

Figura 9 - Projeções da PAG para o RTN: traçador retrógrado

Figura 10 - Projeções da PAG para o RTN: traçador anterógrado 50

Figura 11 - Projeções indiretas da SN para o RTN, envolvendo a PAG 51

Figura 12 - Alterações respiratórias observadas em um modelo animal de DP induzido pela injeção bilateral de 6-OHDA no CPu

Figura 13 - Redução na densidade de neurônios que expressam NeuN e no número de varicosidades catecolaminérgicas na PAG num modelo experimental de DP. 55

Figura 14 - A injeção bilateral de 6-OHDA no CPu leva à redução de neurônios $\mathrm{TH}+$ na SN.

Figura 15 - A injeção bilateral de 6-OHDA no $\mathrm{CPu}$ leva à redução no número de projeções da PAG para o RTN que são ativadas por hipercapnia ............................. 59

Figura 16 - Injeção bilateral do agonista gabaérgico muscimol na PAG 60

Figura 17 - Respostas respiratórias basais ou produzidas por hipercapnia em animais que receberam injeção de veículo ou muscimol na PAG ou em animais submetidos ao modelo da DP

Figura 18 - Respostas respiratórias produzidas pela injeção endovenosa de KCN em animais que receberam injeção de veículo ou muscimol na PAG ou em animais submetidos ao modelo da DP. 
Figura 19 - Esquema representativo de projeções entre SN e RTN por meio da PAG e alterações na citoarquitetura neuronal desta via no modelo animal da DP induzido pela injeção de 6-OHDA. 


\section{LISTA DE TABELAS}

Tabela 1 - Informações a respeito dos anticorpos utilizados nos protocolos de histoquímica

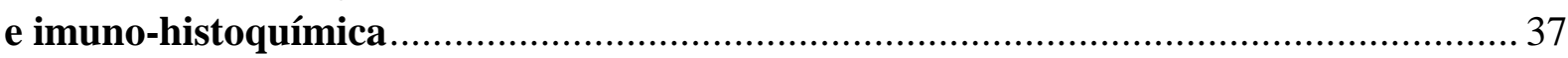




\section{LISTA DE ABREVIATURAS E SIGLAS}

\begin{tabular}{|c|c|}
\hline AbdEMG & Eletromiografia do abdominal \\
\hline BötC & Complexo de Bötzinger \\
\hline $\mathrm{CO}_{2}$ & Dióxido de carbono \\
\hline $\mathrm{CPu}$ & Caudado e Putâmen \\
\hline CRV & Coluna respiratória ventral \\
\hline cVRG & Grupamento respiratório ventral caudal \\
\hline DiaEMG & Eletromiografia do diafragma \\
\hline DP & Doença de Parkinson \\
\hline FG & Fluorogold \\
\hline $\mathrm{KCN}$ & Cianeto de potássio \\
\hline $\mathrm{Mn}$ & Motoneurônio \\
\hline OHDA & Hidroxidopamina \\
\hline PA & Pressão arterial \\
\hline $\mathrm{pCO}_{2}$ & Pressão parcial de $\mathrm{CO}_{2}$ \\
\hline PAG & Substância Cinzenta periaquedutal \\
\hline PAP & Pressão arterial pulsátil \\
\hline
\end{tabular}


PEEP Pressão positiva expiratória de saída

pFRG Grupamento respiratório parafacial

$\mathrm{pO}_{2} \quad$ Pressão parcial de $\mathrm{O}_{2}$

pre-BötC Complexo de pre-Bötzinger

RTN Núcleo retrotrapezóide

Rvrg Grupamento respiratório ventral rostral

SNC Sistema nervoso central

SN Substância Negra

TH Tirosina hidroxilase 


\section{SUMÁRIO}

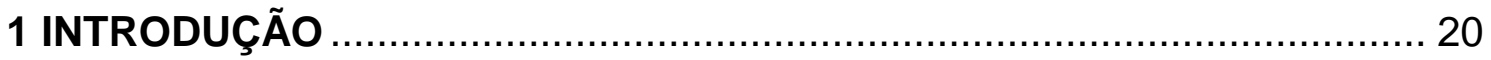

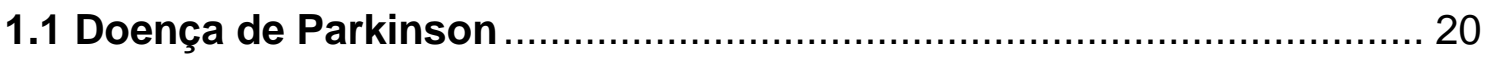

1.2 Modelo experimental da indução da doença de Parkinson 6-OHDA ..22

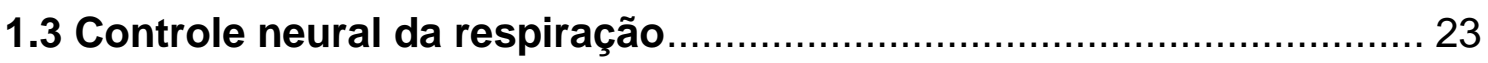

1.4 Alterações respiratórias associadas a doença de Parkinson .......27Erro! Indicador não definido.

2 OBJETIVOS

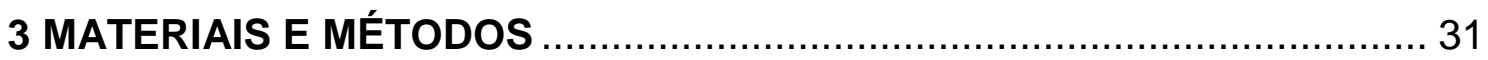

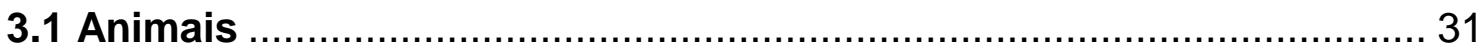

3.2 Procedimentos cirúrgicos: estereotaxia ………............................... 31

3.3 Medida de ventilação pulmonar ...................................................

3.4 Hipercapnia

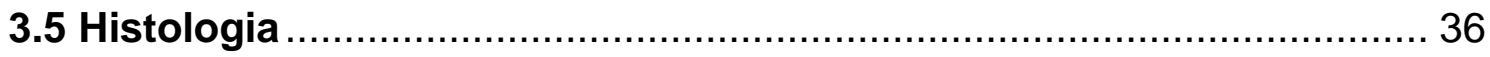

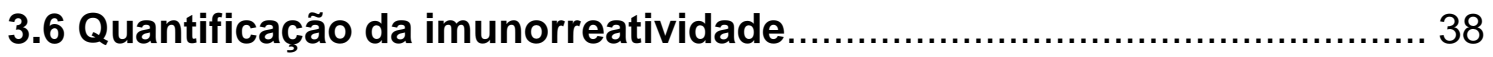

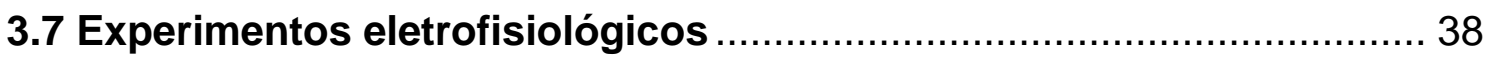

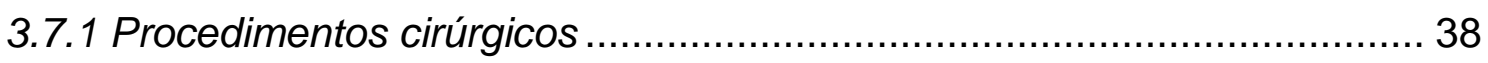

3.7.2 Registro de pressão arterial .............................................................. 40

3.7.3 Eletromiografia dos músculos respiratórios ......................................... 40

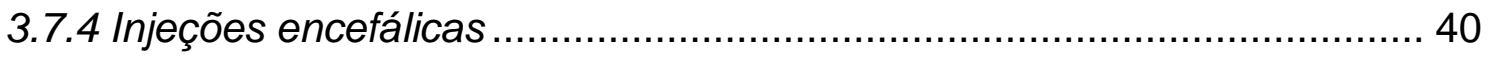

3.7.5 Ativação do quimiorreflexo central e periférico ...................................... 41

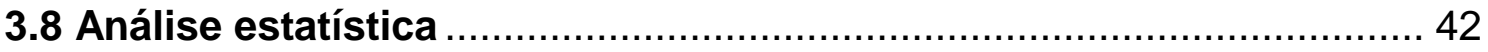

4 RESULTADOS

4.1 Estudo neuroanatômico de animais controles ................................. 43

4.1.1 Avaliação de projeções diretas da SN para o RTN ……………............. 43 
4.1.2 Avaliação de projeções indiretas da $S N$ para o $R T N$, envolvendo a PAG.

4.1.2.1 Avaliacão de projecões diretas da SN para a PAG 45

4.1.2.2 Projecões diretas da PAG para o RTN 48

4.1.2.3 Avaliacões de projecões da SN para os neurônios da PAG e destes para o RTN: tracador anterógrado e retrógrado 51

4.2 Estudo neuroanatômico na PAG em animais submetidos ao modelo da DP induzido pela injeção bilateral de 6-OHDA no CPu 52

4.2.1 Efeitos da injeção de 6-OHDA no CPu na imunorreatividade para TH de corpos celulares na SN e de varicosidades na região da PAG e para NeuN na região da $P A G$. 52

4.2.2 Alterações no número de neurônios da PAG que se projetam para o RTN e são ativados por hipercapnia observadas no modelo da DP induzido pela injeção de 6-OHDA no CPu..... 56

4.3 Estudo funcional em animais controles ou no modelo da DP 60

4.3.1 Efeitos da inibição da PAG ou injeção de 6-OHDA na CPu nas respostas respiratórias basais e induzidas pela ativação do quimiorreflexo central ou periférico.

5 DISCUSSÃO 65

5.1 Eferências da SNc 65

5.2 Aferências e eferências da PAG 67

5.3 RTN e a respiração 69

5.4 PAG e o quimiorreflexo. 70

5.5 DP e a respiração 71

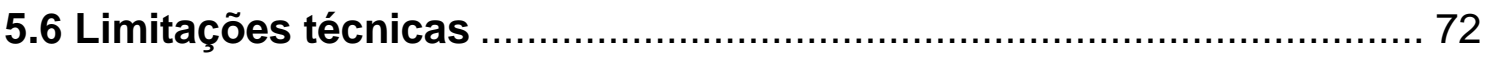

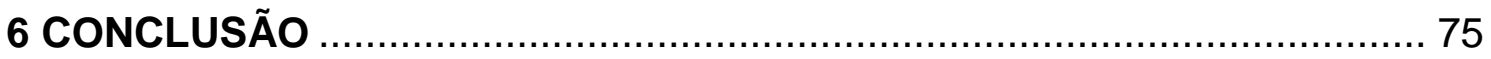

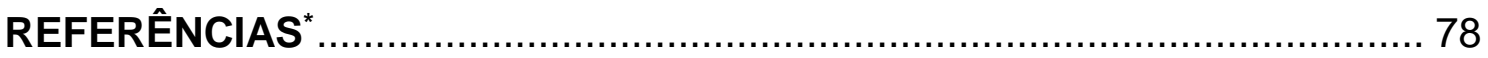




\section{INTRODUÇÃO}

\subsection{Doença de Parkinson}

A doença de Parkinson (DP) foi descrita pela primeira vez por James Parkinson, médico inglês em 1817 (revisado por BLUM et al., 2001; PARKINSON, 1817). Um século depois, estudos mostraram que fisiopatologicamente a doença estava relacionada à: 1) perda neuronal progressiva no grupo de células ventrolaterais da substância negra (SN) em sua porção compacta $(\mathrm{SNc})$ ao nível do mesencéfalo, com subseqüente disfunção dopaminérgica na via nigroestriatal e 2) formação de corpúsculos de Lewy, que são agregados proteicos de alfa-sinucleína presentes também em outras desordens neurodegenerativas (SPILLATINI et al.,1998; TRETIAKOFF, 1919).

Apesar dos inúmeros progressos obtidos na pesquisa da DP, a sua etiopatogenia ainda permanece obscura. Atualmente, algumas hipóteses têm sido estudadas para tentar elucidar o mecanismo que leva à morte neuronal na DP. Alguns exemplos são:

\section{A) Formação de corpúsculos de Lewy por aumento do estresse oxidativo:} na DP são observadas na SN redução da ferritina uma importante enzima responsável pela degradação do ferro. Com isso, observa-se aumento nas concentrações de ferro nesta região, podendo gerar estresse oxidativo pela produção de radicais livres. Portanto, os estudos têm relacionado a diminuição da ferritina ao aumento do estresse oxidativo e à presença de corpúsculos de Lewy (DEXTER et al., 1989; HIRSCH et al., 1991).

B) Formação de radicais livres: o excesso da produção de radicais livres pode levar ao aumento do estresse oxidativo, como dito anteriormente, e à ativação de mecanismos apoptóticos. Na DP, a peroxidação lipídica está aumentada na $\mathrm{SN}$, o que sugere um aumento na produção de radicais livres (DEXTER et al., 1989). Além disso, são observadas reduções na concentração de importantes enzimas desintoxicantes como a superóxido-desmutase mitocondrial e a glutationa-peroxidase glial (MARTILLA et al., 1990; NORDERA et al., 2016). Existem também outros fatores, como a própria degradação da dopamina pela monoaminaoxidase (MAO) e a síntese de melanina pela SN, que colaboram para a formação de radicais livres (HIRSCH et al., 1988). 
C) Rompimento da barreira hematoencefálica (BHE): estudos recentes têm demonstrado que a BHE pode estar rompida na DP (KORTEKAAS et al., 2005; LEE; PIENNAR, 2014). A integridade da BHE permite uma fina regulação nos movimentos iônicos, moleculares e de células entre os neurônios e o sangue (DANEMAN, 2012; WONG et al., 2013), mantendo a homeostase iônica, hormonal e níveis de transmissores e transporte de nutrientes adequados no sistema nervoso central (SNC) (LUISSINT et al., 2012). Além de prevenir a formação de lesões adicionais durante doenças e acidentes cerebrovasculares (ABBOTT et al., 2006).

D) Neuroinflamação na região da SN: ainda não se sabe ao certo o quanto a neuroinflamação contribui para promover ou proteger a neurodegeneração. Estudos têm demonstrado que ocorre um aumento nos níveis de componentes relacionados à imunidade inata incluindo citocinas na região da SN (LIU et al ,2003); também foi observada a presença de anticorpos para melanina e para alfa-sinucleína em pacientes portadores da DP (PAPACHRONI et al, 2007; YANAMANDRA et al, 2011).

E) Microbiota intestinal e a neurodegeneração: estudos mais recentes têm procurado relacionar alterações na microbiota intestinal e processos neurodegenerativos. Esses estudos são baseados na conexão que existe entre encéfalo e intestino, via nervo vago, conhecido como "eixo cérebro-intestino". Esses estudos sugerem que disfunções intestinais podem desencadear respostas imunes que poderiam colaborar para a manifestação precoce da DP. Nessa hipótese, acredita-se que a maior expressão de agregados de alfasinucleína gerada no intestino decorrente de inflamações intestinais que desencadeiam respostas imunes pode atingir o SNC por meio do nervo vago. Com isso, ocorreria também acúmulo de alfa- sinucleína em regiões encefálicas, como a SN. Entretanto, mais estudos são necessários para comprovação dessa hipótese (GHAISAS S et al., 2015; HOUSER; TANSEY., 2017)

Os núcleos da base são considerados complexos de núcleos subcorticais que desempenham papel fundamental na integração da atividade somatomotora (CALNE, 1994; FEARNLEY \& LEES, 1991; MINK, 1999). Os sinais e sintomas de parkinsonismo provêm de uma perturbação da função em duas regiões dos núcleos da base - SN e o corpo estriado (núcleos Caudado e Putâmen: $\mathrm{CPu}$ ). Assim, a DP é definida como uma doença neurodegenerativa crônica 
progressiva que promove distúrbios motores extrapiramidais, tais como bradicinesia (lentidão dos movimentos voluntários ou dificuldades em iniciar os movimentos) ou acinesia (falta de movimentos), tremores de repouso, rigidez muscular, alterações da marcha e instabilidade postural com quedas freqüentes e falta de expressão facial (AGID, 1991).

Sintomas cognitivos ou não motores podem estar presentes, causando lentidão dos pensamentos, demora em responder perguntas, desconexão com o ambiente (ausência), falta de iniciativa e demência. O quadro depressivo é descrito em cerca de $40 \%$ dos pacientes além de distúrbios relacionados ao sono (CUMMINGS, 1992). Além desses sintomas, os pacientes também apresentam alterações respiratórias como obstrução de vias aéreas superiores, atelectasias, hipoventilação e dispnéia causadas por discinesias musculares, pneumonia por aspiração (WERMUTH et al, 1995), além da apnéia obstrutiva do sono, que tem sido a principal causa de morte súbita em pacientes portadores da DP (MEHANNA et al, 2010). Os sintomas motores da doença só aparecem após redução de $60 \%$ dos neurônios nigrais e de $80 \%$ dos níveis dopaminérgicos no estriado (FALKENBURGUER; SCHULZ., 2004); porém, os sintomas não motores da doença aparecem antes ou após esse período. Exemplos são a deficiência respiratória que só aparece em estágios mais avançados (TUPPY et al., 2015) e a depressão que tem sido observada muito antes dos sintomas motores, sendo que alguns trabalhos sugerem uma relação do aparecimento dela com a degeneração de neurônios noradrenérgicos do Locus Coerulus e serotoninérgicos da Raphe (AGID,1991; CUMMINGS, 1992).

A ocorrência da doença na maioria dos casos é de origem idiopática e apenas $5 \%$ dos casos têm natureza hereditária. Esta se manifesta numa média etária de 55 anos, afetando cerca de $1 \%$ da população com mais de 50 anos. O índice aumenta para $2 \%$ com o avanço da idade, passando a $2 \%$ da população após os 65 anos (HUGHES et al., 1993).

\subsection{Modelo experimental da doença de Parkinson: 6-OHDA}

Algumas substâncias são empregadas em estudos animais por possuírem propriedades diversas capazes de produzir a mesma lesão seletiva de neurônios dopaminérgicos na SNc, acompanhada de sintomas semelhantes ao parkinsonismo, permitindo, assim, o desenvolvimento de modelos animais desta 
doença. Entre estas substâncias estão: 1) as análogas da dopamina como a 6hidroxidopamina (6-OHDA) (JELLINGER et al., 1995); 2) contaminantes da heroína sintética - 1-metil-4-fenil-1, 2, 3,6-tetrahidropiridina (MPTP); 3) herbicidas e pesticidas como a rotenona, paraquat e maneb; 4) metais como manganês.

A 6-OHDA foi o primeiro agente neurotóxico utilizado no modelo de DP, sendo uma substância seletiva para células catecolaminérgicas (UNGERSTEDT, 1968), produzindo um modelo que gera ampla resposta inflamatória (BLANDINI et al., 2008). Originalmente, a 6-OHDA foi isolada por SENOH e WITKOP (1959) e Senoh e colaboradores (1959); seus efeitos biológicos foram demonstrados pela primeira vez em 1963, por Porter e colaboradores. Seus estudos demonstraram que a 6-OHDA era muito eficiente na diminuição de noradrenalina no nervo simpático (PORTER et al., 1963, 1965). A injeção de 6-OHDA na porção centro-lateral do CPu é o modelo que mais se aproxima do quadro encontrado em humanos (TILLERSON et al., 2002), principalmente se a lesão for bilateral (revisado por DEUMENS et al., 2002), por promover uma lesão um pouco mais lenta e progressiva dos neurônios da SN. Já quando as injeções de 6-OHDA são direcionadas diretamente na SNc e no feixe prosencefálico medial, a perda dos neurônios catecolaminérgicos ocorre logo após as injeções (KONDO et al., 2004), ficando estável após 2 semanas (LABANDEIRA-GARCIA et al., 1996). Após a injeção local, esta neurotoxina é captada pelas células e promove a produção de radicais livres e disfunções mitocondriais. Ocorre assim inibição dos complexos I e IV da cadeia respiratória mitocondrial e, consequentemente, estresse oxidativo. Como resultado final ocorre a morte neuronal devido à ativação de mecanismos apoptóticos dependentes de caspase 3 (TANAKA et al., 2006). A liberação de espécies reativas de oxigênio leva à formação de quinonas que reagem com grupamentos nucleofílicos. A lesão assim produzida não gera corpúsculos de Lewy, típicos do tecido nervoso de pacientes parkinsonianos.

\subsection{Controle neural da Respiração}

O controle da respiração é feito por diversos grupamentos neuronais que formam a coluna respiratória dorsal (DRC) e a coluna respiratória ventral (VRC) (Figura 1). A DRC se localiza na região do núcleo do trato solitário (NTS) e é 
composta por diferentes grupos neuronais com atividade inspiratória, pósinspiratória ou expiratória, exercendo uma atividade modulatória sobre a respiração (SUBRAMANIAN et al., 2007).

A VRC possui neurônios com importante papel no controle da atividade respiratória basal (BIANCHI et al., 1995; DEL NEGRO; FELDMAN, 2006). Este grupamento se divide em regiões funcionalmente distintas e orientadas no sentido rostro-caudal (Figura 1):

A) complexo Bötzinger (BötC): região que é considerada a principal fonte da atividade expiratória basal formado por um grupamento de interneurônios inibitórios predominantemente glicinérgicos que se conectam com outros neurônios da coluna respiratória em sua porção mais caudal (SMITH et al., 2009.,SMITH et al., 2013;);

B) complexo pré-Bötzinger (pré-BötC): grupo de neurônios predominantemente glutamatérgicos e que expressam receptores para substância $P$ de neurocinina 1 (NK1). São neurônios considerados essenciais para a geração da atividade inspiratória. Quando ativados, estimulam os neurônios da porção rostral do grupamento respiratório ventrolateral (CONNELLY et al., 1992; STORNETTA et al., 2003; TAN et al., 2010);

C) porção rostral do grupamento respiratório ventrolateral (rVRG): contém neurônios pré-motores inspiratórios, participando então da atividade inspiratória (BIANCHI et al., 1995; EZURE, 1990; EZURE et al., 2003; SMITH et al., 1991; SMITH et al., 2007);

D) porção caudal do grupamento respiratório ventrolateral (cVRG): contém neurônios pré-motores expiratórios, participando da expiração ativa (BIANCHI et al., 1995; EZURE, 1990; EZURE et al., 2003; SMITH et al., 1991; SMITH et al., 2007);

Mais recentemente, foi incorporado rostralmente a essa coluna, um grupo de neurônios que se localiza abaixo do núcleo motor do facial, denominado de núcleo retrotrapezóide (RTN) (CONNELLY et al.,1989) (Figura 1). Seus neurônios são glutamatérgicos e apresentam o fator de transcrição Phox2 $\mathrm{b}^{+}$. Este fator de transcrição está envolvido na diferenciação neuronal, é expresso 
no período embrionário em grupamentos de neurônios envolvidos no controle autônomo e se mantém no indivíduo adulto em alguns grupamentos, como é o caso do RTN (BROSENITSCH; KATZ, 2002; PATTYN et al., 1997; TIVERON et al., 1996). Funcionalmente, sabe-se que esse grupo de neurônios é altamente sensível ao aumento da pressão parcial de $\mathrm{CO}_{2}$ (hipercapnia) e queda de $\mathrm{pH}$ in vivo, sendo por isso denominados de neurônios responsáveis por conter os quimiorreceptores centrais. Além disso, existem evidências de que esses neurônios estejam também envolvidos na inspiração e na geração da atividade expiratória (JANCZEWSKI; FELDMAN, 2006a; 2006b). Eles formam uma coluna de aproximadamente 2100 neurônios no rato, os quais se estendem desde a porção caudal do corpo trapezóide até a região caudal do núcleo motor do facial, englobando uma distância de aproximadamente 2,0 mm (TAKAKURA et al., 2008) (Figura 1). Os neurônios do RTN se projetam para diversos grupamentos da VRC (ROSIN et al, 2006).

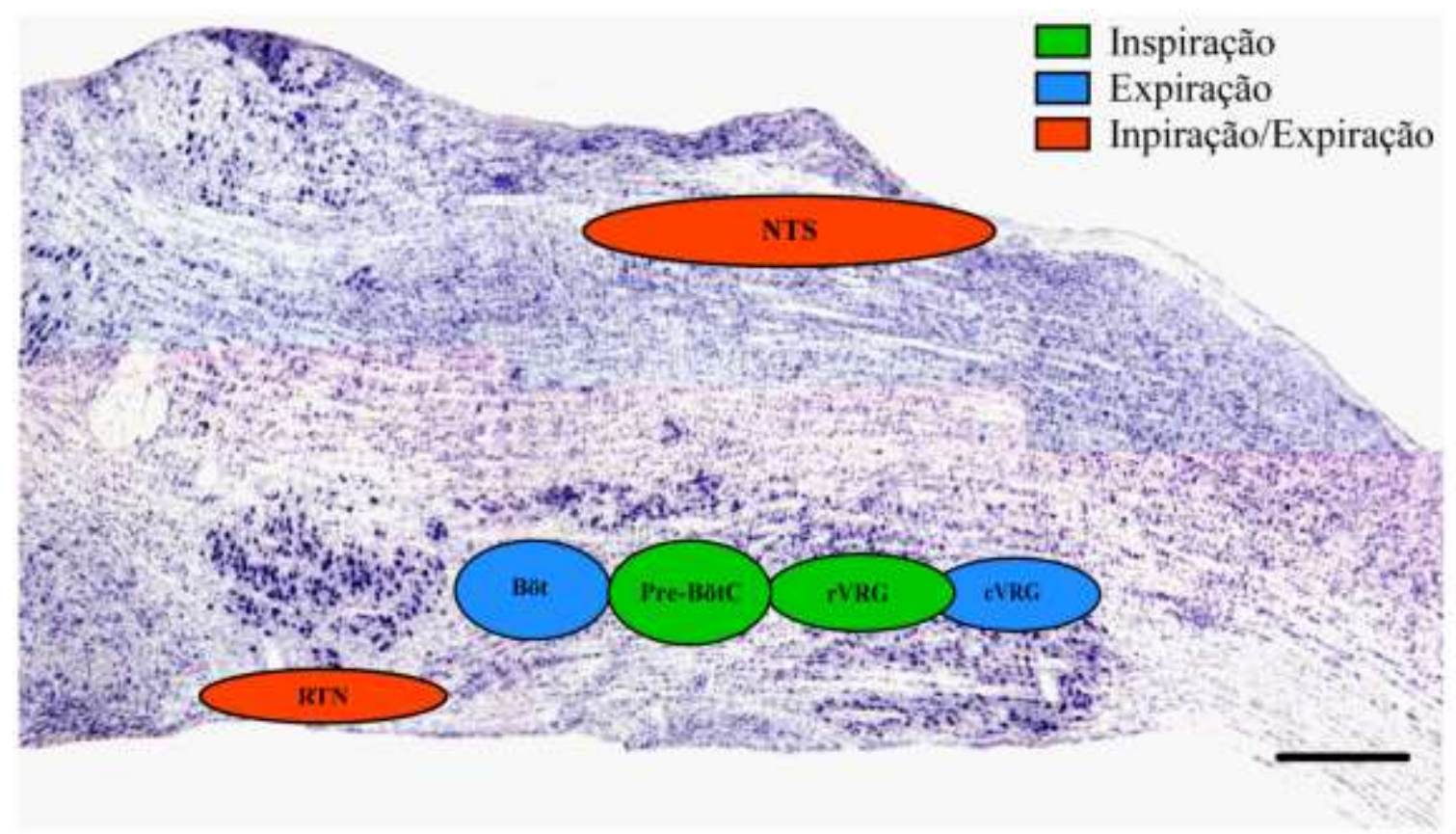

Figura 1 - Fotomicrografia de um corte sagital de encéfalo de rato com representação esquemática da localização da coluna respiratória ventral (VRC) e dorsal (DRC). Abreviações: Böt: complexo Bötzinger; pre-BötC: complexo pré-Bötzinger; rVRG: porção rostral do grupamento respiratório ventrolateral; cVRG: porção caudal do grupamento respiratório ventrolateral; RTN: núcleo retrotrapezóide, compondo a VRC e NTS: núcleo do trato solitário, compondo a DRC.Escala: $1 \mathrm{~mm}$ (Rosin et al., 2006, modificada). 
Além de todas essas regiões citadas acima, envolvidas no controle da respiração em situações basais, existem ainda outras regiões que podem participar do controle da respiração, mas em situações específicas. A substância cinzenta periaquedutal (PAG) é um exemplo. Ela está envolvida em alterações respiratórias relacionadas a mudanças de comportamentos. Situações estressantes podem gerar no individuo dois tipos de comportamento, o primeiro é o de luta e fuga quando o indivíduo percebe a possibilidade de escapar, um bom exemplo seria quando na presença de um predador, a presa ao calcular a distância do mesmo consegue ter a reação comportamental de fugir, e a outra situação é a reação de congelamento e imobilidade gerada em situações onde o indivíduo julga ser uma situação em que não se pode escapar. Essas reações comportamentais estão diretamente envolvidas com a ativação da PAG que promove respostas cardiorrespiratórias correspondentes ao estímulo comportamental gerado (BANDLER et al., 1988; BANDLER et al., 1991; BANDLER et al., 2000., DAMPNEY et al., 2013). A PAG está localizada no mesencéfalo e possui uma estrutura colunar disposta ao redor do aqueduto mesencefálico, estas colunas são divididas em dorsomedial, dorsolateral, ventrolateral e ventral (Figura 2). E dados na literatura demonstraram que 0 estímulo das regiões dorsais estão envolvidas com respostas cardiorrespiratórias ligadas ao comportamento de luta e fuga como hipertensão, taquicardia e taquipnéia. Já o estímulo de regiões ventrais promovem respostas cardiorrespiratórias relacionadas ao comportamento de congelamento e imobilidade como bradicardia, hipotensão e bradipnéia ou até mesmo apnéia (BANDLER; SHIPLEY, 1991; BANDLER; SHIPLEY, 1994). Estudos já demonstraram projeções diretas da PAG para regiões envolvidas diretamente no controle neural da respiração como o preBötC (SUBRAMANIAN et al.; 2008) e RTN (ROSIN et al.; 2006). Além disso, foi observado que o estímulo excitatório de diferentes regiões da PAG pode levar à ativação ou ao silenciamento dos neurônios do preBötC (Figura 2), que é o gerador do ritmo respiratório. 


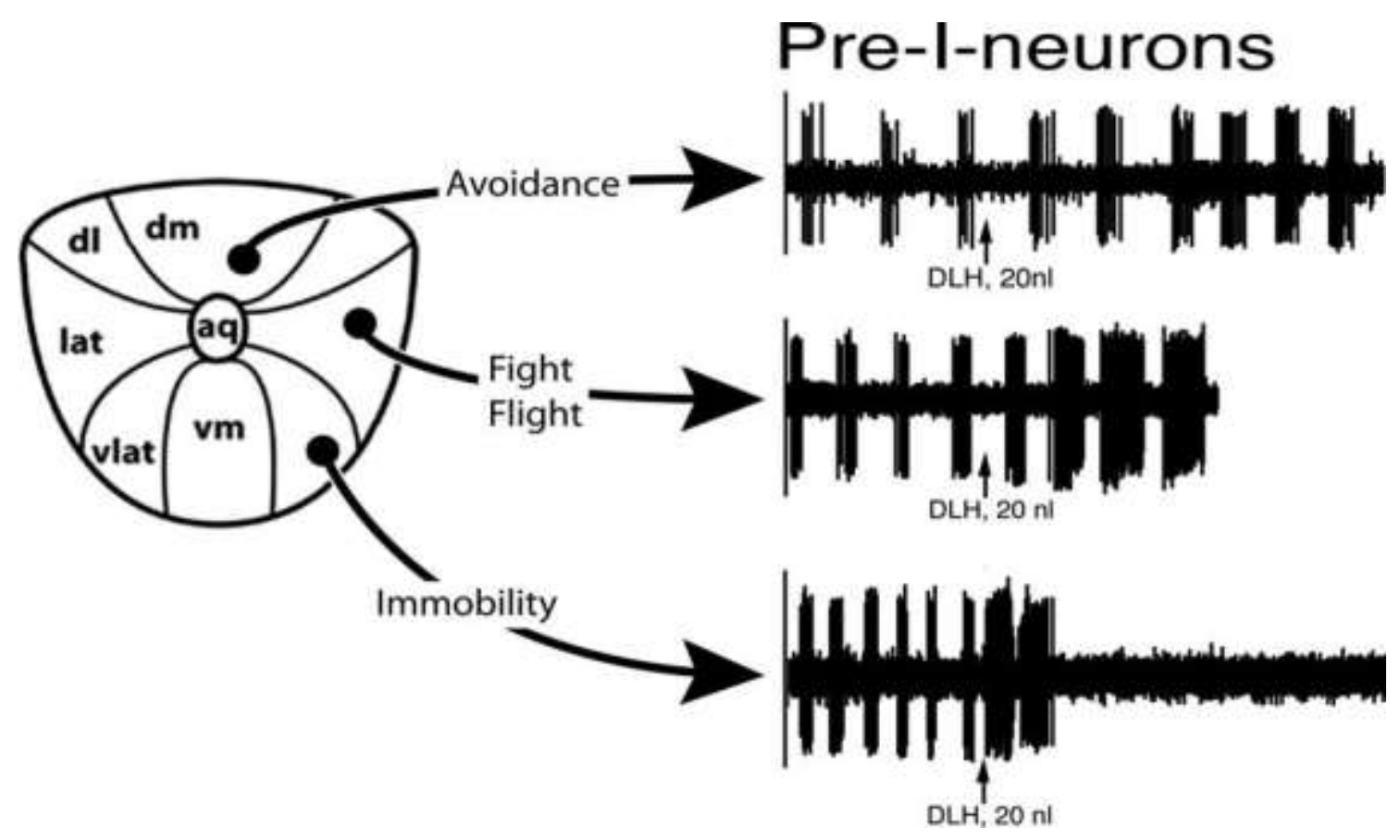

Figura 2 - Esquema representativo dos efeitos da estimulação da PAG pela injeção de $\mathrm{D}$, L, ácido homocisteico (DLH, $50 \mathrm{mM}, 20 \mathrm{nl}$ ) em neurônios pré-inspiratórios (pré-l) do pre-BötC. A estimulação da PAG dorsal produz excitação fásica no contexto do comportamento de fuga (evasão), enquanto a estimulação no PAG lateral produz excitação tônica no contexto de luta e fuga. Já a estimulação no PAG ventrolateral produz inibição de neurônios pré-I no contexto de congelamento e imobilidade. (Subramanian et al., 2013).

\subsection{Alterações respiratórias associadas à Doença de Parkinson}

O aparecimento de problemas respiratórios é comum com o avanço da DP e são responsáveis por substancial mortalidade e morbidade. Obstrução de vias aéreas superiores, diminuição da complacência da caixa torácica e discinesias musculares podem causar dispnéia, hipoventilação e atelectasias facilitando assim um quadro de pneumonia, causada por aspiração (WERMUTH et al, 1995). Segundo Mehanna e colaboradores (2010) a apnéia obstrutiva do sono (AOS) é uma das principais causas de morte entre os pacientes portadores da DP (MEHANNA et al, 2010). A patofisiologia da AOS, na DP, ainda é desconhecida; alguns trabalhos sugerem ocorrer uma degeneração no SNC, em neurônios responsáveis por comandar a atividade respiratória, porém são apenas especulações (GILMAN et al, 2003). Benarroch e colaboradores em 2003 mostraram pela primeira vez uma neurodegeneração em uma importante 
região no controle do ritmo respiratório, ao analisar encéfalos pós-mortem de seres humanos com a DP, onde ele detectou redução de densidade de receptores NK1 na região correspondente ao preBötC (gerador do ritmo inspiratório) comparados a indivíduos sem a DP. Além disso, mais recentemente, Secombe e colaboradores (2011) mostraram por meio de estudos clínicos funcionais em pacientes portadores da DP evidências de um controle ventilatório anormal na DP por disfunções não motoras o que nos sugere que as alterações respiratórias na DP podem ocorrer por um comprometimento no controle neural respiratório.

Estudos recentes de nosso laboratório mostraram que o modelo de indução de DP pela injeção de 6-OHDA no estriado leva a redução de neurônios dopaminérgicos da $\mathrm{SN}$, como já era de se esperar, porém estes estudos correlacionaram este fato a uma perda neuronal de neurônios que contêm o fator de transcrição Phox2b na região do RTN e a uma redução na função respiratória basal e induzida por hipercapnia (Figura 3) (TAKAKURA et al, 2006; TAKAKURA et al, 2008; TUPPY et al., 2015). No RTN, esse grupamento de neurônios está envolvido no controle da inspiração e quimiorrecepção central (TAKAKURA et al., 2006; TAKAKURA et al., 2008). Com isso, levanta-se a hipótese de que existe uma correlação entre a perda da função respiratória com a perda de neurônios em regiões que controlam a respiração, como o RTN. Diante disso, a principal questão levantada pela presente tese foi investigar os motivos pelos quais a redução de neurônios dopaminérgicos da $S N$ leva à redução de neurônios bulbares, como do RTN. Poucos trabalhos até hoje buscaram identificar as projeções eferentes dos neurônios da SN. A maioria dos trabalhos verificou a existência de projeções para diversos componentes dos gânglios da base, tálamo e núcleo pedunculopontino tegmental (PRENSA; PARENT, 2001). Entretanto, até o presente momento, nenhum trabalho da literatura mostrou evidências de projeções da SN para os núcleos bulbares envolvidos no controle neural da respiração, apesar de esta patologia estar associada a distúrbios respiratórios. A fim de responder essa pergunta, o principal objetivo desse 
trabalho foi investigar a existência de uma via direta entre os neurônios da SN e do RTN e se no modelo experimental da DP, essa via estaria prejudicada.

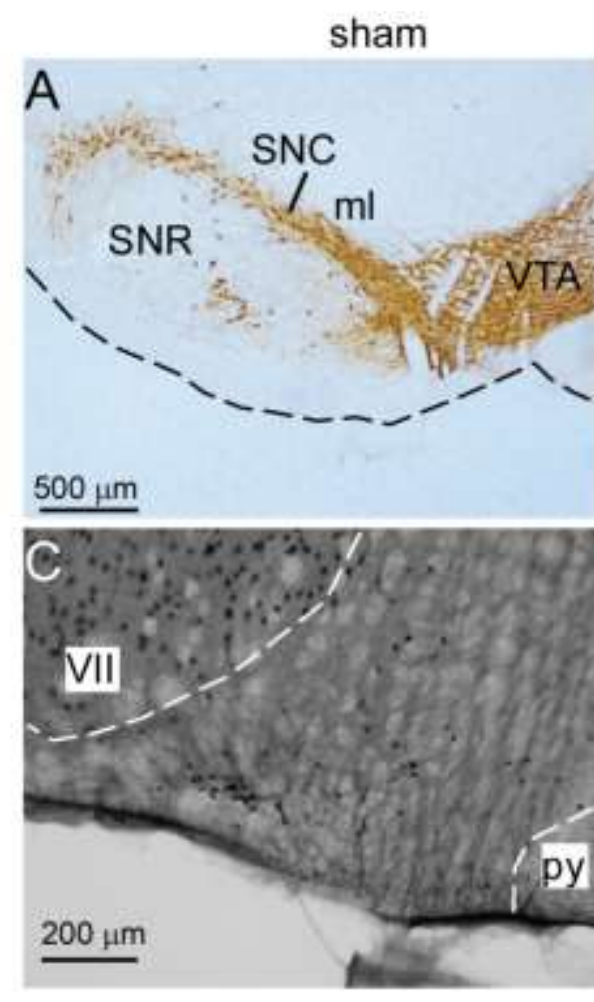

$E$
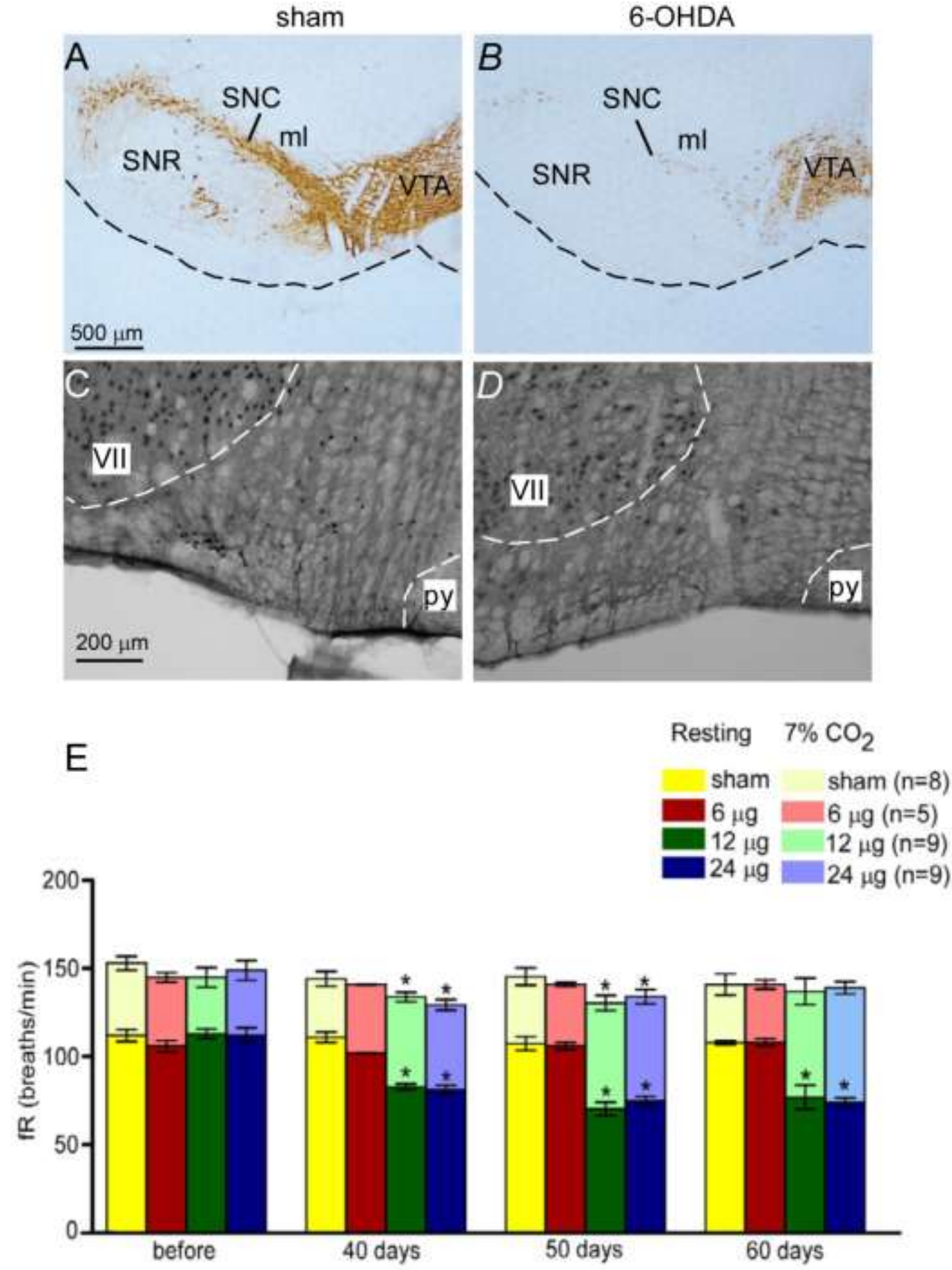

Figura 3 - Fotomicrografias mostrando os efeitos da injeção bilateral de veículo (sham) ou 6-OHDA $(24 \mu \mathrm{g} / \mu \mathrm{l})$ no CPu. Imunorreatividade de A e B) neurônios catecolaminérgicos da SN; C e D) neurônios Phox2b do RTN. E) Efeitos da injeção bilateral de 6-OHDA ou veículo no $\mathrm{CPu}$ na frequência respiratória de animais nãoanestesiados. Abreviações: SNr: substância negra reticular; SNc: substância negra compacta; ml: leminiscu medial; VTA: área tegmental ventral; VII: núcleo motor do facial; py: trato piramidal. *diferença estatística em relação ao sham (Tuppy et al; 2015, modificada). 


\section{OBJETIVOS}

Pelo exposto, torna-se importante investigar a existência de uma via entre a SNc e o RTN que pudesse justificar a neurogeneração no RTN e verificar a função dessa via nas respostas de ativação do quimiorreflexo.

Assim, esta tese objetivou:

A) Investigar, utilizando a injeção de traçadores anterógrado e retrógrado, a existência de projeções excitatórias ou inibitórias da SNc para o RTN;

B) Investigar se essa projeção estaria prejudicada em um modelo animal da $\mathrm{DP} e$

C) A função dessa via na ativação do quimiorreflexo central e periférico. 


\section{MATERIAIS E MÉTODOS}

\subsection{Animais}

Foram utilizados ratos Wistar adultos ( $N=92)$, com peso entre 250 e 300 gramas, oriundos do Biotério de Produção de Ratos (Instituto de Ciências Biomédicas, Rede USP de Biotérios). Os animais foram mantidos no Biotério do Departamento de Farmacologia - Unidade I, em caixas com no máximo quatro animais por caixa, com acesso a água e ração ad libitum. A temperatura do biotério variou entre $22^{\circ} \mathrm{C}$ e $24^{\circ} \mathrm{C}$, com ciclo claro-escuro mantido de 12 horas (ciclo claro iniciando às 7 horas da manhã e encerrando às 7 horas da noite). Os protocolos experimentais estão de acordo com certificado aprovado pela Comissão de Ética no Uso de Animais (CEUA) do Instituto de Ciências Biomédicas da Universidade de São Paulo registrados sob n 99, na folha 22, do livro 03 e normas estabelecidas pelo Conselho Nacional de Controle e Experimentação Animal (CONCEA).

\subsection{Procedimentos cirúrgicos: estereotaxia}

Toda a nomenclatura anatômica foi baseada no atlas de Paxinos e Watson (1998) e em trabalhos anteriores (TAKAKURA e cols., 2006; MOREIRA e cols., 2006; WESTON e cols., 2003). Em todos os procedimentos cirúrgicos foram utilizados métodos assépticos para evitar os riscos de infecções. As injeções dos traçadores foram realizadas em animais anestesiados intraperitonealmente (i.p.) com uma mistura anestésica de cetamina (100 mg/kg) e xilasina $(5 \mathrm{mg} / \mathrm{kg}$ ). Diferentes grupos de animais foram adaptados a um aparelho estereotáxico e receberam injeções sob pressão com nitrogênio, utilizando-se pipetas de vidro com a ponta de diâmetro de $20 \mu \mathrm{m}$ (Sutter Instrument Co, CA) acopladas ao aparelho PicoSpritzer II (General Valve Corporation, $\mathrm{NJ}$ ) do traçador anterógrado dextrana-amina biotinilada (BDA-lysine fixable, MW 10000; 10\% w/v em 10 mM PBS, pH 7.4; Molecular Probes) ou do traçador retrógrado Fluorogold (2\% FG em salina estéril; Fluorochrome, Inc., Englewood, CO) seguindo os seguintes protocolos: 
A
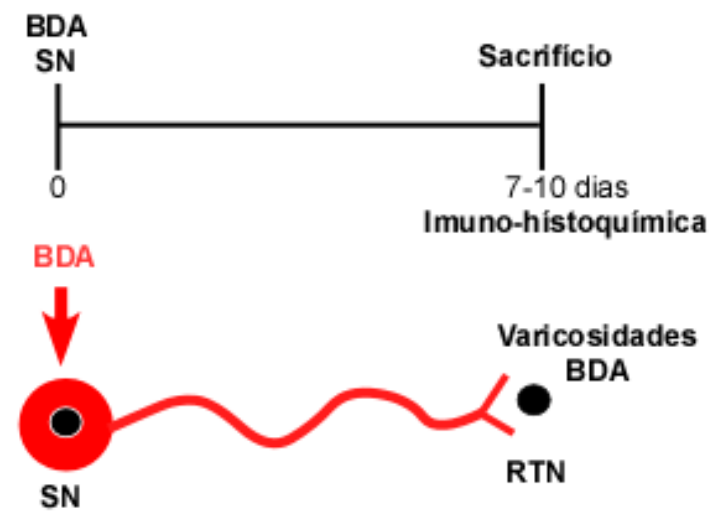

C
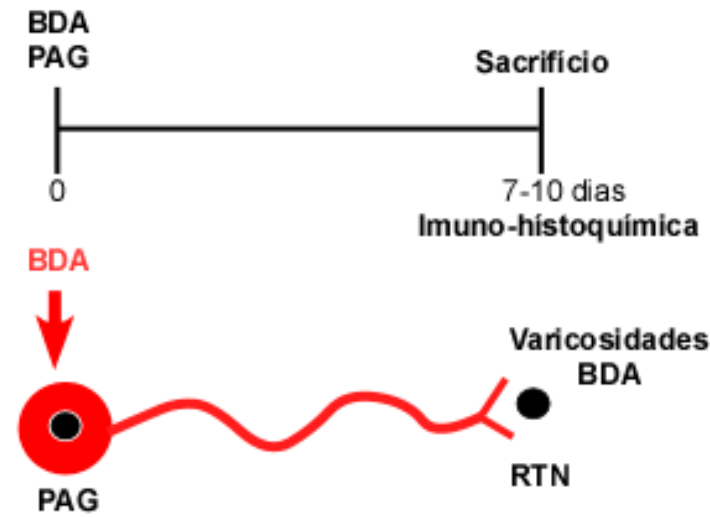

E

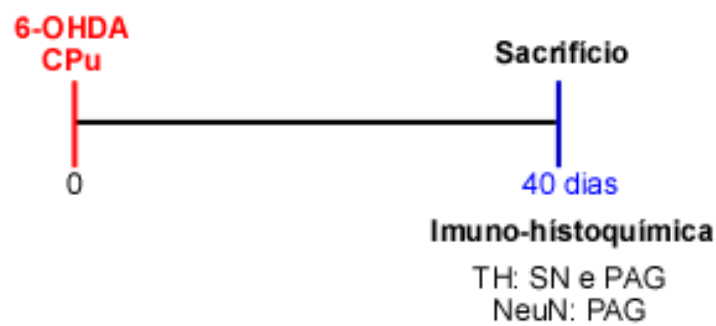

$B$
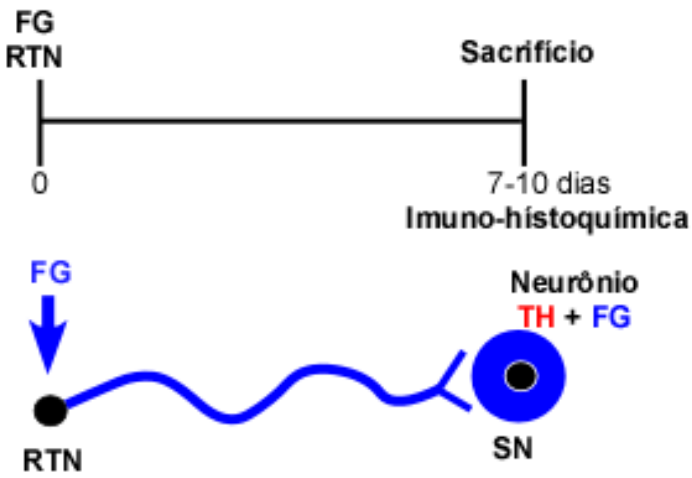

D
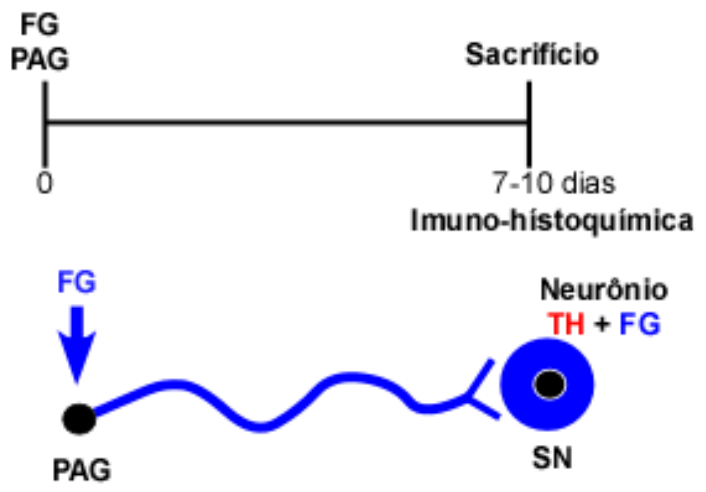

F

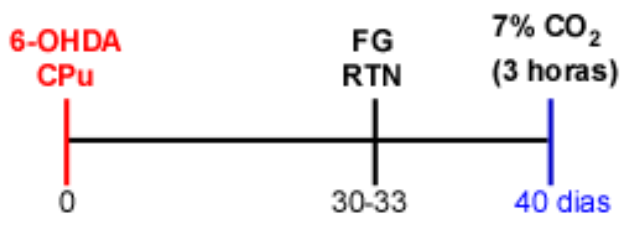

Imuno-hístoquímica

TH: SN

fos: PAG

Figura 4 - Esquema representativo dos protocolos experimentais propostos. A) injeção do traçador anterórgrado BDA na SN; B) injeção do traçador retrógrado FG no RTN; C) injeção do traçador anterógrado BDA na PAG; D) injeção do traçador retrógrado FG na PAG; E) indução do modelo experimental da DP F) indução do modelo experimental da DP, injeção do traçador retrógrado FG no RTN e ativação do quimiorreflexo central por hipercapnia. Abreviações:BDA: dextrana-amina biotinilada; PAG: substância cinzenta periaquedutal; $\mathrm{TH}$ : tirosina-hidroxilase; $\mathrm{CPu}$ : caudado e putâmen; 6-OHDA: 6hidroxidopamina; FG: fluorogold; NeuN: marcador neuronal nuclear; RTN: núcleo retrotrapezóide; SN: substância negra. 
- BDA na SNc unilateral: utilizando as seguintes coordenadas: $7,8 \mathrm{~mm}$ ventral à superfície do osso, 2,3 $\mathrm{mm}$ lateral à linha média e 5,3 $\mathrm{mm}$ caudal ao Bregma a fim de investigar inicialmente a presença de varicosidades contendo BDA na região do RTN (Figura 4A), indicando projeções diretas entre SN e RTN;

- FG no RTN unilateral: utilizando as seguintes coordenadas: $8,8 \mathrm{~mm}$ ventral à dura-máter, 1,8 $\mathrm{mm}$ lateral à linha média e 2,8 mm caudal ao Lambdaa fim de confirmarmos a existência de marcação retrógrada dos neurônios da SN que possam inervar essa região do RTN (Figura 4B);

- BDA na PAG unilateral: utilizando as seguintes coordenadas: 5,3 mm ventral à dura-máter, 0,6 mm lateral à linha média e 6,8 mm caudal ao Bregma para investigar a presença de varicosidades contendo BDA na região do RTN (Figura 4C), indicando projeções diretas entre PAG e RTN.

- FG na PAG unilateral: utilizando as seguintes coordenadas: $5,3 \mathrm{~mm}$ ventral à dura-máter, 0,6 $\mathrm{mm}$ lateral à linha média e 6,8 $\mathrm{mm}$ caudal ao Bregma a fim de verificar a existência de marcação retrógrada dos neurônios da SN que possam inervar essa região (Figura 4D),

Todos esses animais em que foram feitas injeções de traçadores sobreviveram por 7-10 dias. Após esse período, eles foram profundamente anestesiados com pentobarbital ( $60 \mathrm{mg} / \mathrm{kg}$ ) e perfundidos através do ventrículo cardíaco esquerdo com tampão fosfato de sódio (PBS, pH 7,4) seguido de paraformaldeído ( $4 \%$ em $0,1 \mathrm{M}$ de fosfato, $\mathrm{pH} 7,4$ ), como será descrito posteriormente.

Para as injeções bilaterais de 6-OHDA $(24 \mu \mathrm{g} / \mu \mathrm{l})$ ou salina $+0,3 \%$ de ácido ascórbico (controle) no estriado, foram feitas 2 injeções de $0,5 \mu \mathrm{l}$ em 2 coordenadas distintas. Dessa forma, as coordenadas utilizadas para atingir 0 CPu foram: 1) 2,7 mm lateral à linha média, $0 \mathrm{~mm}$ rostral ao Bregma e 4,5 mm ventral à dura-máter e 2) 3,2 $\mathrm{mm}$ lateral à linha média, 0,5 mm rostral ao Bregma e $4,5 \mathrm{~mm}$ ventral à dura-máter. Após 40 dias, os animais foram sacrificados, perfundidos e os encéfalos retirados para análise imuno-histoquímica. A extensão da lesão foi estimada analisando-se a quantidade de neurônios 
imunorreativos para tirosina-hidroxilase remanescentes na região da SNc (Figura 4E).

\subsection{Medida da ventilação pulmonar}

A avaliação da ventilação (VE) foi realizada por meio de registros pletismográficos automáticos e contínuos (EMKA Technologies, Falls Church, VA, USA). Este método baseia-se no princípio de que um animal, dentro de uma câmara, terá seu volume de ar corrente inspirado aquecido, da temperatura da câmara à temperatura corporal e saturado com vapor de água. Durante a expiração, o volume de ar corrente é resfriado até a temperatura da câmara, havendo perda de vapor de água. Essas condições, de aquecimento e umidificação do ar inspirado bem como de resfriamento e desidratação do ar expirado, são acompanhadas de mudanças de pressão no interior da câmara de registro (MENKES; DUBOIS, 1969).

A câmara de pletismografia utilizada neste protocolo foi uma caixa de acrílico de 5 litros, onde os animais foram colocados, permitindo sua livre movimentação. Esta câmara é composta por quatro vias de acesso, sendo duas de entrada e duas vias de saída. A primeira via de entrada conecta-se com o ventilador (VENT-4C1) ofertando uma mistura de gás que foi inalado pelo animal durante o experimento em questão. $O$ fluxo e a pressão de gás são regulados pelo sistema (Flow regulation - Alicat Scientific) de acordo com o protocolo proposto. A segunda via de entrada corresponde ao sistema de calibração, a qual, um volume referencial de ar é injetado na câmara fechada e vazia, por meio de uma seringa de $20 \mathrm{ml}$ (no intervalo de tempo de 2s). As vias de saída referemse aos sensores de umidade, temperatura e ao transdutor diferencial de pressão (DPT Respiratory Flow Head, EMKA Technologies), conectados a um préamplificador e ao software de análise (modelo EMKA-IOX 2, versão 2.8.0.1.9). Ademais, uma bomba de sucção de ar (VENT-2) conectada a um dispositivo desumidificador com sílica em seu interior, remove o ar expirado completando 0 circuito. Duas variáveis respiratórias foram medidas; a frequência respiratória (fR) e o volume corrente (VT) ${ }^{1}$. A VE foi calculada pelo produto entre fR e VT. 
Foram realizadas medidas da temperatura corporal de cada animal por meio de termômetro digital clínico (Termo Med Incoterm) antes e após a avaliação pletismográfica. Os parâmetros respiratórios foram automaticamente calculados, utilizando a fórmula de Drorbaugh and Fenn (1955) e posteriormente corrigidos pela massa corporal. Modificações na temperatura, umidade e pressão atmosférica dentro da câmara de registro foram continuamente registradas e utilizadas para correção automática do cálculo do VT. A principal vantagem deste método de pletismografia automática em relação ao método de captação de dados analógico consiste no fato de que não se faz necessário abrir a câmara entre os registros. Deste modo, o registro contínuo permite que o microambiente no interior da câmara seja preservado.

Os animais permaneceram inicialmente livres para exploração e posterior adaptação ao ambiente da câmara por um período de 45 a 60 minutos. Antes de cada registro a câmara foi ventilada com ar atmosférico $\left(21 \%\right.$ de $\left.\mathrm{O}_{2}\right)$. Após a fase exploratória, a mensuração das variáveis respiratórias basal foi efetuada por 15 minutos. Em seguida, os animais foram submetidos por um período de 10 minutos à hipercapnia (mistura gasosa de $7 \%$ de $\mathrm{CO}_{2}$, balanceada com $21 \%$ de $\mathrm{O}_{2}$ e $72 \%$ de nitrogênio $\left(\mathrm{N}_{2}\right)$ ). Ao final desse intervalo, a câmara foi ventilada com ar atmosférico por 30 minutos e as variáveis respiratórias mensuradas novamente. Os procedimentos de registros nesse pletismógrafo foram realizados 1 dia antes e 40 dias após a injeção de veículo ou 6-OHDA no CPu.

${ }^{1}$ Fórmula de cálculo para VT :

$$
\underset{P K}{V T}=\frac{P T}{T R} \times \text { VK } \times \frac{\text { TC }}{(P B-P C)-\underline{T C} \times(P B-P R)}
$$

$\mathrm{Tb}$

Definição dos símbolos da equação: VT: Volume de ar corrente; VK: Volume de ar injetado na câmara do animal para calibração; PT: Deflexão de pressão associada com cada volume de ar corrente; PK: Deflexão de pressão associada ao volume injetado para calibração; Tb: Temperatura corporal (em Kelvin); TC: Temperatura do ar dentro da câmara do animal; PB: Pressão barométrica; PR: Pressão de vapor de água a temperatura corporal; PC: Pressão de vapor de água na câmara do animal; TR: Temperatura ambiente.

\subsection{Hipercapnia}

Em um grupo de animais, sete a dez dias após a injeção de FG no RTN de animais submetidos à indução prévia do modelo de 6-OHDA, os animais foram expostos por 3 horas a uma mistura de gases $\left(7 \% \mathrm{CO}_{2}, 21 \% \mathrm{O}_{2}\right.$, 
balanceado com $\mathrm{N}_{2}$ ) em uma câmara de pletismografia de corpo inteiro, a qual consiste em uma caixa de acrílico de 5 litros. Nesse ambiente, temos um fluxo de gás de $1 \mathrm{~L} /$ min e o animal pode mover-se livremente (Figura 4F).

\subsection{Histologia}

Ao término dos experimentos, os animais foram profundamente anestesiados com pentobarbital de sódio $(60 \mathrm{mg} / \mathrm{kg}$ ) e perfundidos através do ventrículo cardíaco esquerdo com solução salina tamponada com fosfato (PBS,pH 7,4) seguido de paraformaldeído ( $4 \%$ em 0,1 M de fosfato, $\mathrm{pH} 7,4)$. Os encéfalos foram retirados e guardados nesse fixador por 3-4 horas a $4{ }^{\circ} \mathrm{C}$. Após este período, o material foi transferido para uma solução contendo sacarose. Após 24 horas, os encéfalos foram cortados em micrótomo numa espessura de $40 \mu \mathrm{m}$ e guardados em solução anti-congelante, preservando a qualidade do tecido encefálico para posterior tratamento histoquímico ou imuno-histoquímico (Schreihofer \& Guyenet,1997) com anticorpos específicos (Tabela 1) para cada tratamento desejado. Não foi observada marcação quando o processo foi realizado com a ausência do anticorpo primário.

Depois de finalizados os tratamentos imuno-histoquímicos, os cortes encefálicos foram analisados num microscópio (Zeiss Axioskop 2) para conferir os locais das injeções e para localização e quantificação dos neurônios marcados com os traçadores e com a presença da imunorreatividade para $\mathrm{TH}$, NeuN, e fos, As varicosidades foram analisadas e fotografadas no microscópio cofocal (Nikon E1000). 


\begin{tabular}{|c|c|c|}
\hline $\begin{array}{l}\text { ANTICORPO } \\
\text { PRIMÁRIO OU } \\
\text { STREPTAVIDINA }\end{array}$ & ANTICORPO SECUNDÁRIO & FINALIDADE \\
\hline $\begin{array}{c}\text { mouse anti-TH } \\
(1: 2000) \\
\text { Millipore }\end{array}$ & $\begin{array}{c}\text { Cy3 goat anti-mouse (1:200) } \\
\text { Jackson Imunno Res. Lab. } \\
\text { donkey anti-mouse biotin. (1:500) } \\
\text { Chemicon international }\end{array}$ & $\begin{array}{l}\text { Revelar a expressão da } \\
\text { enzima } \quad \text { tirosina } \\
\text { hidroxilase }\end{array}$ \\
\hline $\begin{array}{l}\text { guinea pig anti-Vglut2 } \\
\qquad(1: 2500) \\
\text { Chemicon international }\end{array}$ & $\begin{array}{c}\text { Cy3 ou Alexa } 488 \text { goat anti- guinea pig (1:200) } \\
\text { Molecular Probes }\end{array}$ & $\begin{array}{l}\text { Revelar a expressão do } \\
\text { transportador vesicular } \\
\text { de glutamato do tipo } 2\end{array}$ \\
\hline $\begin{array}{l}\frac{2 \text { mouse anti-NeuN }}{} \\
\qquad(1: 5000) \\
\text { Jackson Imunno Res. } \\
\text { Lab. }\end{array}$ & $\begin{array}{c}\text { donkey anti-mouse biotinilado (1:500) } \\
\text { Chemicon international }\end{array}$ & $\begin{array}{l}\text { Revelar a expressão do } \\
\text { marcador neuronal } \\
\text { NeuN }\end{array}$ \\
\hline $\begin{array}{l}\frac{\text { rabbit anti-GAD67 }}{(1: 2500)} \\
\text { Chemicon international }\end{array}$ & $\begin{array}{c}\text { Cy3 ou Alexa } 488 \text { goat anti-rabbit }(1: 200) \\
\text { Molecular Probes }\end{array}$ & $\begin{array}{l}\text { Revelar a expressão do } \\
\text { ácido } \quad \text { glutâmico } \\
\text { descarboxilase } 67\end{array}$ \\
\hline $\begin{array}{c}\text { rabbit anti-fluorogold } \\
\text { (1:5000) } \\
\text { Millipore }\end{array}$ & $\begin{array}{c}\text { Alexa } 488 \text { goat anti - rabbit }(1: 200) \\
\text { Millipore }\end{array}$ & $\begin{array}{l}\text { Revelar a expressão do } \\
\text { traçador fluorogold }\end{array}$ \\
\hline $\begin{array}{c}\frac{\text { rabbit anti-fos }}{(1: 10000)} \\
\text { Santa Cruz }\end{array}$ & $\begin{array}{c}\text { Cy3 donkey anti-rabbit (1:200) } \\
\text { Invitrogen }\end{array}$ & $\begin{array}{l}\text { Revelar a expressão de } \\
\text { ativação neuronal pela } \\
\text { imunorreatividade da } \\
\text { proteína fos }\end{array}$ \\
\hline $\begin{array}{l}\text { Alexa } 488 \text { ou Cy3 } \\
(1: 200) \\
\text { Jackson Imunno Res. } \\
\text { Lab. }\end{array}$ & & $\begin{array}{l}\text { Revelar } \quad 0 \quad \text { traçador } \\
\text { anterógrado BDA }\end{array}$ \\
\hline
\end{tabular}

Tabela 1 - Informações a respeito dos anticorpos utilizados nos protocolos de histoquímica e imuno-histoquímica da presente tese. 


\subsection{Quantificação da imunorreatividade}

Um microscópio convencional foi utilizado para as observações e captura de imagens das regiões neuronais de interesse, o programa ImageJ programa de software de domínio público (disponível a partir do site http://rsb.info.nih.gov/ij/) foi utilizado para contar diversos perfis neuronais dentro de uma área estabelecida por meio de seções que foram definidas a partir de referências pré estabelecidas na literatura. Foram analisados 1 em 6 cortes de $40 \mu \mathrm{m}$ cada. Assim, a distância entre um corte e outro era de $240 \mu \mathrm{m}$. A referência utilizada para SN foi onde finaliza o núcleo geniculado medial. Esse corte foi definido como Bregma -6,6 mm e não foi considerado para quantificação. A partir deste Bregma, foram analisados 5 cortes rostrais. A referência para RTN foi determinada pelo fim do núcleo facial e início das olivas inferiores. Para esse corte, definiu-se o Bregma de -11,6 mm e a partir dele foram quantificados mais 4 cortes rostrais a esse corte referência, totalizando 5 cortes analisados do RTN. A referência utilizada para a PAG foi a abertura do aqueduto mesencefálico (Bregma $=-8,8 \mathrm{~mm}$ ) e foram quantificadas mais 4 cortes rostrais a esse corte referência, totalizando 5 cortes analisados de PAG. Toda nomenclatura aqui descrita foi determinada de acordo com o atlas de Paxinos e Watson (1998).

\subsection{Experimentos eletrofisiológicos}

\subsubsection{Procedimentos cirúrgicos}

Animais controles ou submetidos ao protocolo de indução da DP foram anestesiados com isoflurano (5\%) em 100\% de oxigênio. Posteriormente, foram traqueostomizados com uma cânula de metal e acoplados à ventilação mecânica, mantendo-os com $2 \%$ de isoflurano diluído em $100 \%$ de oxigênio, frequência respiratória de 60-80 ciclos/s, volume de 1 a 1,2 ml/100g de rato e com uma pressão positiva no final da expiração (PEEP) de $1 \mathrm{cmH}_{2} \mathrm{O}$ durante todos os procedimentos cirúrgicos. Os animais foram submetidos aos seguintes procedimentos cirúrgicos:

A) Vagotomia bilateral com a finalidade de evitar influências inibitórias dos receptores de distensão pulmonar sobre o padrão respiratório; 
B) Canulação da artéria e veia femorais para registro da pressão arterial pulsátil (PAP) e administração de drogas, respectivamente;

C) Posicionamento em um aparelho estereotáxico (modelo Kopf 900);

D) Remoção do osso occipital para inserção de micropipetas de vidro preenchidas com os fármacos utilizados;

E) Acoplamento de eletrodos de prata nos músculos diafragma, genioglosso e reto abdominal para avaliar a atividade inspiratória (diafragma e genioglosso) e expiratória ativa (abdominal), por meio de duas incisões longitudinais na região abdominal, adotando-se a costela inferior e a linha média abdominal do animal como referências.

Com o término dos procedimentos cirúrgicos, o anestésico inalatório isoflurano foi substituído pelo anestésico endovenoso uretano $(1,2-1,4 \mathrm{~g} / \mathrm{kg})$, mantendo os animais ventilados com $100 \%$ de oxigênio.

Antes de iniciar os experimentos, a ventilação foi ajustada para níveis de $\mathrm{CO}_{2}$ expirado em $4 \%$ (valores basais) ( 60 a 80 ciclos/s; volume de 1 a $1,2 \mathrm{ml} / 100$ $\mathrm{g}$ de animal). Essas condições foram selecionadas porque $4 \%$ de $\mathrm{CO}_{2}$ expirado está abaixo do limiar de atividade expiratória ativa, ou seja, da atividade do músculo abdominal nas nossas condições experimentais. A estimulação dos quimiorreceptores centrais foi realizada aumentando-se os valores de $\mathrm{CO}_{2}$ expirado de $4 \%$ para $10 \%$ e a estimulação dos quimiorreceptores periféricos foi realizada com a injeção endovenosa de cianeto de potássio (KCN; $40 \mu \mathrm{g} / 0,1$ $\mathrm{ml})$.

Durante todo o procedimento, os animais receberam uma sonda retal para monitorização da temperatura corpórea, mantendo-a em $37 \stackrel{\circ}{\mathrm{C}}$ utilizando-se um colchão com resistência interna para aquecimento. $\mathrm{O}$ índice de $\mathrm{CO}_{2}$ expirado pelo animal foi monitorado durante o experimento por meio de um capnômetro (Columbus Instruments, Ohio, USA) acoplado ao ventilador. O nível de anestesia foi sempre monitorado, testando-se a ausência do reflexo de retirada de pata ao seu pinçamento. 


\subsubsection{Registro da pressão arterial}

Para o registro da PAP, os animais foram submetidos à canulação da artéria femoral com tubo de polietileno (PE-10 conectado a um PE-50). A cânula da artéria femoral foi conectada a um transdutor de pressão (Physiological Pressure Transducer mod. MLT844, ADInstruments) acoplado a um préamplificador (Bridge Bio Amplifier mod. ML221, ADInstruments) e ao sistema de registro computadorizado Cambridge Electronic Design (CED-1401) de 8 canais. Os animais tiveram a veia femoral canulada com tubo de polietileno (PE-10 conectado a um PE-50) para a infusão de drogas sistêmicas.

\subsubsection{Eletromiografia dos músculos respiratórios}

Durante os procedimentos cirúrgicos, eletrodos bipolares constituídos por fios de prata isolados e com as pontas expostas foram implantados nos músculos diafragma, genioglosso e abdominal dos animais com o objetivo de registrar a atividade eletromiográfica dos mesmos. Todos os sinais foram amplificados em $20 \mathrm{~K}$, filtrados de 100 a $3000 \mathrm{~Hz}$ e adquiridos por meio de um conversor analógico digital (CED 1401, Cambridge Electronic Design, UK) de 8 canais. O sinal foi copiado para um sistema de aquisição de dados versão 6.16 do Spike 2 software (CED, Cambridge Electronic Design, UK).

Os resultados foram gravados em DVD para posterior análise. Por meio das análises das atividades dos músculos diafragma e genioglosso avaliamos a atividade inspiratória, e da atividade do músculo abdominal avaliamos a atividade expiratória ativa. As atividades integradas do diafragma (DiaEMG), genioglosso (GGEMG) e do abdominal (AbdEMG) foram obtidas após retificação e suavização $(T=0,03)$ a partir do sinal original. Os ruídos foram subtraídos antes de se realizar qualquer cálculo, e a atividade muscular fisiológica (Basal: frequência e amplitude) foi considerada no momento imediatamente antes de qualquer estímulo realizado.

\subsubsection{Injeções encefálicas}

Em animais controles, foram realizadas injeções bilaterais (uma por lado) na PAG de salina ou muscimol (2 mM, agonista GABAérgico, pH 7,4; Sigma Chemicals, St. Louis, MO, USA) diluído em salina estéril. As injeções foram 
realizadas sob pressão com nitrogênio durante 8-15 ms, utilizando micropipetas de vidro (diâmetro interno de 0,5 mm, Sutter Instrument Co, CA) acopladas ao aparelho PicoSpritzer II (General Valve Corporation, NJ), mantendo um volume de $30 \mathrm{nl} /$ injeção. Salina ou muscimol continham 5\% de microesferas de látex fluorescentes (Lumafluor, New City, NY, USA) para posterior análise histológica (MOREIRA et al., 2006; MOREIRA et al., 2011; TAKAKURA et al., 2006a).

Para atingir a PAG, as injeções foram feitas utilizando as seguintes coordenadas: 5,3 $\mathrm{mm}$ ventral à dura-máter, 0,6 $\mathrm{mm}$ lateral à linha média e 6,8 $\mathrm{mm}$ caudal ao Bregma. Após o término dos experimentos, os animais foram sacrificados, perfundidos e os encéfalos retirados para verificação do sítio de injeção.

\subsubsection{Ativação do quimiorreflexo central e periférico}

Em animais controles ou submetidos ao protocolo de indução da DP, o quimiorreflexo central foi testado pelo aumento na concentração de $\mathrm{CO}_{2}$ oferecida para o animal (hipercapnia: 10\% $\mathrm{CO}_{2}$ ). Da mesma forma, nesses animais também foi testado o quimiorreflexo periférico pela injeção intravenosa de cianeto de potássio ( $\mathrm{KCN}, 40 \mu \mathrm{g} / 0,1 \mathrm{ml}$ ) (Figura $5 \mathrm{~A}-\mathrm{B}$ ).

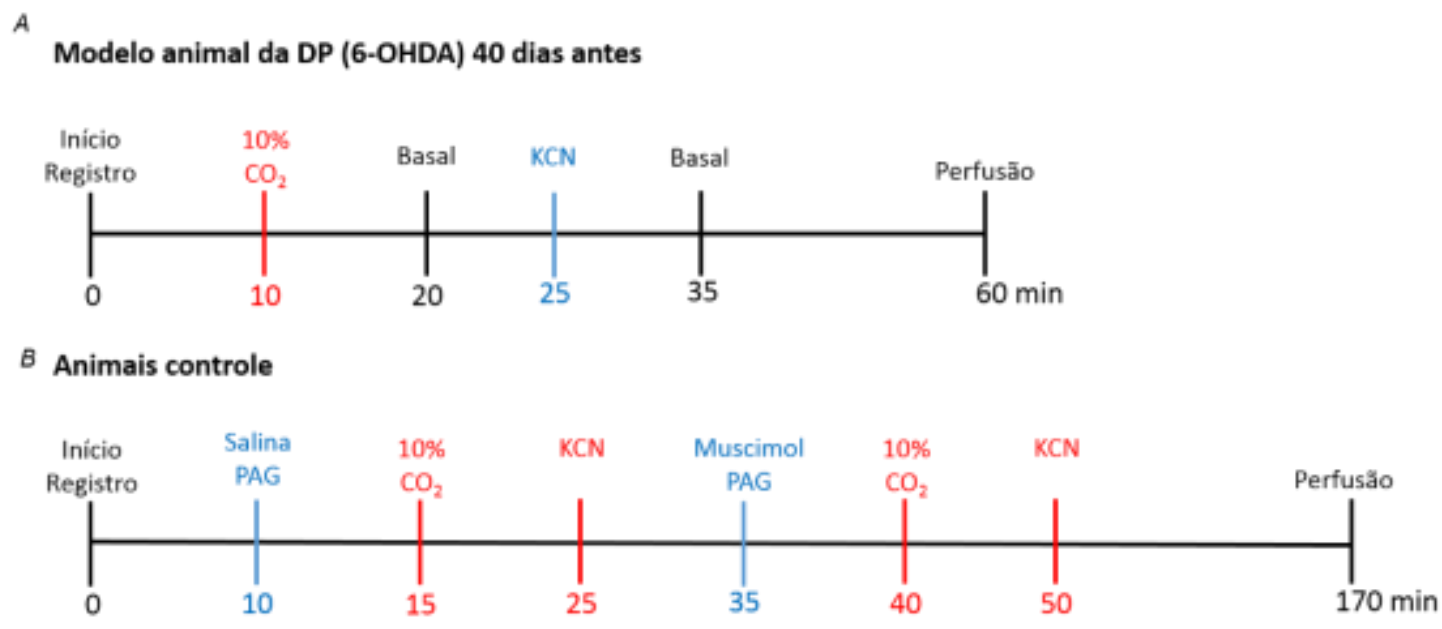

Figura 5 - Esquemas representativos dos protocolos experimentais funcionais. A) modelo da DP em que foi realizada a injeção bilateral de 6-OHDA no CPu 40 dias anteriores aos experimentos eletrofisiológicos que consistiam em registros da atividade dos músculos envolvidos na respiração frente a estímulos do quimiorreflexo central $\left(\mathrm{CO}_{2}\right)$ e periférico (cianeto de potássio: $\mathrm{KCN}$ ); B) animais controles que receberam injeções bilaterais de salina e muscimol em diferentes tempos e foram realizados registros da atividade dos músculos envolvidos na respiração frente a estímulos do quimiorreflexo central $\left(\mathrm{CO}_{2}\right)$ e periférico $(\mathrm{KCN})$. 


\subsection{Análise estatística}

A análise estatística foi realizada utilizando-se o programa Sigma Stat 3.0 (Jandel Corporation, Point Richmond, CA). Os dados foram tabelados e representados em gráficos como média \pm erro padrão da média. Para os experimentos neuroanatômicos, foi realizado o Teste t e para os experimentos eletrofisiológicos, foi realizada análise de variância de uma via seguida do Teste de Student-Newman-Keuls para comparação entre as médias. $O$ índice de significância foi fixado em $p<0,05$. 


\section{RESULTADOS}

\subsection{Estudo neuroanatômico em animais controles}

Esta série de experimentos foi realizada a fim de investigar as possíveis projeções entre SN e RTN (Figura 6A).

\subsubsection{Avaliação de projeções diretas da SN para o RTN}

A análise histológica mostrou que o traçador anterógrado BDA foi injetado unilateralmente na $S N$, região em que se concentra a maior densidade de neurônios dopaminérgicos, conforme evidenciado pela figura 6C. Foram realizadas 12 injeções, sendo que destas, 4 estavam localizadas na SN (Figura 6B - esquema superior). Como podemos observar, existe uma grande densidade de neurônios marcados com $\mathrm{TH}$ na região da $\mathrm{SN}$, situada no mesencéfalo. A SN é formada por uma parte reticulada (situada na borda medial das fibras descendentes córticofugas da base do pedúnculo cerebral) e uma parte compacta (adjacente à área tegmental ventral com a qual se assemelha citoarquitetural e funcionalmente). A parte compacta é formada por neurônios que contêm melanina (o pigmento que the confere a cor negra), têm como neurotransmissor dopamina e projetam-se para o neostriado (fibras nigroestriadas), podendo excitá-lo ou inibí-lo, dependendo do receptor dos neurônios pós-sinápticos (D1 excita e D2 inibe). A parte reticular é formada por neurônios inibitórios GABAérgicos, cujos axônios têm grande número de colaterais que possibilitam um largo território de ação. Em todos os casos positivos apresentados na figura 6B, não houve a presença de imunorreatividade para BDA na região do RTN, nosso alvo de estudo.

No grupo de animais em que foi feita a injeção do traçador retrógrado $F G$ no RTN, a análise histológica mostrou que o traçador foi injetado unilateralmente abaixo da porção caudal do núcleo facial, atingindo a região em que se concentra a maior densidade de neurônios $\mathrm{CO}_{2}$-sensíveis, conforme evidenciado pela figura 6D. Os resultados obtidos são referentes a 4 animais (total de 8) que apresentaram injeções localizadas no RTN (Figura 6B - esquema inferior). Em 
todos os casos apresentados na figura 6B, não houve a presença de corpos celulares marcados retrogradamente (imunorreativos para FG) na região da SN.
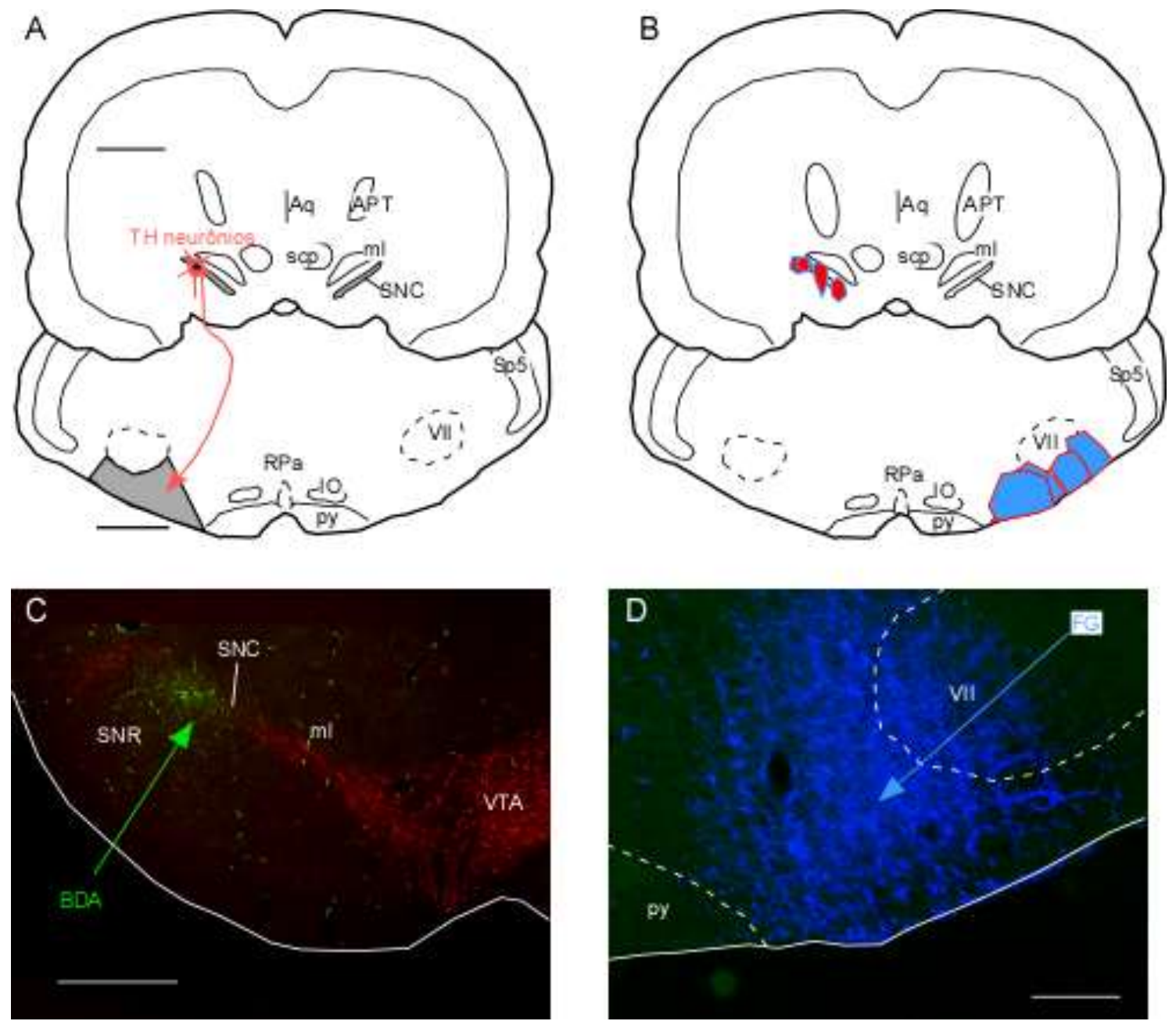

Figura 6 - Local das injeções na SN e RTN

A) Esquema representativo da via investigada entre neurônios dopaminérgicos da SN e neurônios do RTN. B) Representação esquemática das injeções de BDA na SN (em vermelho, no esquema superior) e FG no RTN (em azul, no esquema inferior). C) Fotomicrografia mostrando o local da injeção do traçador anterógrado dextrana-amina biotinilada (BDA) na região da substância negra (SN). Vermelho são exemplos de neurônios que foram imunorreativos para a enzima tirosina-hidroxilase (TH). D) Fotomicrografia mostrando o local da injeção do traçador retrógrado Fluorogold (FG) na região do núcleo retrotrapezóide (RTN). Abreviações: SNR: substância negra reticular; SNC: substância negra compacta; VTA: área tegmental ventral; ml: leminiscu medial, Aq: aqueduto mesencefálico, scp: pedúnculo cerebelar superior, APT: núcleo anterior pretectal; py: trato piramidal; Sp5: trato espinal do trigêmio; VII: núcleo motor do facial; $\mathrm{RPa}$ : núcleo da rafe pallidus. Escalas em $A=1 \mathrm{~mm}$ para $A-B, C=1 \mathrm{~mm}$ e $D=0,5 \mathrm{~mm}$. 
4.1.2 Avaliação de projeções indiretas da SN para o RTN, envolvendo a PAG

Apesar de não observarmos evidências de projeções diretas entre a SN e o RTN por meio do protocolo anterior, ao analisarmos os cortes originados desses grupos experimentais, pudemos observar a presença de varicosidades reativas para BDA e corpos celulares marcados com FG na região da PAG. Dessa forma, nossa próxima série de experimentos foi avaliar a existência de projeções diretas entre SN/PAG (Figura 7A) e PAG/RTN (Figura 9A). Para isso, analisamos os cortes decorrentes do protocolo anterior, fizemos mais 2 grupos experimentais com injeções de traçadores anterógrado e retrógrado na PAG e fizemos em um único animal a injeção do traçador anterógrado na $\mathrm{SN}$ e do retrógrado no RTN a fim de confirmarmos a existência dessas projeções.

\subsubsection{Avaliação de projeções diretas da SN para a PAG}

Em todos os casos com injeção positiva de BDA na SN exemplificados na figura 6B (esquema superior), observou-se reatividade para BDA na região da $P A G$, região envolvida em situações de perigo, em que o animal precisa mudar a sua respiração (SUBRAMANIAN e cols., 2008) (Figura 7B). Dessas projeções $30,8 \pm 9 \%$ eram glutamatérgicas e $37,7 \pm 14 \%$ eram GABAérgicas (Figuras 7BD) e se projetavam para a região dorsal da PAG, ao passo que na região ventral da PAG $36 \pm 3 \%$ das projeções eram glutamatérgicas e $40 \pm 6 \%$ eram GABAérgicas (Figura 7B-D). A proporção entre a quantidade de varicosidades excitatórias ou inibitórias foi semelhante em ambas regiões da PAG.

Para comprovar a existência dessa projeção direta da $S N$ para os neurônios da PAG, foram realizadas injeções de FG na PAG. $A$ análise histológica mostrou que o traçador retrógrado $F G$ foi injetado unilateralmente na PAG ventrolateral (Figura 8B). Foram realizadas 15 injeções, sendo que destas, 4 estavam localizadas na PAG (Figura 8A). Em todos os casos positivos apresentados na figura $8 \mathrm{~A}$, observou-se uma densa presença de corpos celulares marcados retrogradamente (imunorreativos para $F G$ ) na região da $S N$ que se colocalizaram com neurônios dopaminérgicos da SN (95 $\pm 2 \%$, Figuras $8 C-D)$. 
$A$

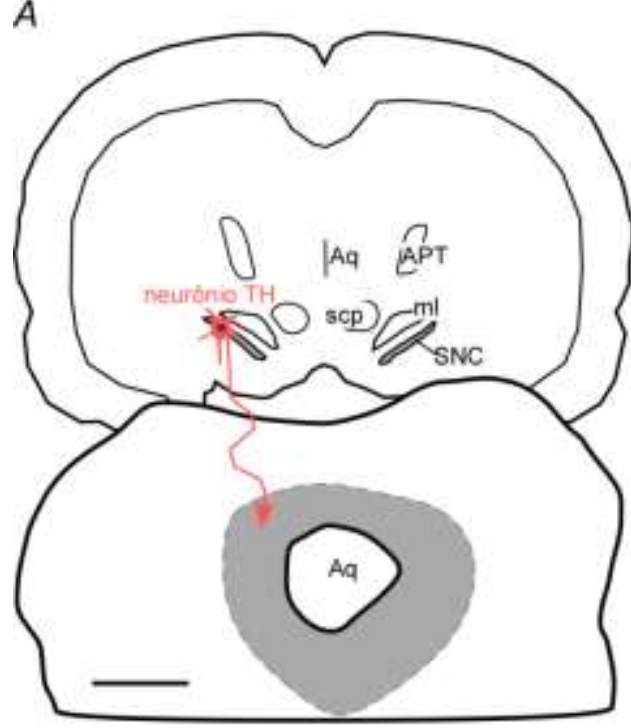

C

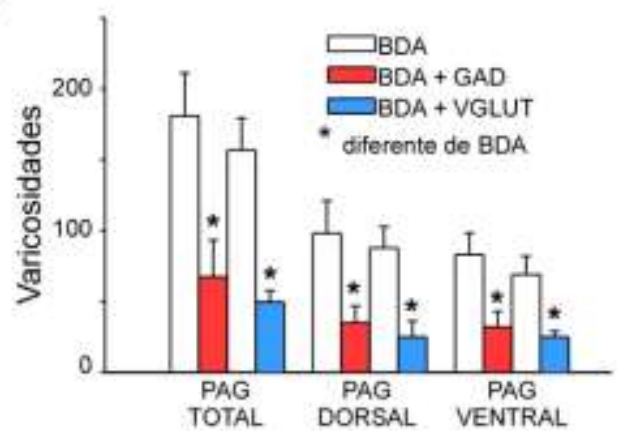

B1

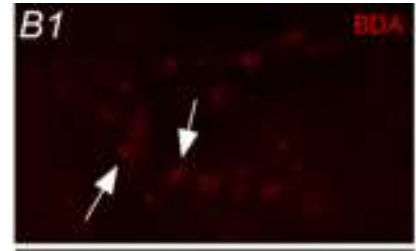

B2
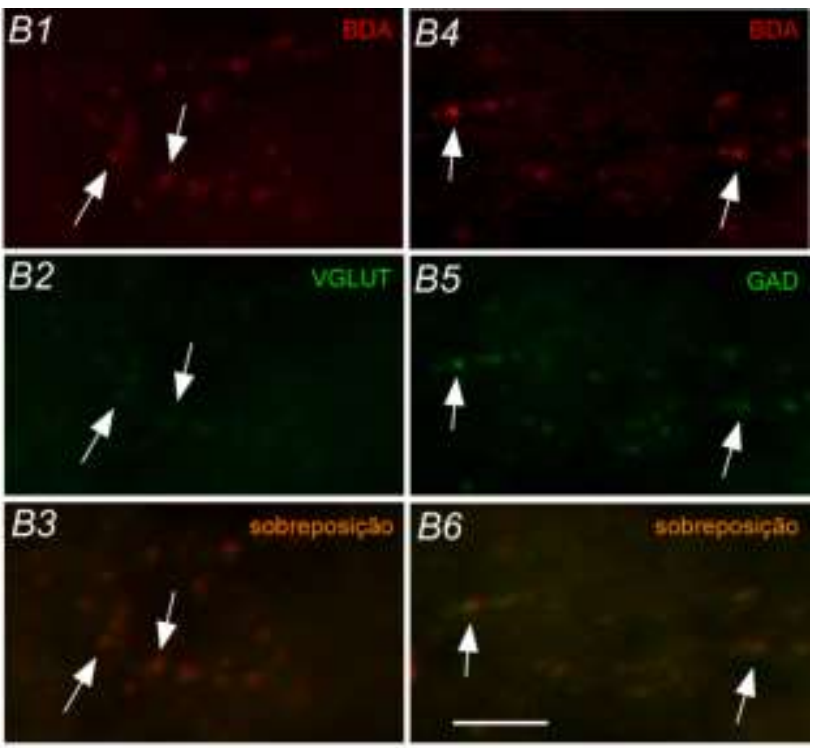

$\overline{B 5}$

$D$

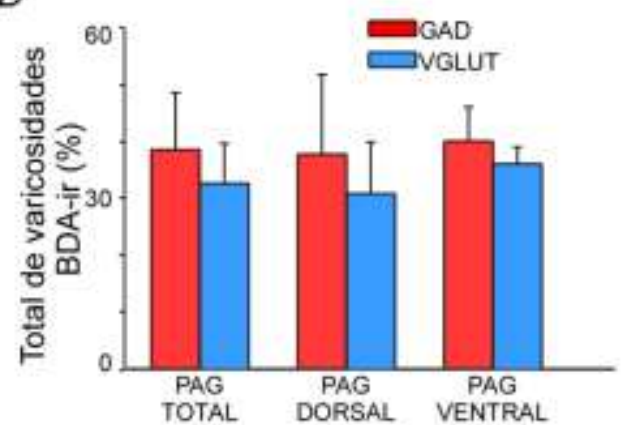

Figura 7 - Projeções da SN para a substância cinzenta periaquedutal (PAG): traçador anterógrado

A) Esquema representativo da via investigada entre neurônios dopaminérgicos da SN e neurônios da PAG. B) Varicosidades reativas com: BDA (vermelho), VGLUT2 ou GAD67 (verde) e a sobreposição das imagens (laranja); C) Número de varicosidades reativas para BDA que contêm imunorreatividade para VGLUT2 ou GAD67 nas regiões dorsal e ventral da PAG. D) porcentagem do total de varicosidades reativas para BDA na PAG que contêm imunorreatividade para VGLUT2 ou GAD67. * diferente de BDA. Abreviações: SNC: substância negra compacta; ml: leminiscu medial, Aq: aqueduto mesencefálico, scp: pedúnculo cerebelar superior, APT: núcleo anterior pretectal. Escalas em $\mathrm{A}=1 \mathrm{~mm}$ e $\mathrm{B} 6=5 \mu \mathrm{m}$ para $\mathrm{B} 1-\mathrm{B} 6$. 

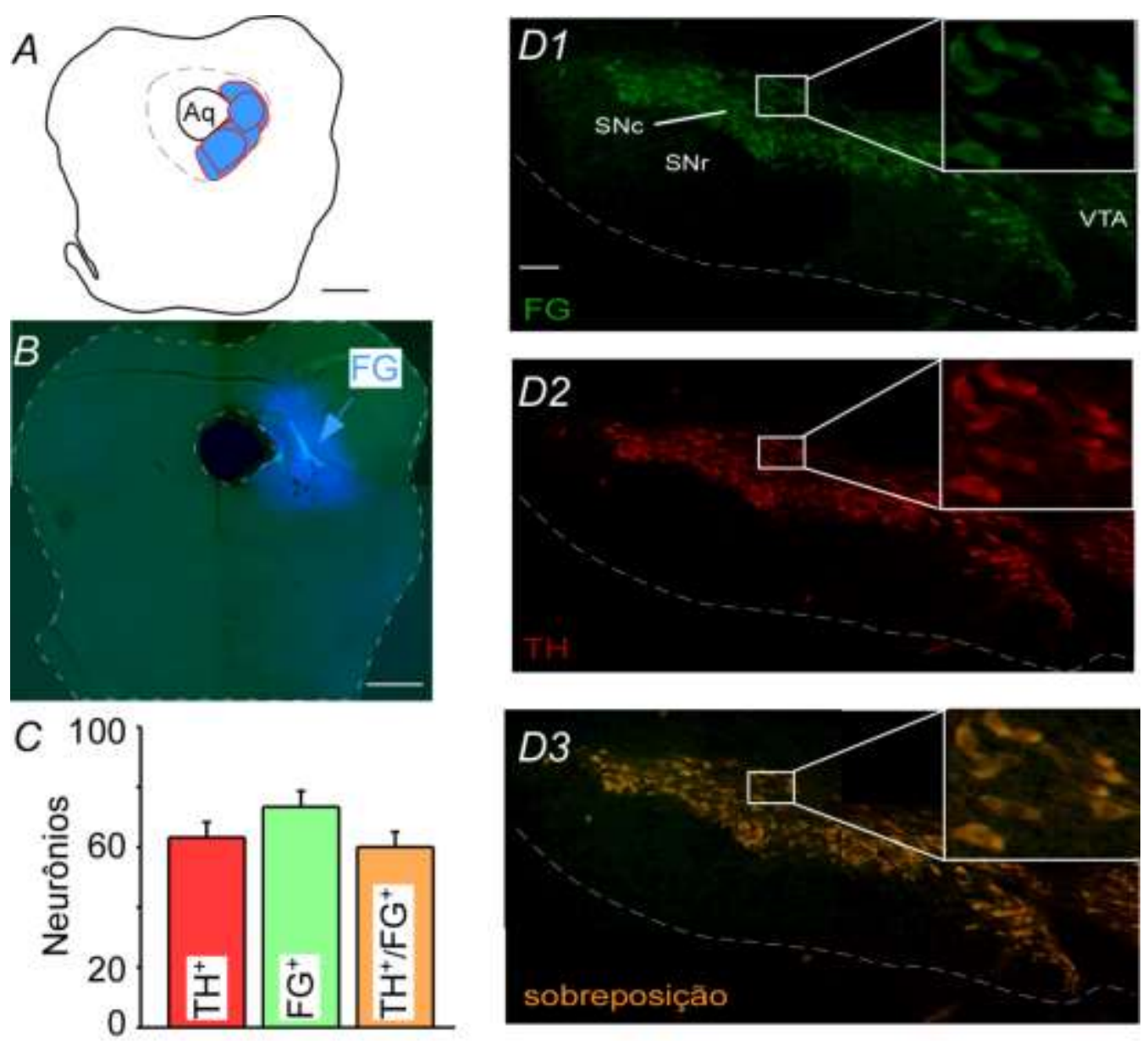

Figura 8 - Projeções da SN para a substância cinzenta periaquedutal (PAG): traçador retrógrado

A) Representação esquemática das injeções de FG na PAG. B) fotomicrografia mostrando o local da injeção do traçador retrógrado Fluorogold (FG) na região da PAG. C) Gráfico mostrando o número de neurônios que são dopaminérgicos $\left(\mathrm{TH}^{+}\right.$: barra vermelha), projetam-se para a PAG ( $\mathrm{FG}^{+}$: barra verde) e são dopaminérgicos e se projetam para a PAG $\left(\mathrm{TH}^{+} / \mathrm{FG}^{+}\right.$: barra laranja). D) Fotomicrografias de neurônios na região da SN marcados com FG (verde - D1), TH (vermelho - D2) e sobreposição (laranja - D3). Abreviações: Aq: aqueduto mesencefálico, SNc: substância negra compacta; SNr: substância negra reticular; VTA: área tegmental ventral. Escalas: A e B $=1 \mathrm{~mm} ; \mathrm{D} 1=100 \mu \mathrm{m}$ para D1-D3. 


\subsubsection{Projeções diretas da PAG para o RTN}

Em todos os casos com injeção positiva de FG no RTN exemplificados na figura 6B (esquema inferior), observou-se a presença de corpos celulares marcados com FG em todas as região da PAG (DM: $57 \pm 4$; DLe: $150 \pm 5$; DLd: $64 \pm 3$, V: $9 \pm 1$; VLe: $128 \pm 2$; VLd: $60 \pm 1$, Figuras 9B-D)

Para comprovar a existência dessa projeção direta da PAG para o RTN, foram realizadas injeções de BDA na PAG. A análise histológica mostrou que 0 traçador anterógrado BDA foi injetado unilateralmente na PAG dorsolateral ou ventrolateral (Figura 10G-H). Foram realizadas 10 injeções, sendo que destas, 2 estavam localizadas na PAG dorsolateral e 2 na PAG ventrolateral (Figura 10G). Em todos os casos positivos apresentados na figura 10G, observou-se imunoreatividade para BDA na região do RTN. Dessas projeções 46,29 $\pm 0,26 \%$ eram glutamatérgicas e $32,8 \pm 0,15 \%$ (Figuras 10C-F) eram GABAérgicas (Figuras 10A-F e 10I). Não houve diferença com relação à distribuição e quantidade de varicosidades encontradas no RTN nos diferentes casos em que o traçador foi injetado na porção dorso ou ventrolateral. 


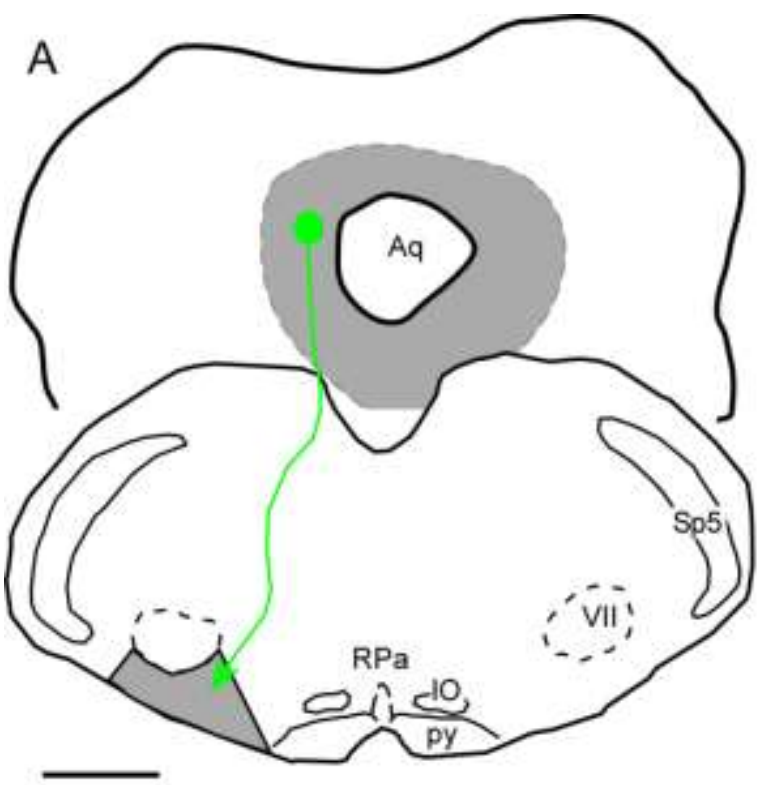

B
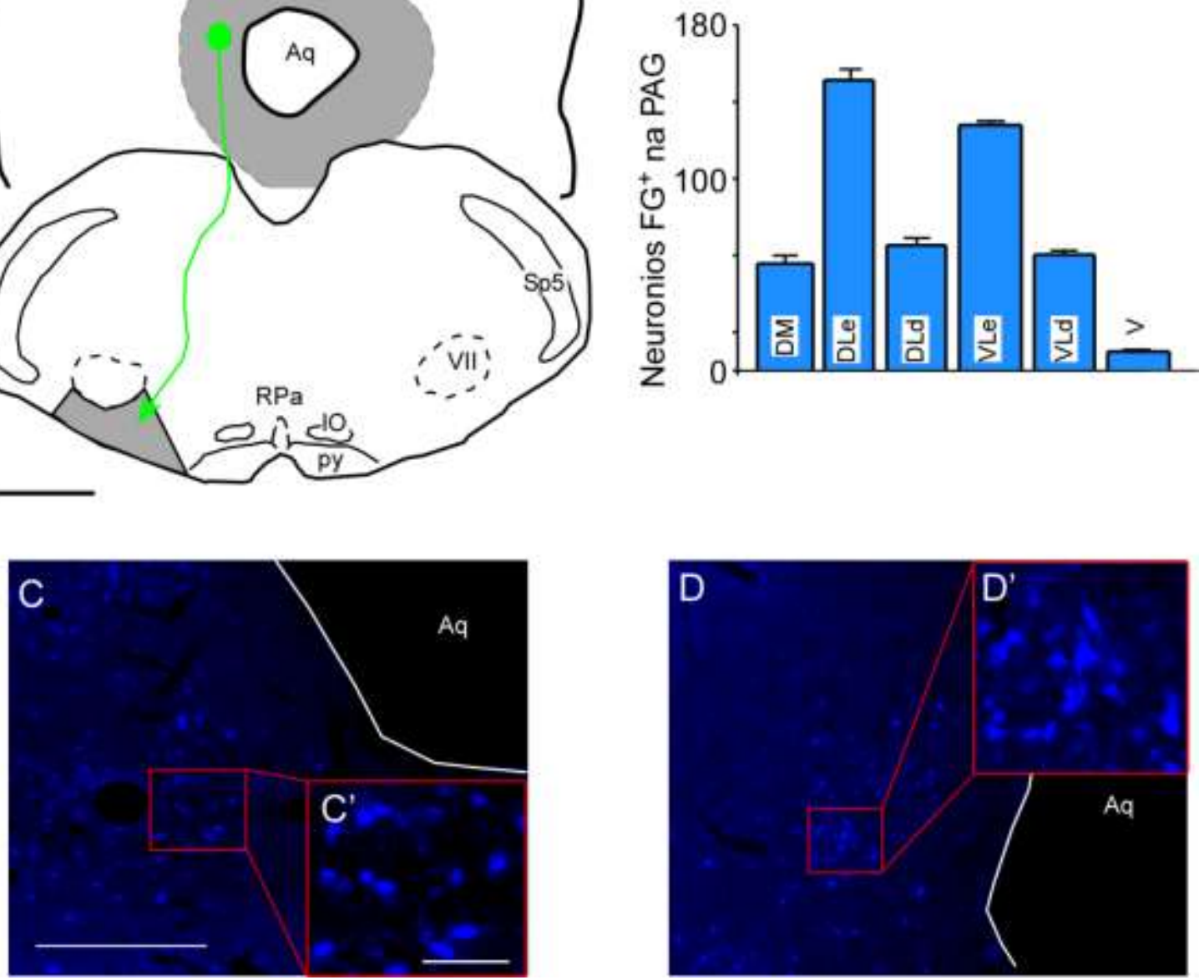

Figura 9 - Projeções da PAG para o RTN: traçador retrógrado

A) Esquema representativo da via investigada entre neurônios da PAG e neurônios do RTN. B) Gráfico representativo do número de neurônios de 4 ratos contados em 5 seções por encéfalo com FG nas diferentes regiões PAG. C) Fotomicrografia mostrando neurônios marcados com FG na região ventral da PAG. C') ampliação da região demarcada em vermelho na Fig. 9C. D) Fotomicrografia mostrando neurônios marcados com FG na região dorsal da PAG. D') ampliação da região demarcada em vermelho na Fig. 9D. Abreviações: Aq: aqueduto mesencefálico; RPa: núcleo da rafe pallidus: py: trato piramidal; Sp5: trato espinal do trigêmio; VII: núcleo motor do facial; IO: oliva inferior. Escalas: $A=1 \mathrm{~mm} ; C=250 \mu \mathrm{m}$ para $C-D ; C^{\prime}=50 \mu \mathrm{m}$ para $C^{\prime}-D^{\prime}$. 

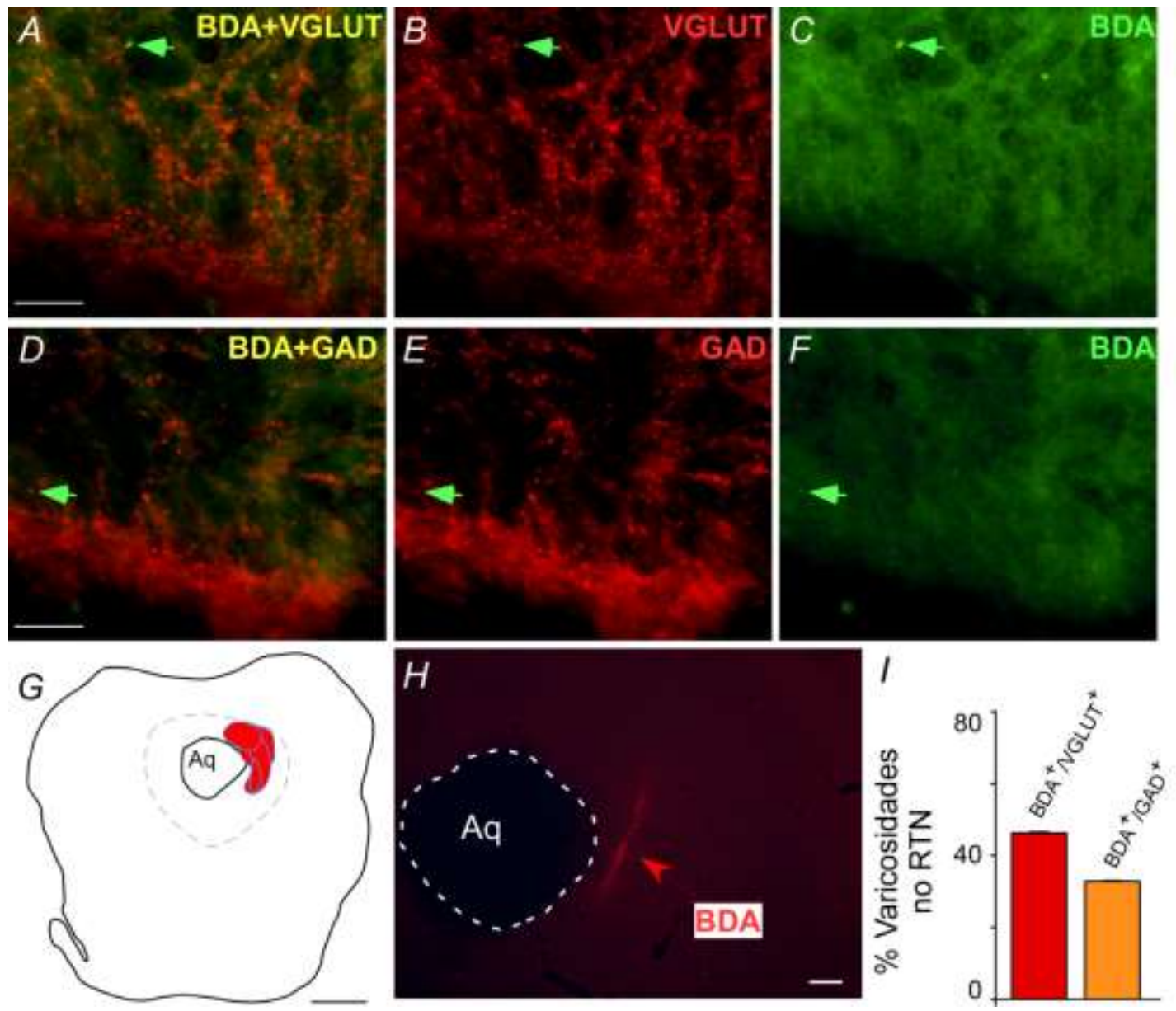

Figura 10 - Projeções da PAG para o RTN: traçador anterógrado

A) Fotomicrografia mostrando varicosidades duplamente marcadas com BDA e VGLUT2 na região do RTN. B) Fotomicrografia mostrando varicosidades marcadas com VGLUT2 na região do RTN. C) Fotomicrografia mostrando varicosidades marcadas com BDA na região do RTN. D) Fotomicrografia mostrando varicosidades duplamente marcadas com BDA e GAD67 na região do RTN. E) Fotomicrografia mostrando varicosidades marcadas com GAD67 na região do RTN. F) Fotomicrografia mostrando varicosidades marcadas com BDA na região do RTN. G) Representação esquemática das injeções de BDA na PAG. H) Fotomicrografia do sítio de injeção de BDA na PAG. I) Gráfico representativo da porcentagemde varicosidades contadas em 5 seções por encéfalo com BDA, GAD67 e/ou VGLUT2 nas diferentes regiões do RTN de 4 ratos. Abreviação: Aq: aqueduto mesencefálico. Escalas: $A$ e $D=25 \mu \mathrm{m}$ para A-F; $G=1 \mathrm{~mm}$; $\mathrm{H}=200 \mu \mathrm{m}$. 


\subsubsection{Avaliações de projeções da SN para os neurônios da PAG e destes para o RTN: traçador anterógrado e retrógrado}

Em um único caso foi realizada a injeção no mesmo animal do traçador anterógrado BDA na SN e do traçador retógrado FG no RTN. Ao analisarmos a PAG, pudemos observar a presença de varicosidades contendo BDA próximas a corpos celulares contendo FG, mais um indício de que os neurônios da SN se projetam para a região da PAG e se comunicam com neurônios da PAG que se projetam para a região do RTN (Figura 11).
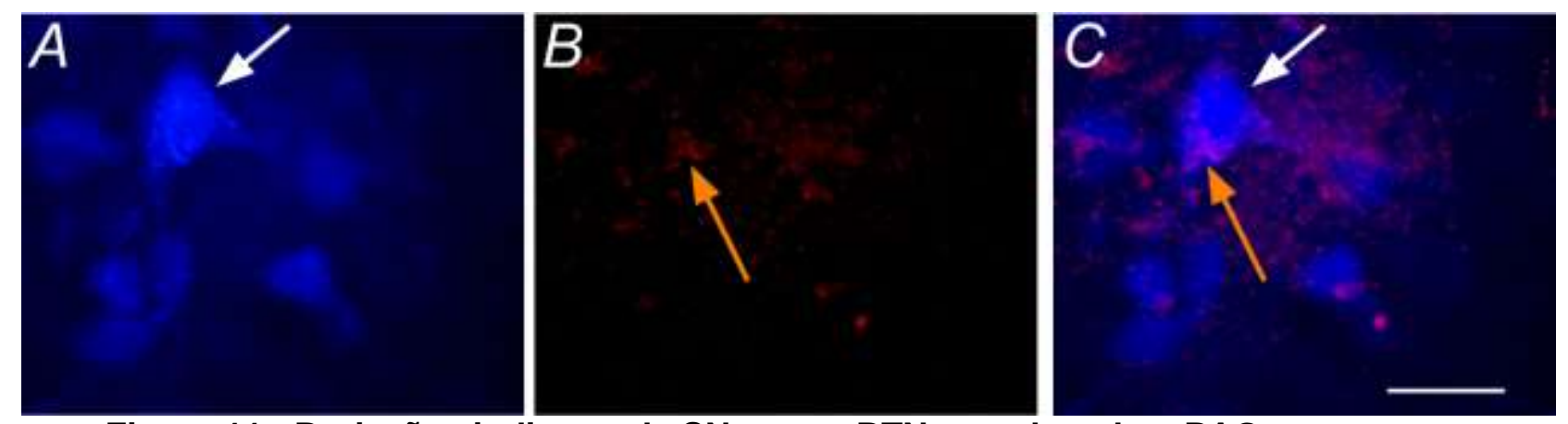

Figura 11 - Projeções indiretas da SN para o RTN, envolvendo a PAG

A) Fotomicrografia mostrando exemplos de neurônios marcados com FG na região da PAG (azul). B) Fotomicrografia mostrando exemplos de varicosidades imunorreativas para BDA na região da PAG (vermelho). C) Sobreposição das figuras 11A e 11B mostrando a proximidade entre os neurônios marcados com FG e as varicosidades contendo BDA na PAG. Escala em $\mathrm{C}=20 \mu \mathrm{m}$ para A - C. 


\subsection{Estudo neuroanatômico na PAG em animais submetidos ao modelo da DP induzido pela injeção bilateral de 6-OHDA no CPu}

Esta série de experimentos foi realizada para verificarmos se num modelo da DP induzido pela injeção da 6-OHDA no $\mathrm{CPu}$, em que observamos redução do número de neurônios da SN e RTN (Tuppy et al., 2015), também observaremos redução dos neurônios da PAG que se projetam para o RTN e são ativados por hipercapnia.

\subsubsection{Efeitos da injeção de 6-OHDA no CPu na imunorreatividade para TH de corpos celulares na $\mathrm{SN}$ e de varicosidades na região da PAG e para NeuN na região da PAG}

A toxina 6-OHDA $(24 \mu \mathrm{g} / \mu \mathrm{l})$ ou veículo foram injetados bilateralmente no $\mathrm{CPu}$ em ratos ( $n=5 /$ grupo). A imunorreatividade para tirosina-hidroxilase $(\mathrm{TH})$ foi analisada na região da $\mathrm{SN}$. Os neurônios $\mathrm{TH}^{+}$foram contados em 5 seções coronais por rato. Cada seção era de $240 \mu \mathrm{m}$ de distância. A figura 12A é uma fotomicrografia de um animal representativo do grupo controle, em que foi administrado veículo bilateralmente no $\mathrm{CPu}$. Como podemos observar, nos animais controles existe uma grande densidade de neurônios marcados com $\mathrm{TH}$ na região da $\mathrm{SN}$, situada no mesencéfalo. A figura 12B é uma fotomicrografia de um animal representativo do grupo 6-OHDA, onde podemos observar uma redução no número de neurônios $\mathrm{TH}^{+}$na $\mathrm{SN}$. Os resultados dos grupos indicaram que 6-OHDA foi efetiva em reduzir a quantidade de neurônios $\mathrm{TH}^{+}$na SN (462 \pm 33 , vs. veículo: $1850 \pm 25$ neurônios, $p<0,05$, Figura 12C). A dose utilizada da toxina reduziu o número de neurônios $\mathrm{TH}^{+}$em $75 \%$. Nesses animais, observamos também, como já descrito previamente, redução na freqüência respiratória basal $(66,1 \pm 1,0$ vs. veículo: $100,1 \pm 5,0$ respirações $/ \mathrm{min} ; p<0,05)$ e ventilação (394,1 $\pm 1,9$ vs. veículo: $545,6 \pm 21,4 \mathrm{ml} / \mathrm{kg} / \mathrm{min}, \mathrm{p}<0.001)$, sem alterar o volume corrente (6,0 $\pm 0,1$ vs. veículo: $5,5 \pm 0,4 \mathrm{ml} / \mathrm{kg}, \mathrm{p}>0.05)$ (Figura $12 \mathrm{D}-\mathrm{F})$. No mesmo grupo de animais, hipercapnia (7\% CO2) produziu um menor aumento na freqüência respiratória $(91,6 \pm 2,7$ vs. veículo: $128,3 \pm 8,1$ respirações/min, $p=0.005)$ e ventilação $(988,1 \pm 35,1$ vs. veículo: $1218,2 \pm 72,9$ $\mathrm{ml} / \mathrm{kg} / \mathrm{min}, \mathrm{p}=0.02$ ) comparado ao grupo controle (Figura 12D e 12F). 
Nesses animais, verificamos ainda se a injeção bilateral de 6-OHDA no CPu poderia também levar a uma redução do número de neurônios e de varicosidades imunorreativas para $\mathrm{TH}$ na PAG. A figura $13 \mathrm{~A}$ é uma fotomicrografia de um animal representativo do grupo controle em que foi administrado veículo bilateralmente no $\mathrm{CPu}$ e podemos observar uma grande densidade de neurônios marcados com NeuN na região da PAG. A figura 13B é uma fotomicrografia de um animal representativo do grupo 6-OHDA, em que podemos observar uma redução na densidade de neurônios marcados com NeuN na mesma região. Os resultados mostraram que a injeção de 6-OHDA foi capaz de reduzir a densidade de neurônios na região dorsomedial (10 \pm 3 , vs. veículo: $23 \pm 1 \%, p<0,05)$, dorsolateral ( $15 \pm 6$, vs. veículo: $38 \pm 2 \%, p<0,05)$ e ventrolateral ( $14 \pm 5$, vs. veículo: $30 \pm 1 \%, p<0,05)$ da $P A G$, ao passo que não observamos alterações na densidade de neurônios na região ventral $(11 \pm 4$, vs. veículo: $17 \pm 1 \%, p>0,05$ ) (Figura 13C). A figura 13D é uma fotomicrografia de um animal representativo do grupo controle em que foi administrado veículo bilateralmente no $\mathrm{CPu}$ e podemos observar uma grande quantidade de varicosidades imunorreativas para $\mathrm{TH}^{+}$na região da PAG. A figura 13E é uma fotomicrografia de um animal representativo do grupo 6-OHDA, em que podemos observar uma redução quantidade de varicosidades imunorreativas para $\mathrm{TH}^{+}$na mesma região. Os resultados mostraram que a injeção de 6-OHDA não foi capaz de reduzir significantemente a quantidade de varicosidades $\mathrm{TH}^{+}$na região dorsomedial ( $7 \pm 4$, vs. veículo: $24,5 \pm 12$, $p>0,05$ ), dorsolateral (37 \pm 9 , vs. veículo: $54 \pm 25, p>0,05)$, ventrolateral $(474 \pm 72$, vs. veículo: $863 \pm 161, p>0,05)$ e ventral da PAG (260 \pm 60 , vs. veículo: $396 \pm 66$, p>0,05) (Figura13F). 

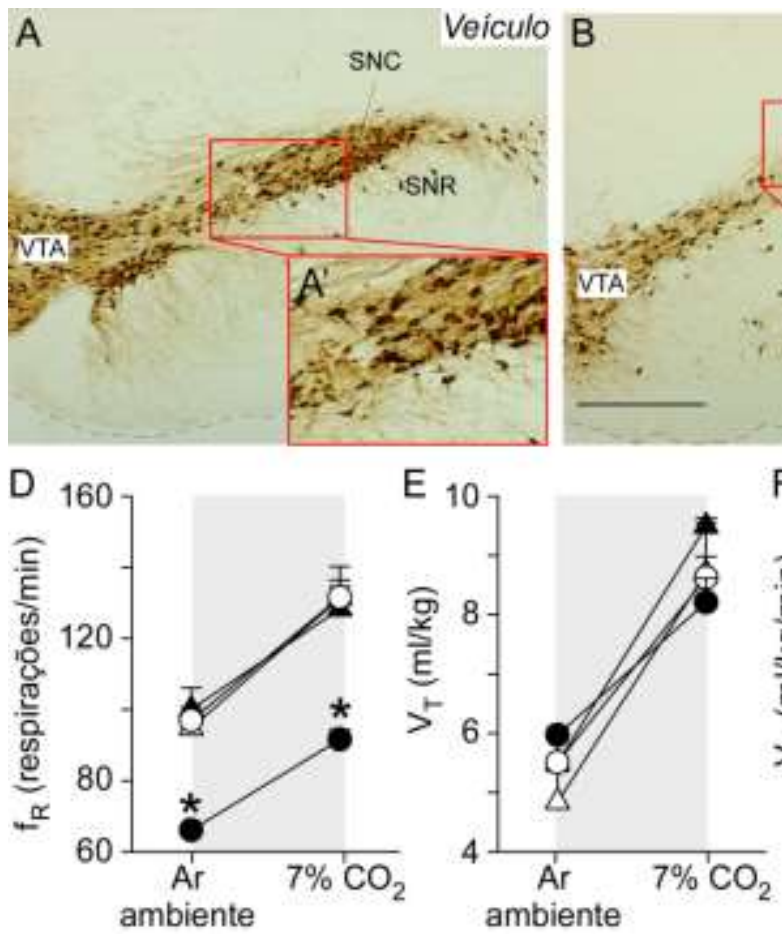
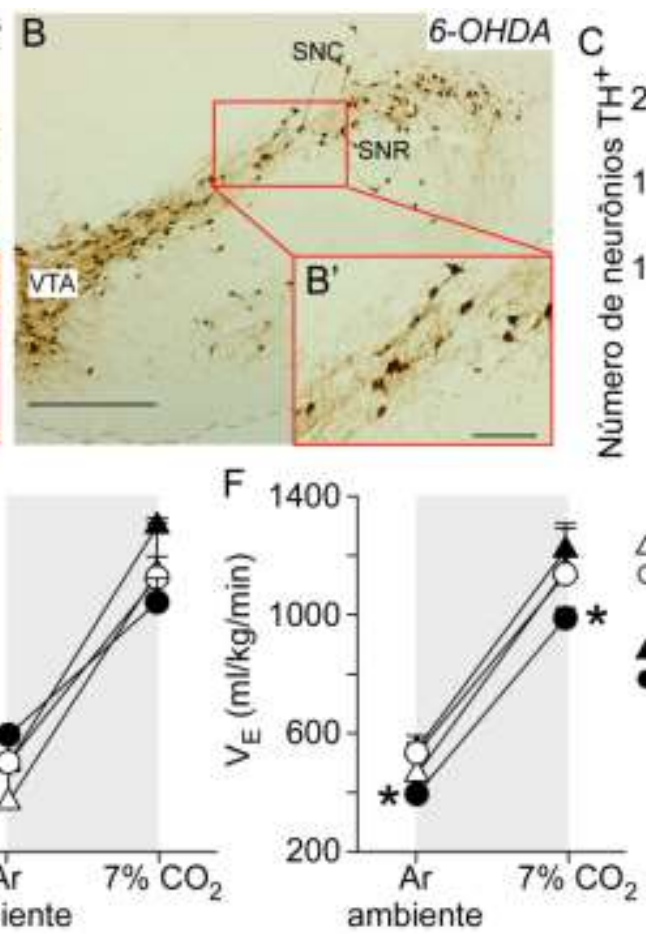

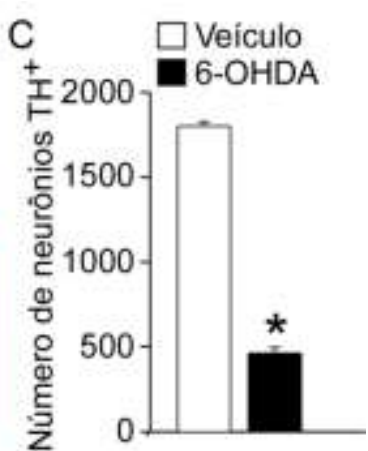

$\triangle$ Veículo (antes) 6-OHDA (antes)

Veículo (40 dias) 6-OHDA (40 dias)

Figura 12 - Alterações respiratórias observadas em um modelo animal de DP induzido pela injeção bilateral de 6-OHDA no CPu

Fotomicrografias mostrando a imunorreatividade para $\mathrm{TH}^{+}$na $\mathrm{SNcnos}$ grupos $\mathrm{A}$ ) veículo e B) 6-OHDA (24 $\mu \mathrm{g} / \mu \mathrm{l})$. A' e B') imagens ampliadas da figura 12A e B. C) Número de neurônios $\mathrm{TH}^{+}$em animais que receberam a injeção bilateral de veículo ou 6-OHDA no $\mathrm{CPu}$. Resumo das alterações observadas na $\mathrm{D}$ ) frequência respiratória ( $f R$ ), E) volume corrente (VT) e F) ventilação (VE) em animais que receberam veículo ou 6-OHDA no $\mathrm{CPu}$. *diferente de veículo. Abreviações: SNR: substância negra reticular; SNC: substância negra compacta; VTA: área tegmental ventral. Escalas em B $=500 \mu \mathrm{m}$ para $A-B$ e $B^{\prime}=100 \mu m$ para $A^{\prime}-B^{\prime}$. . 

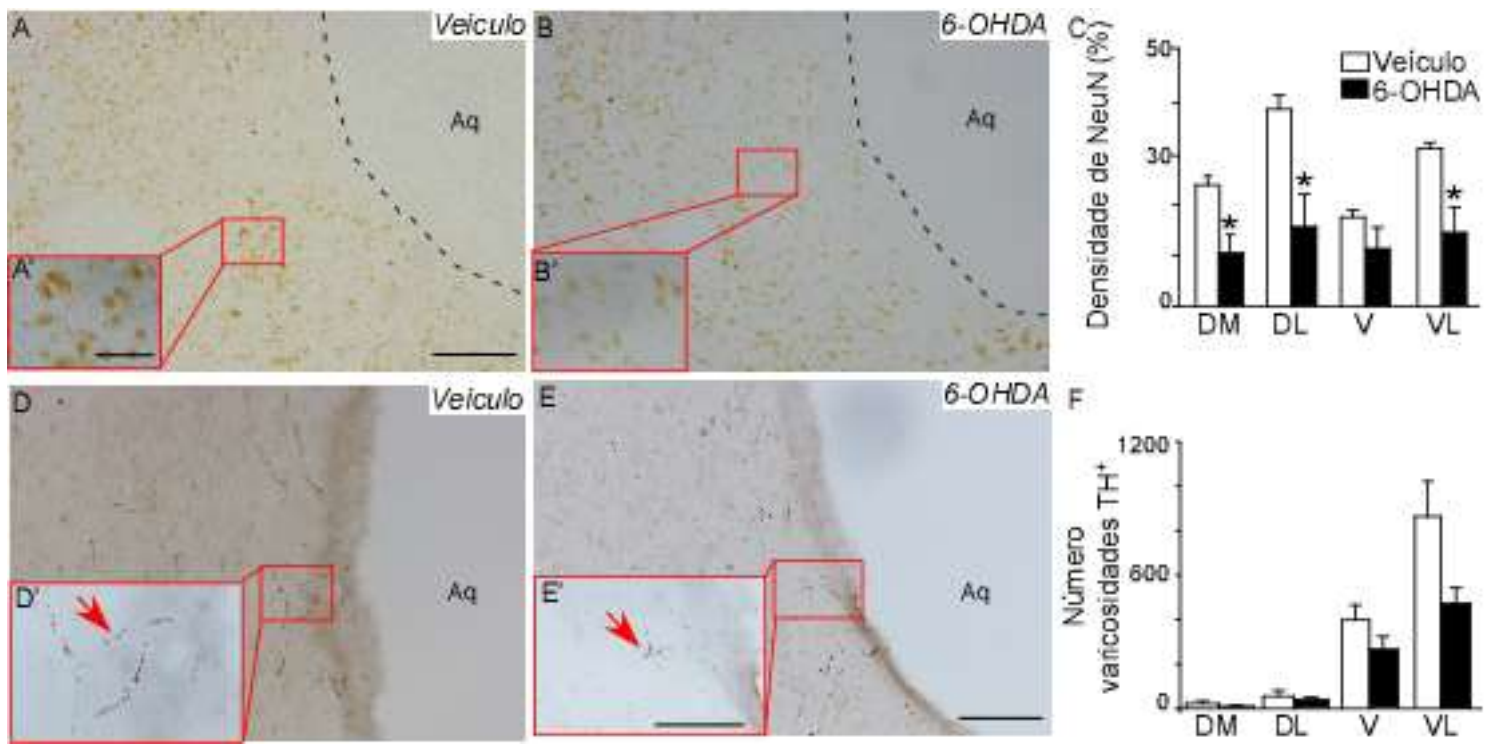

Figura 13 - Redução na densidade de neurônios que expressam NeuN e no número de varicosidades catecolaminérgicas na PAG observadas num modelo experimental de DP

Fotomicrografias de neurônios da PAG imunorreativos para NeuN de animais que receberam a injeção de A) veículo e B) 6-OHDA no CPu. Fotomicrografias de varicosidades da PAG imunorreativas para $\mathrm{TH}$ de animais que receberam a injeção de D) veículo e E) 6-OHDA no CPu. C) Densidade de neurônios marcados com NeuN na PAG. F) Número de varicosidades $\mathrm{TH}^{+}$na PAG. *diferente de veículo. Abreviaçções: Aq, aqueduto mesencefálico. Escalas em $A=400 \mu \mathrm{m}$ para $A-B, A^{\prime}=50 \mu \mathrm{m}$ para $A^{\prime}-B^{\prime}, D=$ $200 \mu \mathrm{m}$ para $\left.D_{-}-E\right)$ e $D^{\prime}=50 \mu \mathrm{m}$ para $D^{\prime}-E^{\prime}$. 
4.2.2 Alterações no número de neurônios da PAG que se projetam para o RTN e são ativados por hipercapnia observadas no modelo da DP induzido pela injeção de 6-OHDA no CPu

6-OHDA $(24 \mu \mathrm{g} / \mu \mathrm{l})$ ou veículo foram injetados bilateralmente no CPu em ratos ( $n=4 / g r u p o$ ). A imunorreatividade para tirosina-hidroxilase $(T H)$ foi analisada da mesma forma e no mesmo número de cortes que explicado no item anterior. A figura 14A é uma fotomicrografia de um animal representativo do grupo controle, em que foi administrado veículo bilateralmente no $\mathrm{CPu}$. Como podemos observar, nos animais controles existe uma grande densidade de neurônios marcados com TH na região da SN. A figura 14B é uma fotomicrografia de um animal representativo do grupo 6-OHDA, em que podemos observar uma redução no número de neurônios $\mathrm{TH}^{+}$na $\mathrm{SN}$. Os resultados dos grupos (Figura 14C) indicaram que 6-OHDA foi efetiva em reduzir a quantidade de neurônios $\mathrm{TH}^{+}$na SN (225 \pm 27 , vs. veículo: $1474 \pm 15$ neurônios, $\left.\mathrm{p}<0,05\right)$. Neste grupo experimental, a dose utilizada da toxina reduziu o número de neurônios $\mathrm{TH}^{+}$em $85 \%$.

Para testar se a injeção bilateral de 6-OHDA no CPu poderia também levar a uma redução de neurônios da PAG que se projetam para o RTN, analisamos a presença de corpos celulares na PAG marcados com o traçador retrógrado FG injetado no RTN (Figura 15A). A localização das injeções do traçador no RTN pode ser observada na Figura 15A-B. A figura 15C é uma fotomicrografia de um animal representativo do grupo controle em que foi administrado veículo bilateralmente no $\mathrm{CPu}$ e podemos observar uma grande densidade de neurônios marcados com FG na região da PAG . A figura $15 \mathrm{~F}$ é uma fotomicrografia de um animal representativo do grupo 6-OHDA, em que podemos observar uma intensa redução na densidade de neurônios marcados com FG na mesma região. Os resultados mostraram que a injeção de 6-OHDA foi capaz de reduzir o número de neurônios marcados com FG na região dorsomedial ( $9 \pm 1$, vs. veículo: $64 \pm$ 3 , $p<0,05$ ), dorsolateral esquerda (32 \pm 1 , vs. veículo: $150 \pm 5, p<0,05$ ), dorsolateral direita ( $24 \pm 0$, vs. veículo: $57 \pm 4, p<0,05$ ), ventrolateral esquerda ( $60 \pm 1$, vs. veículo: $128 \pm 2, p<0,05$ ), ventrolateral direita ( $20 \pm 1$, vs. veículo: 60 \pm 1 , $p>0,05)$ e região ventral ( $3 \pm 1$, vs. veículo: $9 \pm 1$, $p>0,05$ ) (Figura 15l). 
Esses mesmos animais foram expostos a um protocolo de 3 horas de hipercapnia antes de serem sacrificados para que pudéssemos observar se os neurônios reduzidos da PAG que se projetam para o RTN seriam também os neurônios ativados por $\mathrm{CO}_{2}$. As figuras $15 \mathrm{C}$-D são fotomicrografias de um animal representativo do grupo controle em que foi administrado veículo bilateralmente no $\mathrm{CPu}$ e podemos observar a presença de neurônios duplamente marcados com $F G$ e fos na região da PAG (Figuras $15 D-E$ ). As figuras $15 F-H$ são fotomicrografias de um animal representativo do grupo 6-OHDA, em que podemos observar uma redução na densidade de neurônios duplamente marcados com $F G$ e fos na mesma região (Figuras 15G-H). Os resultados mostraram que a injeção de 6-OHDA foi capaz de reduzir o número de neurônios duplamente marcados com $F G$ e fos na região da PAG dorsolateral esquerda $(0,75 \pm 0$, vs. veículo: $10 \pm 1, p>0,05)$, ventrolateral esquerda ( $3 \pm 2$, vs. veículo: 23 $\pm 2, p>0,05)$, ventrolateral direita ( $1 \pm 0$, vs. veículo: $10 \pm 0$, $p>0,05)$, mas não houve redução significativa na PAG ventral $(0 \pm 0$, vs. veículo: $2 \pm 0, p>0,05)$, dorsolateral direita ( $1 \pm 0$, vs. veículo: $10 \pm 0, p>0,05)$, dorsomedial $(0 \pm 0$, vs. veículo: $2 \pm 1, p>0,05$ ) (Figura 15l). 


\section{VEÍCULO}

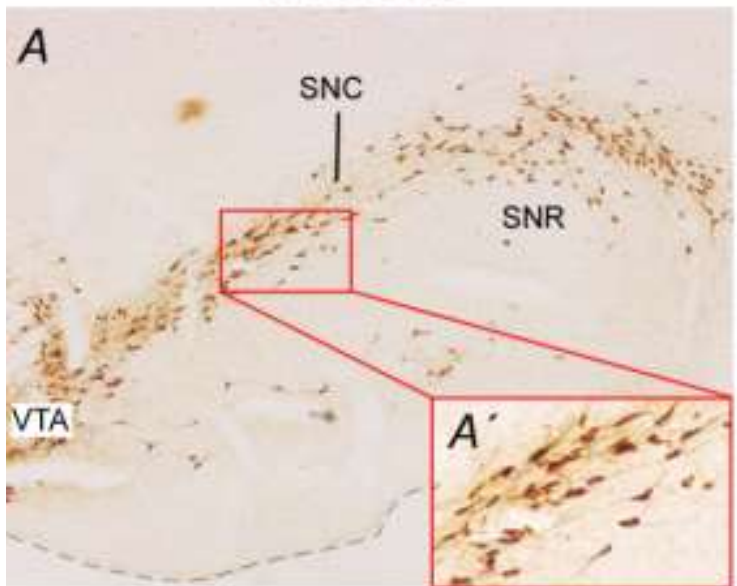

C

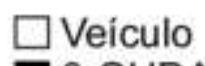

6-OHDA

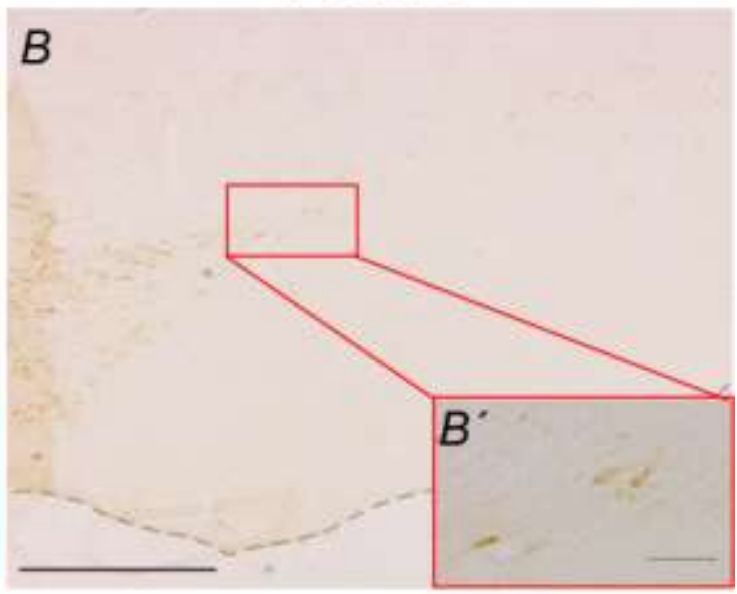

6-OHDA

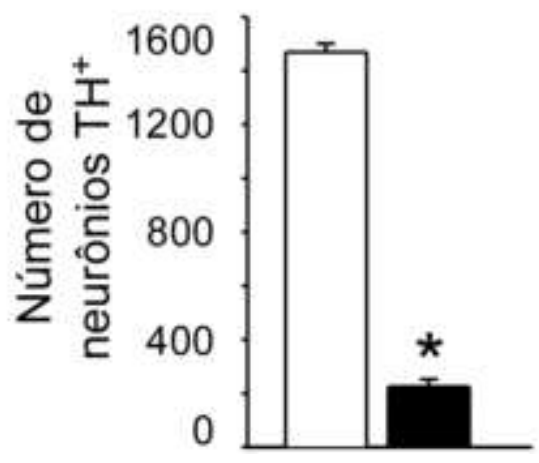

Figura 14 - A injeção bilateral de 6-OHDA no CPu leva à redução de neurônios $\mathrm{TH}^{+}$na SN.

A) Fotomicrografias mostrando a imunorreatividade para $\mathrm{TH}$ na $\mathrm{SN}$ nos grupos $\mathrm{A}$ ) veículo, A') imagem ampliada da figura 14A e B) 6-OHDA (24 $\mu \mathrm{g} / \mu \mathrm{l})$, B') imagem ampliada da figura 14B. C) Número de neurônios $\mathrm{TH}^{+}$em animais que receberam a injeção bilateral de veículo ou 6-OHDA $(24 \mu \mathrm{g} / \mu \mathrm{l})$ no $\mathrm{CPu} .{ }^{*}$ diferente de veículo. Abreviações: SNC: substância negra compacta; SNR: substância negra reticulada; VTA: área tegmental ventral. Escalas: $B=200 \mu \mathrm{m}$ para A-B e B' $=400 \mu \mathrm{m}$ para A'-B'. 

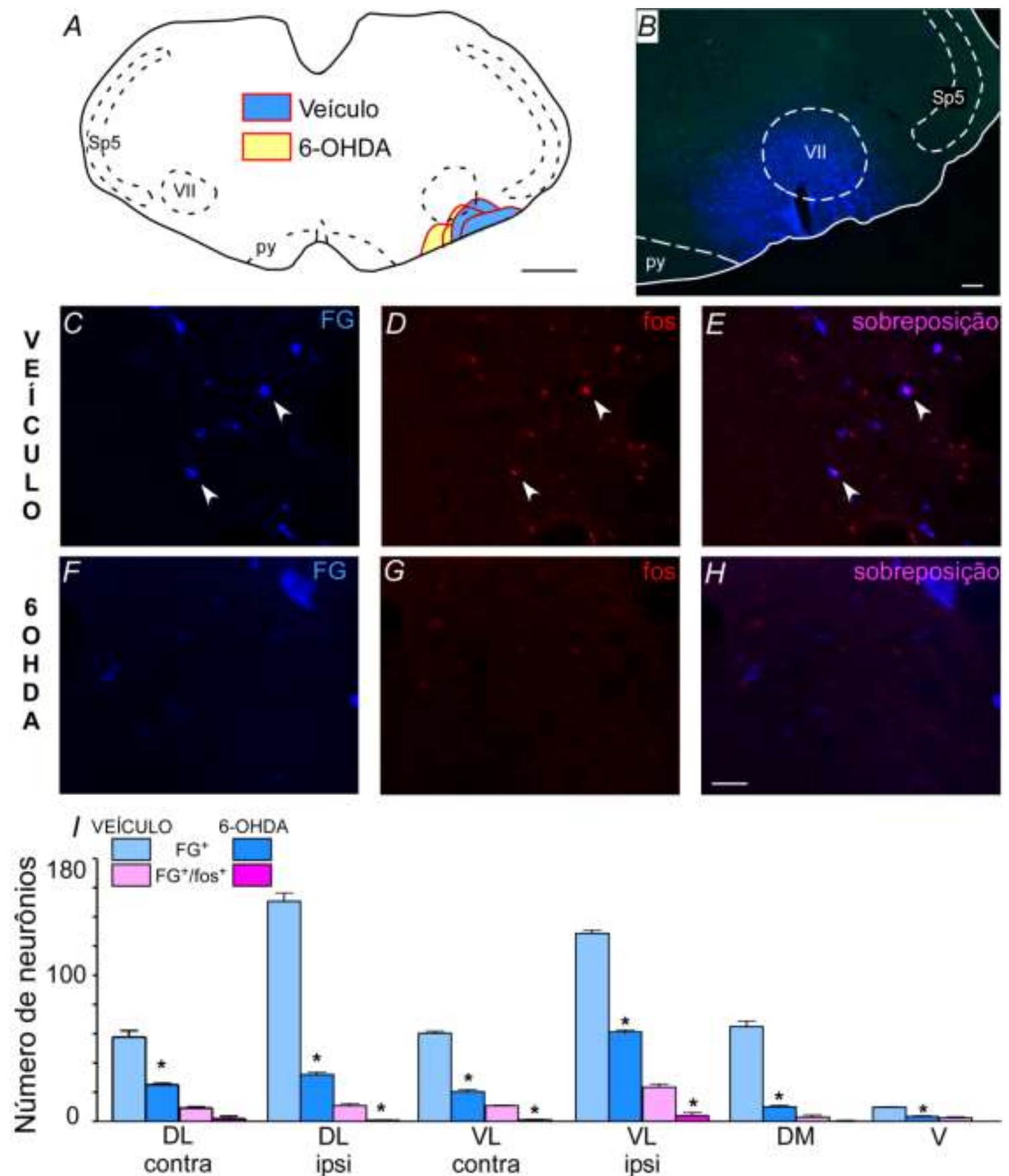

Figura 15 - A injeção bilateral de 6-OHDA no CPu leva à redução no número de projeções da PAG para o RTN que são ativadas por hipercapnia.

A) Representação esquemática dos sítios de injeção do traçador retrógrado FG injetado no RTN. B) Fotomicrografia do sítio de injeção de FG no RTN. C-H) Fotomicrografias da PAG de animais que receberam a injeção de veículo (C-E) ou 6-OHDA $(24 \mu \mathrm{g} / \mu \mathrm{l})(\mathrm{F}-\mathrm{H})$ no $\mathrm{CPu}$. $\mathrm{C}$ e F) neurônios marcados com $\mathrm{FG}, \mathrm{D}$ e $\mathrm{G}$ ) neurônios ativados por hipercapnia $\left(\right.$ fos $^{+}$) e $E$ e H) sobreposição das imagens C-D e F-G, respectivamente. I) Número de neurônios $\mathrm{FG}^{+}$e fos ${ }^{+}$na $\mathrm{PAG}$ de animais que receberam a injeção bilateral de veículo ou 6-OHDA $(24 \mu \mathrm{g} / \mu \mathrm{l})$ no $\mathrm{CPu}$. * diferente de veículo. Abreviações: Aq: aqueduto mesencefálico; py: trato piramidal; Sp5: trato espinal do trigêmio; VII: núcleo motor do facial. Escalas: $A=1 \mathrm{~mm}, \mathrm{~B}=200 \mu \mathrm{m}$, e $\mathrm{H}=200 \mu \mathrm{m}$ para $\mathrm{C}-\mathrm{H}$. 


\subsection{Estudo funcional em animais controles ou no modelo da DP}

A próxima série de experimentos foi realizada para observarmos se a inibição bilateral dos neurônios da PAG promoveria alterações nas respostas cardiorrespiratórias basais, induzidas por hipercapnia ou hipóxia em animais controles semelhantes às observadas em animais com DP.

Nos animais controles, as injeções de muscimol (agonista GABAérgico) foram realizadas bilateralmente na PAG (Figuras 16A-B). Foram realizadas 26 injeções. Destas apenas 6 estiveram localizadas na PAG, sendo que destas, 4 foram localizadas na região dorsolateral (região que quando ativada leva a aumento da frequência respiratória frente a estímulos como luta e fuga) e 2 na região ventrolateral (região com um importante papel na inibição da respiração frente a estímulos como congelamento e imobilidade) da PAG (Figuras 16A-B) (SUBRAMANIAN et al 2008; SUBRAMANIAN et al 2013). A Figura $16 \mathrm{~A}$ ilustra uma localização típica de injeções bilaterais de muscimol para o PAG e a figura $16 \mathrm{~B}$ representa um esquema que mostra a localização de seis injeções bilaterais de muscimol. A dispersão do microbeads contendo a droga foi de aproximadamente $250 \mu \mathrm{m}$ na direção rostro-caudal do centro da injeção.
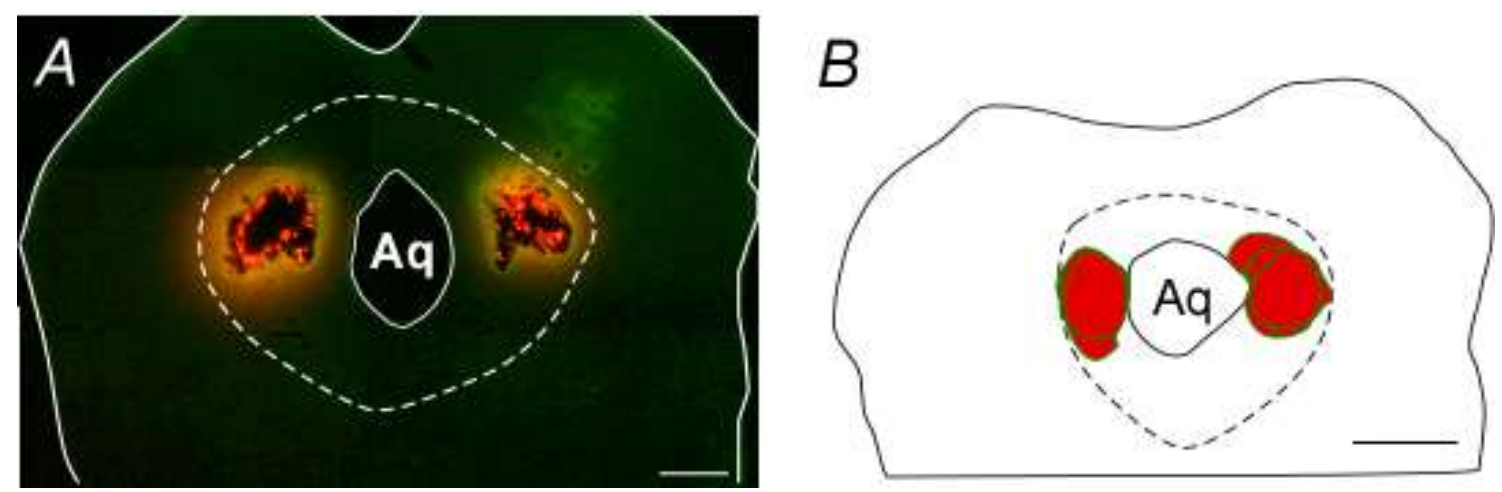

Figura 16 - Localização das injeções bilaterais do agonista GABAérgico muscimol na PAG

A) Fotomicrografia de um corte transversal do mesencéfalo de um rato mostrando a presença das microesferas de látex (beads) no local da injeção na região da PAG. B) Representação esquemática dos sítios positivos de injeções bilaterais de muscimol na PAG. Abreviações: Aq: aqueduto mesencefálico. Escalas: $A=400 \mu \mathrm{m}$ e $B=1 \mathrm{~mm}$. 
4.3.1 Efeitos da inibição da PAG ou injeção de 6-OHDA na CPu nas respostas respiratórias basais e induzidas pela ativação do quimiorreflexo central ou periférico

A injeção de muscimol na PAG não promoveu alterações na atividade basal do diafragma (DiaEMG frequência: 37,70 $\pm 1,75$ vs. veículo: 41,93 $\pm 2,29$ bpm; DiaEMG amplitude: 0,326 \pm 0,078 vs. veículo: 0,308 $\pm 0,024 \mathrm{mV}, \mathrm{p}>0,05$ ) e do genioglosso (GGEMG frequência: $37,00 \pm 2,06$ vs. veículo: 44,20 $\pm 2,71$ bpm; GGEMG amplitude: 0,379 \pm 0,076 vs. veículo: 0,382 $\pm 0,015 \mathrm{mV}, \mathrm{p}>0,05$ ) (Figuras 17A-C e 17E-F). Entretanto, em animais submetidos ao modelo experimental da DP, que apresentaram uma redução de $87 \%$ dos neurônios dopaminérgicos da SNpc (1474 \pm 15 neurônios vs. veículo: $225 \pm 27$ neurônios), observa-se uma redução na frequência do DiaEMG $(33,58 \pm 2,16$ vs. veículo: $41,93 \pm 2,29 \mathrm{bpm})$ e do GGEMG (30,92 $\pm 2,29$ vs. veículo: 44,20 $\pm 2,71)$ e na amplitude do GGEMG (0,228 \pm 0,012 vs. veículo: 0,382 $\pm 0,015 \mathrm{mV}, \mathrm{p}<0,05)$, sem alterar a amplitude do DiaEMG (Figuras 17A-C e 17E-F).

A ativação do quimiorreflexo central por hipercapnia $\left(7 \% \mathrm{CO}_{2}\right)$ promoveu um pequeno aumento na amplitude do abdominal (AbdEMG: 0,303 0 0,051 vs. veículo: $0,529 \pm 0,061 \mathrm{mV}, \mathrm{p}<0.05)$ e do GGEMG $(0,778 \pm 0,148$ vs. veículo: $1,278 \pm 0,058 \mathrm{mV}, \mathrm{p}<0,05)$ em animais controles que receberam a injeção de muscimol na PAG, sem alterar a freqüência e amplitude do DiaEMG ea freqüência do AbdEMG e GGEMG (Figuras 17A-G). O mesmo estímulo em animais submetidos ao modelo experimental de DP promoveu um pequeno aumento na freqüência do DiaEMG (44,69 $\pm 3,26$ vs. veículo: 61,63 $\pm 2,87$ bpm, p < 0,05) e do GGEMG (44,65 $\pm 2,94$ vs. veículo: $61,24 \pm 3,28$ bpm, $p<0,05)$ e na amplitude do GGEMG (0,631 $\pm 0,081$ vs. veículo: 1,278 $\pm 0,058 \mathrm{mV}, \mathrm{p}<0,05)$, freqüência do AbdEMG (34,47 $\pm 2,79$ vs. veículo: 53,28 $\pm 1,34$ bpm) e amplitude do AbdEMG (0,266 \pm 0,036 vs. veículo: 0,529 $\pm 0,061 \mathrm{mV}, \mathrm{p}<0,05)$ (Figuras $17 A-G)$. 
Decidimos também testar um diferente estímulo respiratório pela ativação dos quimiorreceptores periféricos com a injeção endovenosa de KCN $(40 \mu \mathrm{g} / 0,1$ $\mathrm{ml}$ ). Os resultados mostraram que a inibição da PAG por muscimol ou pela indução prévia do modelo de DP não promoveu alterações significantes nas atividades do DiaEMG, GGEMG e AbdEMG produzidas pela injeção i.v. de KCN (Figuras 18A-G). 


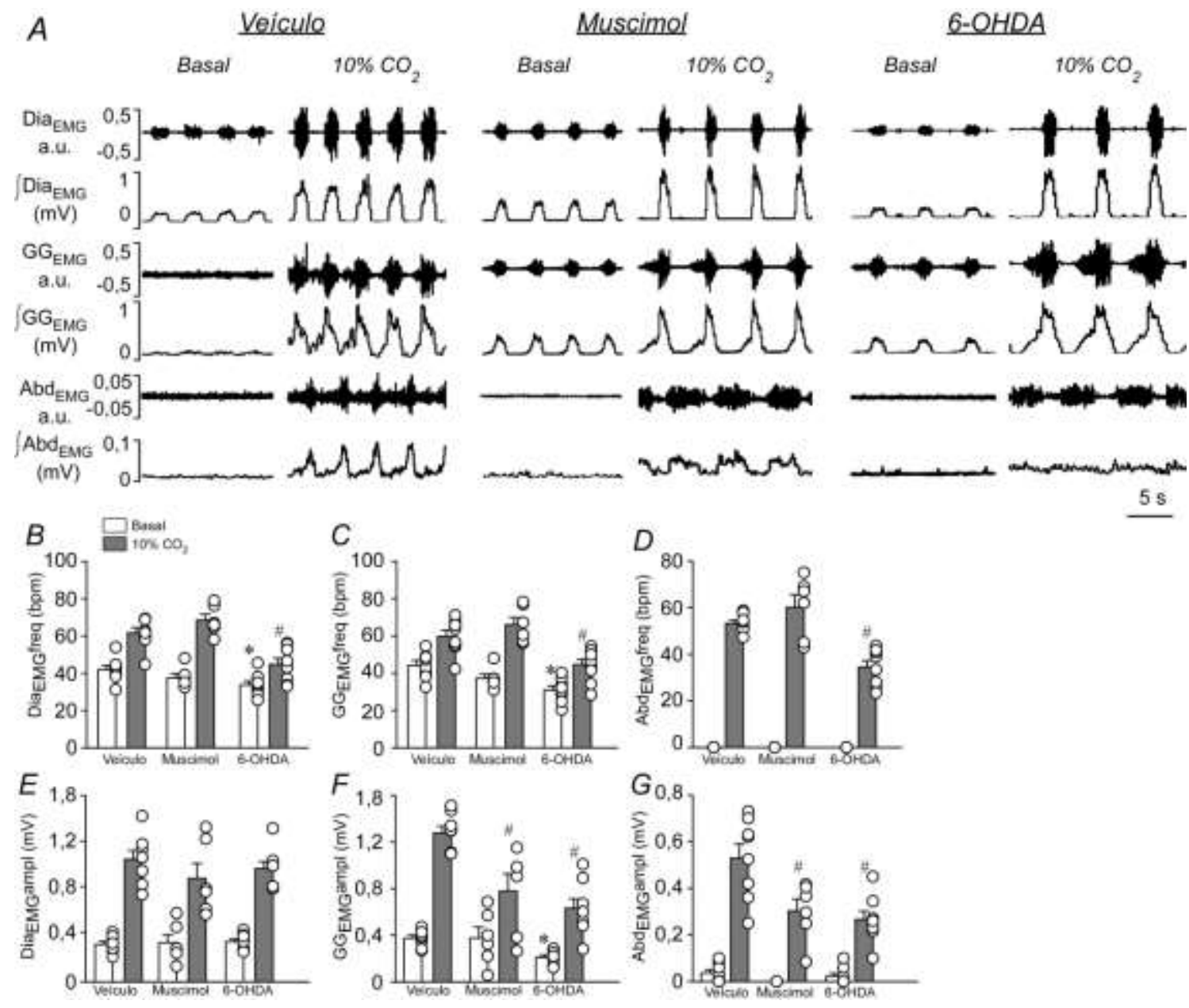

Figure 17 - Respostas respiratórias basais ou produzidas por hipercapnia em animais que receberam injeção de veículo ou muscimol na PAG ou em animais submetidos ao modelo da DP

A) Registro de ratos mostrando os efeitos da injeção bilateral de veículo ou muscimol na PAG, ou 6-OHDA no CPu em condições basais ou após a exosição à hipercapnia, representando alterações na atividade eletromiográfica do diafragma (DiaEMG), genioglosso (GGEMG) e abdominal (AbdEMG). Alterações na frequência do B) DiaEMG C) GGEMG e D) AbdEMG e amplitude do E) DiaEMG, F) GGEMG and G) AbdEMG promovidas pela injeção de veículo ou muscimol na PAG, ou 6-OHDA no CPu em condições basais ou após hipercapnia. *diferente de veículo - Basal $(p<0,05)$ e \# diferente de Veículo $\left(10 \% \mathrm{CO}_{2}\right)$. 


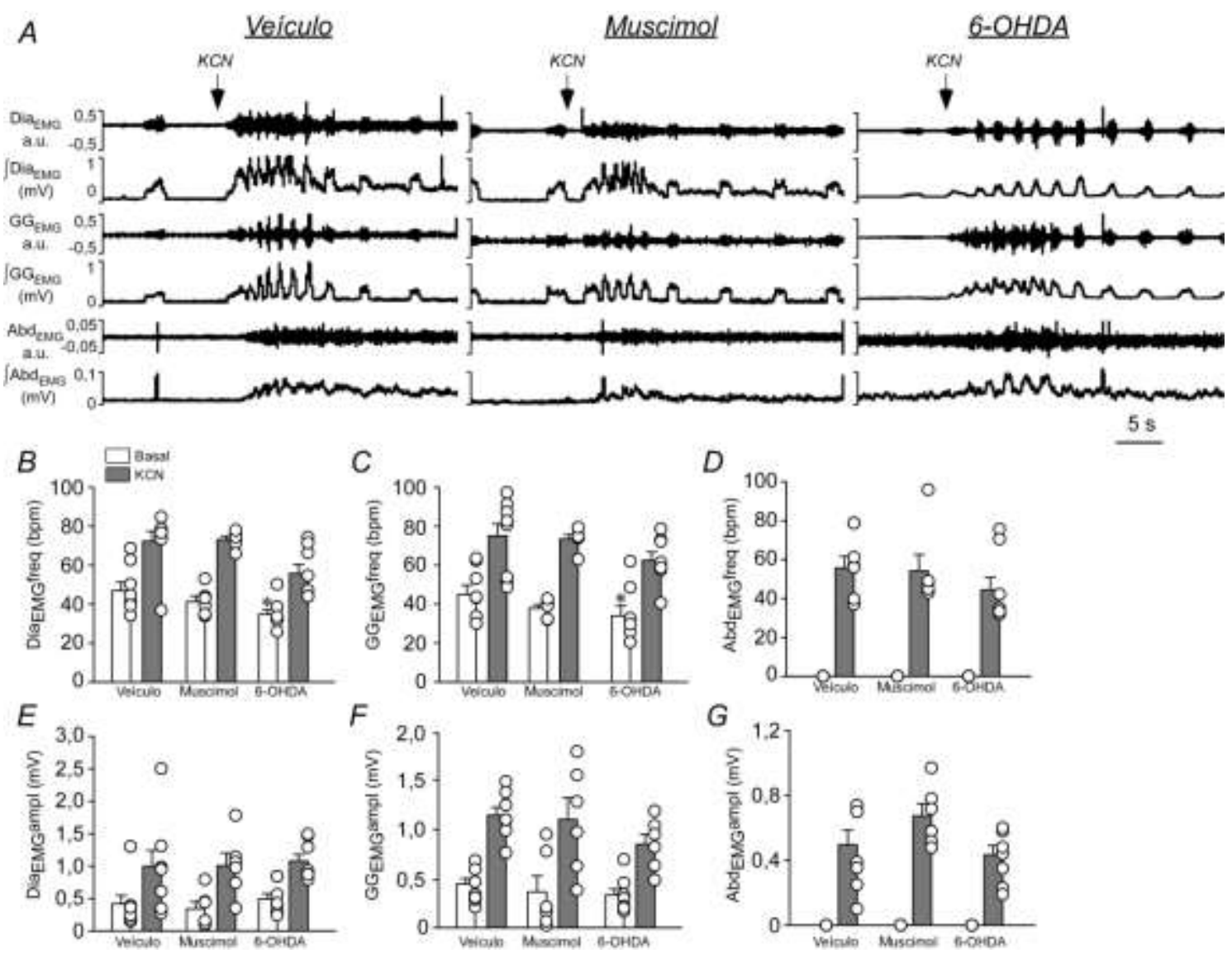

Figure 18 - Respostas respiratórias produzidas pela injeção endovenosa de KCN em animais que receberam injeção de veículo ou muscimol na PAG ou em animais submetidos ao modelo da DP

A) Registro de ratos mostrando os efeitos da injeção bilateral de veículo ou muscimol na PAG, ou 6-OHDA no CPu após a injeção iv de KCN, representando alterações na atividade eletromiográfica do diafragma (DiaEMG), genioglosso (GGEMG) e abdominal (AbdEMG). Alterações na frequência do B) DiaEMG C) GGEMG e D) AbdEMG e amplitude do E) DiaEMG, F) GGEMG and G) AbdEMG promovidas pela injeção de veículo ou muscimol na PAG, ou 6-OHDA no CPu após a injeção de KCN. *diferente de veículo - Basal $(p<0,05)$. 


\section{DISCUSSÃO}

Em um primeiro momento nosso objetivo foi investigar a existência de uma via direta entre SN e RTN que pudesse auxiliar no entendimento das alterações respiratórias e na perda neuronal de regiões que influenciam a respiração no modelo experimental da DP. Entretanto, os dados obtidos mostraram, por meio de injeção de traçadores anterógrado e retrógrado, que não existe uma via direta, mas possivelmente a comunicação entre essas duas regiões faça-se de uma forma indireta, envolvendo neurônios da PAG, onde fica claro que os neurônios dopaminérgicos da SN se projetam de forma direta para os neurônios da PAG e estes, por sua vez, se projetam de forma direta para a região do RTN e que no modelo da DP induzido pela injeção de 6-OHDA no $\mathrm{CPu}$, o número total de neurônios da região da PAG também está reduzido, assim como as projeções de neurônios da PAG para a região do RTN que são ativados por hipercapnia também estão reduzidas. Por fim, os nossos dados também possibilitaram a observação de que, apesar de mais brandas do quando comparadas às alterações respiratórias observadas no modelo experimental da DP, a inibição da PAG em animais controles também leva a deficiências respiratórias induzidas por hipercapnia.

\subsection{Eferências da SNc}

Estudos prévios do nosso laboratório mostraram que a injeção de 6OHDA no CPu leva a uma extensa degeneração de neurônios dopaminérgicos da SN, bem como dos neurônios imunorreativos para o fator de transcrição Phox2b expressos nos neurônios do RTN (TUPPY et al., 2015). Assim, o nosso principal objetivo era investigar se o motivo para essa redução de neurônios bulbares era devido à redução de projeções da SN para o RTN. A SN é uma região localizada no mesencéfalo que é dividida em duas populações neuronais denominadas $\mathrm{SN}$ reticulada $(\mathrm{SNr}$ ) composta por neurônios predominantemente GABAérgicos compondo um grupo de neurônios do núcleo da base que são denominados núcleos de saída (inclui também o globo pálido interno) que envia informações inibitórias para o tálamo a fim de realizar ajustes do movimento. A outra população de neurônios da SN é a porção compacta (SNc) que tem como 
característica a presença de um pigmento preto (neuromelanina), que é um polímero precursor da DOPA, sendo, portanto, esses neurônios dopaminérgicos (ALEXANDER et al., 1986). A SNc também compõe os núcleos da base sendo denominada um dos grupo de neurônios dos núcleos intrínsecos (incluem também o globo pálido externo e área tegmentar ventral). Por serem neurônios dopaminérgicos, a liberação de dopamina dos neurônios da SNc ativa receptores D1 e D2 no estriado. De uma forma bem simples, podemos afirmar que a ativação de receptores D1 ativa a via direta que gera o movimento e a estimulação de receptores D2 ativa a via indireta que inibe o movimento (JOEL et al., 1994).

Entretanto, nada se sabe a respeito de projeções da SNc para regiões bulbares. Os trabalhos da literatura apenas buscaram investigar a presença de projeções da SNc para o estriado (PRENSA; PARENT, 2001) e bulbo olfatório (HÖGLINGERr et al., 2015); ROSIN e colaboradores em 2006 estudaram as aferências e eferências do RTN. Nesse trabalho, fica claro que a injeção de um traçador retrógrado na região do RTN não leva a existência de corpos celulares marcados com o traçador na região da SNc, sendo um indício de que não existem projeções diretas entre essas 2 regiões. Nos nossos resultados, pudemos confirmar esses dados, pois não observamos a presença de varicosidades na região do RTN marcadas com o traçador anterógrado que foi injetado na SNc; e também não observamos a presença de corpos celulares na região da SNc marcados com o traçador retrógrado que foi injetado na região do RTN. Com esses dados, fica claro que não existem projeções diretas entre essas duas regiões.

Entretanto, ao analisarmos os cortes encefálicos do nosso estudo, observamos uma região intermediária entre a SNc e o RTN, que apresentava o traçador retrógrado, ou seja, se projetava para o RTN e o traçador anterógrado, ou seja, recebia projeções da SNc. Essa região era a PAG. Trabalhos anteriores evidenciaram eferências da PAG para a SN por meio da injeção de traçador retrógrado na região da SN (SUCHOW et al, 2013) entretanto não havia sido observado até o momento projeções da SN para a PAG. Assim decidimos confirmar a existência de projeções diretas da SNc para a PAG e desta para o RTN. 


\subsection{Aferências e eferências da PAG}

Diversas estruturas encefálicas que organizam comportamento de defesa e controlam o medo e a ansiedade estão envolvidas com desordens do pânico (DEL-BEN; GRAEFF, 2009). Dentre essas estruturas, podemos citar o córtex préfrontal, amídala, hipocampo, hipotálamo e a PAG (DEL-BEN; GRAEFF, 2009). A PAG constitui um grupo de células organizado em 4 colunas longitudinais (dorsomedial, dorsolateral, lateral e ventrolateral) que se localizam ao redor do aqueduto mesencefálico, e os primeiros estudos sobre esta região demonstraram seu envolvimento na nocicepção (CARRIVE, 2000; MAGOUN et al., 1937). Posteriormente, trabalhos realizados mostraram o papel desta região nas reações comportamentais frente a estímulos emocionais como pânico, ansiedade, sensação de morte eminente que levam a alterações sistêmicas de termorregulação, cardiovasculares e respiratórias (BANDLER et al., 2000; BEHBEHANI, 1995; LOPES et al., 2014; NASHOLD et al., 1969; NAKAMURA; MORRISON, 2007; SUBRAMANIAN et. al., 2008; ZHANG et. al., 2007).

A conexão entre o sistema respiratório e desordens de pânico já foram descritas na literatura (GORMAN et. al., 2000; KLEIN, 1993). Alguns pacientes com desordem de pânico exibem resposta ventilatória à hipercapnia aumentada comparada a indivíduos normais (NARDI et. al., 2009). Entretanto, as respostas cardiorrespiratórias são diferentes dependendo da região da PAG estimulada (CARRIVE \& BANDLER, 1991; CARRIVE, 2000; Zhang e cols., 2007) devido a diferenças de densidades de receptores e conexões existentes nas diferentes subregiões da PAG (BANDLER \& KEAY, 1996).

A estimulação elétrica e química da PAG dorsal promove aumento na frequência respiratória e volume corrente em gatos e ratos (BASSAL \& BIANCHI, 1982; HAYWARD et. al., 2003; SUBRAMANIAN; HOLSTEGE, 2009; SUBRAMANIAN et. al., 2007; ZHANG et. al., 2007). Essa região recebe aferências e envia projeções para diferentes regiões motoras, sensoriais, autônomas e límbicas (BANDLER et. al., 1991; BEITZ, 1990; CANTERAS; SWANSON, 1992; SAWCHENKO et. al., 1983; SEWARDS; SEWARDS, 2002), indicando que a região dorsal da PAG está conectada a múltiplos circuitos neurais responsáveis por modulações fisiológicas que são necessárias à 
sobrevivência. Enquanto a ativação da PAG dorsal aumenta a pressão arterial e a frequência cardíaca, associada ao comportamento de luta ou fuga (BANDLER; SHIPLEY, 1994; CARRIVE, 2000), a estimulação da PAG ventrolateral reduz a pressão arterial e a frequência cardíaca e resulta em comportamento de imobilidade (BANDLER; SHIPLEY, 1994; BANDLER et. al., 2000; CARRIVE, 2000; MENEZES et. al., 2009), sugerindo papéis opostos da PAG ventrolateral e dorsolateral nas respostas autônomas e comportamentais.

Os nossos resultados mostraram que não existe distinção entre o número de neurônios contados na porção dorsolateral ou ventrolateral da PAG que se projetam para a região do RTN. Além disso, com os nossos resultados, podemos observar também que a projeção entre a SN e a PAG envolve neurotransmissores excitatórios e inibitórios de forma semelhante. A existência de projeções diretas entre SNc -> PAG e PAG ->RTN foi comprovada por meio da injeção tanto de traçadores retrógrado quanto anterógrado.

A injeção do traçador anterógrado na $\mathrm{SN}$ mostrou a presença de varicosidades na região da PAG composta por neurotransmissores excitatórios e inibitórios. A injeção do traçador retrógrado FG na PAG nos revelou marcação de corpo celular na SNc e estes neurônios marcados com FG se sobrepõem aos neurônios dopaminérgicos da SNc, mostrando que provavelmente os neurônios catecolaminérgicos da SNc que são degenerados na DP enviam, em sua grande maioria, projeções para a PAG. A injeção de BDA na PAG revelou a presença de varicosidades na região do RTN e a existência dessa via direta foi comprovada pela injeção de FG no RTN, que evidenciou a presença de corpos celulares na PAG marcados com FG. Estes resultados nos dão indícios de que uma das formas da SN se comunicar com o RTN é via PAG. Trabalhos anteriores da literatura já descreveram que a dopamina estimula a neurogênese e a sua ausência pode impedir a proliferação de células precursoras neurais (Freundlieb et al., 2006; Höglinger et al., 2004). Portanto, a falta dessa comunicação pode explicar o motivo pelo qual se observa alterações respiratórias basais e induzidas por hipercapnia no modelo experimental da DP induzido por 6-OHDA (Tuppy et al., 2015). 


\subsection{RTN e a respiração}

O RTN constitui um grupo de neurônios localizados no extremo rostral da coluna respiratória ventral. Ele foi descrito primeiramente pelo laboratório do Dr. Feldman e por seus colaboradores (CONNELLY et. al., 1989). Consiste numa população de neurônios localizados embaixo da porção caudal do núcleo motor facial e muito próximo da superfície ventral do bulbo (CONELLY et. al., 1989). Os neurônios do RTN podem ser, atualmente, identificados histologicamente devido à combinação de marcadores imunoistoquímicos para o gene PHOX2B e glutamatérgicos (VGLUT2) e a ausência de marcadores catecolaminérgicos (TH) e colinérgicos (ChAT) (KANG et. al., 2007; STORNETTA et. al., 2006; TAKAKURA et. al., 2008).

Trabalhos anteriores mostraram que esses neurônios estão envolvidos na regulação dos níveis de $\mathrm{CO}_{2} / \mathrm{H}^{+}$, influenciando os centros respiratórios na tentativa de regular a homeostase respiratória (FELDMAN et. al., 2003; GUYENET \& BAYLISS, 2015; NATTIE et. al., 2002; SATO et. al., 1992; PUTNAN et. al., 2004; TAKAKURA et. al., 2006; 2008).

Apesar de existirem evidências de que esses neurônios sejam responsáveis pelo controle do movimento inspiratório (DOBBINS; FELDMAN, 1994), estudos recentes têm sugerido que a região do RTN seja responsável também pela geração da atividade expiratória (JANCZEWSKI; FELDMAN, 2006a, 2006b; ABDALA et. al., 2009; HUCKSTEPP et al., 2015; SILVA et al., 2016).

Em estudo prévio do nosso laboratório, observamos uma intensa redução do número de neurônios Phox2b do RTN no modelo de DP induzido pela injeção de 6-OHDA no estriado. Essa redução no número de neurônios pode estar associada à deficiência respiratória observada nesses animais e em pacientes que tenham a DP (TUPPY et al., 2015). Assim, buscamos esclarecer o motivo da redução de neurônios nessa região do RTN. A primeira possibilidade testada foi objetivo de estudo da presente tese: evidências de projeções entre SN e RTN. Nos resultados demonstrados no presente estudo, não observamos projeções diretas entre essas duas regiões. Entretanto, ao analisarmos os dados, observamos dados que nos possibilitou concluir que a projeção entre a SN e o 
RTN ocorre de forma indireta, ou seja, via neurônios da PAG, região também envolvida na respiração.

\subsection{PAG e o quimiorreflexo}

Como descrito anteriormente, indivíduos que apresentam desordens de pânico possuem respostas ventilatórias à hipercapnia maiores do que indivíduos normais (NARDli et. al., 2009). Estudos têm mostrado a participação da PAG nessas respostas comportamentais relacionadas a pânico, pois quando ela é estimulada, observam-se respostas semelhantes à de desordens do pânico como taquicardia, aumento da pressão arterial e aumento na respiração (JENCK et al., 1995; SCHENBERG et al., 2001; SCHUTZ et al., 1985). A inibição da PAG pela administração de ácido ibotênico leva a uma redução nas respostas ventilatórias induzida por hipercapnia, mas não por hipóxia em animais acordados (LOPES et al, 2012; Lopes et al,2014). Estes dados da literatura nos mostram um envolvimento da PAG nas respostas respiratórias induzidas pela ativação do quimiorreflexo central. Além disso, Rosin e colaboradores e os dados do presente estudo mostraram evidências de projeções de neurônios da PAG ativados por $\mathrm{CO}_{2}$ para a região do RTN, importante região envolvida no quimiorreflexo central. Esses dados sugerem uma participação da PAG nas respostas à hipercapnia geradas em situações de pânico. Nos nossos dados eletrofisiológicos observamos inibição da amplitude de atividade do Genioglosso e do abdominal frente a estímulos de hipercapnia após a inibição da PAG. Podemos observar, que essas respostas são mais brandas do que as observadas em em animais acordados após lesão da PAG (LOPES et al, 2012). Entretanto, temos que levar em consideração a técnica utilizada, em que os efeitos dos anestésicos discutidos anteriormente poderiam influenciar nas respostas, acrescentando a isso o importante papel da PAG no animal acordado relacionado a respostas comportamentais. Além disso, não podemos descartar o fato da hipercapnia ativar também diretamente os neurônios do RTN e estes serem os responsáveis pelas respostas respiratórias. Assim, num animal controle (modelo experimental utilizado nos experimentos eletrofisiológicos), durante a hipercapnia, as respostas respiratórias não estavam muito alteradas após a inibição dos neurônios da PAG porque os neurônios do RTN estariam sendo ativados diretamente; porém, ao realizarmos os experimentos 
eletrofisiológicos no modelo animal da DP, em que temos redução do número de neurônios da PAG e do RTN, foi observada a redução das respostas respiratórias tanto basais quanto induzidas por hipercapnia, o que reforça e sustenta a hipótese de que a via entre SNc e RTN por meio da PAG seja uma via importante na quimiorrecepção central e que a neurodegeneração desta via pode participar diretamente da redução das respostas respiratórias observadas no modelo animal da DP.

\subsection{DP e a respiração}

A AOS está presente em pacientes portadores da DP. Ela causa repetidas situações de hipóxia, esforço respiratório e hipercapnia (DEMPSEY et al., 2010). Dessa forma, ela ativa diversos mecanismos aferentes, incluindo os quimiorreceptores centrais, como o RTN. Durante uma situação de AOS, ocorre a ativação dos neurônios do RTN que por sua vez ativam os neurônios da VRC, mobilizando a atividade respiratória. No modelo da DP induzido pela injeção de 6-OHDA no $\mathrm{CPu}$, está reduzido o número de neurônios quimiossensíveis do RTN. Assim, podemos especular que nessa situação, o reflexo de aumento da respiração durante a AOS estará provavelmente prejudicado, o que poderia levar a importantes deficiências respiratórias.

Outra possibilidade é o fato de a redução no número de neurônios do RTN estar associada ao rompimento da barreira hematoencefálica ou da redução do número de células gliais nessa região. Entretanto, essa hipótese ainda está em fase de estudo no nosso laboratório. Estes são estudos iniciais e a existência de projeções da SN para o RTN, mesmo que de forma indireta, também auxilia a justificar a redução no número de neurônios do RTN. Nos presentes resultados, bem como em resultados obtidos anteriormente, pudemos observar que no modelo de DP induzido pela injeção de 6-OHDA no CPu existe uma redução do número de neurônios da SNc, PAG e RTN (presentes resultados e Tuppy et al., 2015) além da redução das projeções da PAG para o RTN que são ativadas por hipercapnia.

É descrito na literatura também a dificuldade de comunicação oral em 
pacientes portadores da DP, em que os indivíduos se apresentam afônicos, com disartria (ACKERMANN et al, 1991). A comunicação oral requer também a mudança no padrão respiratório, estudos comportamentais demonstraram em primatas não humanos que sofreram lesões experimentais da SN uma deficiência no comportamento de vocalização (KIRZINGER et al, 1985). A PAG também tem um importante papel relacionado a alterações de vocalização e padrão respiratório associados a estímulos comportamentais (DUJARDIN et al, 2005, JQRGENS et al, 2002; SUBRAMANIAN et al, 2008; SUBRAMANIAN et al, 2013). No nosso presente estudo, evidenciamos uma via entre SNc e PAG e vimos ainda que estas regiões apresentam-se degeneradas no modelo animal da DP por 6-OHDA podendo esta via estar relacionada também às alterações de comunicação oral observadas na DP devido a uma deficiência na mudança de padrão respiratório realizada pela PAG frente a estímulos comportamentais.

\subsection{Limitações técnicas}

Os traçadores neuroanatômicos modernos são baseados no fluxo axonal, um mecanismo de transporte fisiológico inerente em neurônios que foi primeiro descrito em 1948 por Weiss e Hiscoe (WEISS; HISCOE, 1948). Dependendo da direção do transporte, os traçadores são divididos em dois principais grupos: anterógrados e retrógrados. Após a injeção no SNC, o traçador retrógrado é captado pelos terminais axônicos, incorporado em vesículas de transporte e, então, transportado de volta para o corpo celular do neurônio. Dessa forma, como resultado da injeção de um traçador retrógrado em uma determinada região, os corpos celulares dos neurônios que se projetam para essa região se tornam marcados. Já os traçadores anterógrados, em contraste, são captados pelo corpo celular ou dendritos, e são transportados do corpo celular para axônio, onde eles finalmente podem ser detectados em botões terminais.

As dextranas aminas são ferramentas versáteis e sensíveis para a investigação anterógrada e retrógrada de conexões neurais. Devido a sua tolerância a diversas substâncias fixadoras, elas são ideais para vários estudos de fluorescência (REINER et. al., 2000). Elas podem ser injetadas iontoforeticamente ou por pressão e, dependendo do tipo da dextrana amina 
utilizada e o tipo de método de detecção, podem ser visualizadas por microscopia de luz ou de fluorescência. A dextrana amina biotinilada (BDA) de elevado peso molecular, utilizada no presente estudo, é preferencialmente utilizada para marcação de axônios e terminais, embora também possa atuar como um marcador retrógrado (FRITZSCH, 1993).

O Fluorogold foi primeiramente introduzido como um traçador retrógrado por Schmued e Fallon em 1986. Atualmente, ele é muito utilizado para o estudo de conexões neuronais não somente devido à sua excelente e estável fluorescência, mas também devido à simplicidade de sua aplicação, seu exclusivo transporte retrógrado, a falta de captação por fibras intactas ou danificadas que passam pelo sítio de injeção e o excelente preenchimento do corpo celular e dos dendritos principais. O fato de o Fluorogold não necessitar de processamento histológico para visualização, torna essa ferramenta ainda mais atrativa para o estudo de conexões retrógradas.

A descoberta de que a perda de neurônios dopaminérgicos da via nigroestriatal é a causa para o desenvolvimento da DP (CARLSSON, 1972) levou à criação de diversos modelos animais para estudar a perda desses neurônios $e$ as suas consequências. Existem diversos modelos que utilizam toxinas para $o$ estudo da DP: 6-OHDA, MPTP, rotenona e paraquat. A popularidade dessas toxinas reside na sua habilidade de mimetizar a perda de neurônios dopaminérgicos da via nigroestriatal, resultando em alguns dos sintomas motores apresentados pelos pacientes portadores da DP (FEGER et al., 2002; JENNER, 2008). Entretanto, o uso desses modelos para mimetizar os sintomas não motores da DP é limitado pelo fato de muitos desses sintomas não serem dependentes de dopamina. Dentre essas diversas toxinas, optamos por utilizar a 6-OHDA pela facilidade de manejo, segurança e por trabalhos anteriores mostrarem a presença de alterações não-motoras nesse modelo (MCDOWELL \& CHESSELET, 2012). As outras três toxinas são extremamente tóxicas e atravessam a barreira hematoencefálica. Assim, qualquer contato do experimentador poderia levar a sérios riscos para sua saúde. A 6-OHDA não atravessa a barreira hematoencefálica (Blandini et al., 2008) e por isso é mais segura por apresentar efeitos apenas se administrada diretamente no local desejado. 
Nos experimentos eletrofisiológicos, as injeções de fármacos no SNC são comumente utilizadas e nos proporcionam, numa abordagem experimental, investigar os possíveis mediadores, seus mecanismos e como determinadas áreas encefálicas atuam no controle respiratório. Entretanto, apesar de termos administrado as microesferas de látex fluorescentes junto com os fármacos e observarmos um espalhamento das microesferas de aproximadamente $200 \mu \mathrm{m}$ a partir do centro da injeção deste marcador, não podemos afirmar com certeza que o fármaco tenha se espalhado da mesma forma, pois são substâncias que possuem diferentes solubilidades e peso molecular. Outro fator limitante dos nossos resultados é a realização dos experimentos utilizando animais anestesiados. Já é bem descrito na literatura que anestésicos de uma forma geral deprimem o SNC e, dessa forma, poderiam afetar diretamente as respostas induzidas pelo fármaco que estamos utilizando. Entretanto, os anestésicos utilizados no presente projeto são comumente utilizados em experimentos que avaliam os parâmetros cardiorrespiratórios e estudos da literatura já observaram respostas semelhantes quando compararam animais anestesiados ou livres de anestesia (DAMASCENO et al., 2014a; c; HAWRYLUK et al., 2012; MULKLEY et al., 2015; TAKAKURA et al., 2006a; TAKAKURA et al., 2008b TAKAKURA et al., 2014;). Apesar da região inibida neste experimento, a PAG, ter um importante papel nas respostas cardiorrespiratórias observadas em animais acordados (BANDLER et al, 2001; BANDLER et al., 2000; DAMPNEY et al., 2013), optamos por realizar os experimentos em animais anestesiados pois esta condição experimental propicia uma análise mais detalhada das variáveis respiratórias, como atividade inspiratória, expiratória passiva e expiratória ativa. 


\subsection{CONCLUSÃO}

O diagnóstico da DP é baseado em manifestações de deficiências motoras que estão associadas primariamente a, pelo menos, $70 \%$ de perda de neurônios dopaminérgicos da porção compacta da SN (FEARNLEY; LEES, 1991). Assim, o objetivo da terapia dessa patologia é a correção desses sintomas motores com a reposição da dopamina ausente (RAIPUT, 2001; BRONSTEIN et al., 2011; FACTOR, 2008). Entretanto, existem diversos sintomas debilitantes nessa patologia que não respondem ao tratamento de reposição de dopamina, como os sintomas não-motores dessa patologia (WOLTERS, 2009). Dentre esses sintomas, podemos citar deficiências cognitivas, disfunção autônoma e distúrbios do sono causados por problemas respiratórios como a AOS (BASSETTI, 2011; CHAUDHURI et al., 2011). Dessa forma, fica clara a existência de sintomas da DP que não respondem ao tratamento com reposição de dopamina, sendo de fundamental importância a procura de disfunções e degenerações extranigrais que estejam associadas à neurodegeneração nigroestriatal. O presente estudo associado a resultados prévios do laboratório sugerem que a degeneração dos neurônios dopaminérgicos da SNc, induzida pela injeção bilateral da toxina 6-OHDA no estriado, leva ao comprometimento da ventilação em condições de repouso e hipercapnia. Esses efeitos podem ter ocorrido devido a uma alteração na citoarquitetura neuronal de regiões envolvidas no controle da atividade respiratória, como, por exemplo, os neurônios quimiossensíveis do RTN. Uma das causas para essa alteração na citoarquitetura neuronal pode ser explicada pela existência de uma projeção existente entre a SN e o RTN que envolve a PAG. Concluímos ainda que a via entre PAG e RTN que é ativada pelo quimiorreflexo central apresenta-se degenerada no modelo animal induzido pela injeção de 6-OHDA. Isso sugere que o papel desta via nas respostas ventilatórias induzidas por hipercapnia possa estar prejudicado no modelo da DP, o que justificaria nesses animais uma menor resposta ventilatória à hipercapnia. 
A figura 19 representa o esquema que propomos com os dados obtidos na presente tese. Ele define uma via entre SNc e RTN por meio da PAG. Após a indução do modelo da DP induzido pela injeção de 6-OHDA no CPu, é possível observar a redução de neurônios em todas as regiões envolvidas, contribuindo para a deficiência respiratória observada neste modelo. 


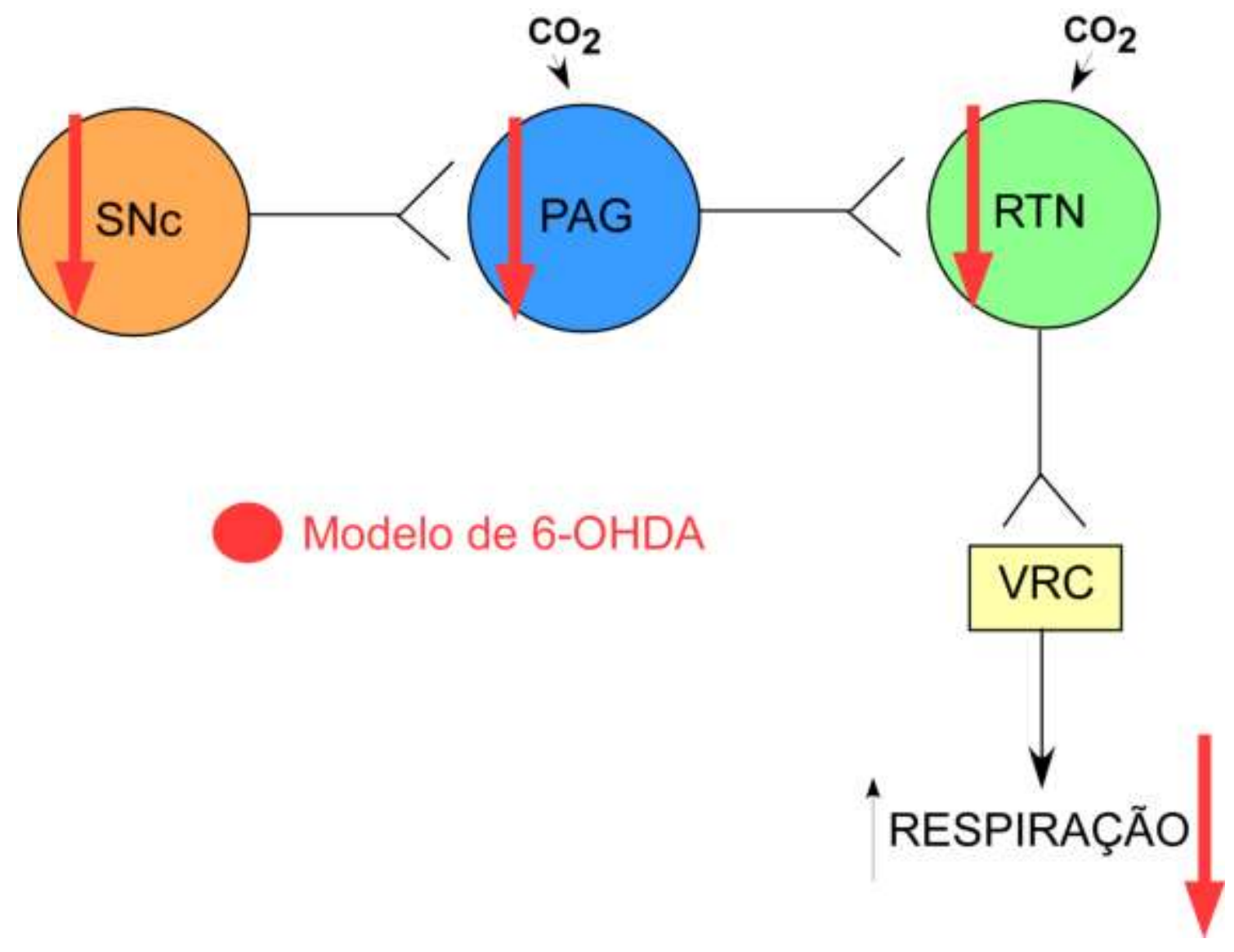

Figura 19 - Esquema representativo de projeções entre SN e RTN por meio da PAG e alterações na citoarquitetura neuronal desta via no modelo animal da DP induzido pela injeção de 6-OHDA

O RTN (verde) é um importante grupo neuronal que contém os quimiorreceptores responsáveis por detectar aumento nos níveis de $\mathrm{CO}_{2}$ ou queda de $\mathrm{pH}$, levando a um aumento nas respostas respiratórias por meio da ativação de grupos neuronais da VRC (amarelo). Nosso esquema propõe a existência de uma via indireta entre SNc (laranja) e RTN por meio da PAG (azul). Essa via é importante para as alterações respiratórias observadas na DP, visto que o no modelo experimental utilizado na presente tese (6OHDA injetada bilateralmente no $\mathrm{CPu}$ ), essa via apresenta perda neuronal significativa em todas as regiões envolvidas (setas vermelhas), levando também à redução nas respostas respiratórias basais e promovidas pela ativação do quimiorreflexo central tanto em animais acordados quanto anestesiados. 


\section{REFERÊNCIAS*}

1. ABDALA, A. P. et al. Structural and functional architecture of respiratory networks in the mammalian brainstem. )Philos Trans $\mathbf{R}$ Soc Lond B Biol Sci.; v.364, p.2577-2587, 1999. Review

2. ABBOTT, N. J. et al. Astrocyte-endothelial interactions at the bloodbrain barrier. In. Nat. Rev. Neurosci; England. p. 41-53. 2006.

3. AGID Y. et al. Parkinson's disease: pathophysiology. LancetJun; V.337, p.1321-1324,1991. Review.

4. BEHBEHANI et al.; Functional characteristics of the midbrain periaqueductal gray.;Prog Neurobiol; 46.p.575-605,1995. Review.

5. BEITZ et al.; Relationship of glutamate and aspartate to the periaqueductal gray-raphe magnus projection: analysis using immunocytochemistry and microdialysis .J Histochem Cytochem; p.233-236, 1990.

6. BIANCHI et al.; Central control of breathing in mammals: neuronal circuitry, membrane properties, and neurotransmitters. Physiol; p.145, 1995. Review

7. BASSAL et al.; Inspiratory onset or termination induced by electrical stimulation of the brain. Respir Physiol; p. 23-40. 1982.

8. BASSETTI et al.; Nonmotor disturbances in Parkinson's disease. Neurodegener Dis; p.95-108, 2011.Review.

9. BLANDER et al.; A conditioned stimulus decreases extracellular dopamine in the nucleus accumbens after the development of a learned taste aversion. Brain Res; p.308-310, 1991

10. BLANDER et al.; Columnar organization in the midbrain periaqueductal gray: modules for emotional expression? Trends Neurosci; p.379389, 1994

11. BLANDER et al.; Columnar organization in the midbrain periaqueductal gray and the integration of emotional expression.; Prog Brain Res;v.107, p. 285-300. 1996 Review..

12. BLANDER et al.; Central circuits mediating patterned autonomic activity during active vs. passive emotional coping; Brain Res; v.53, p. 95-104, 2000.

13. BLANDINI et al.; The 6-hydroxydopamine model: News from the past. Parkinsonism and Related Disorders; v.14: p.124-S129, 2008.

14. BLUM et al.; Molecular pathways involved in the neurotoxicity of 6OHDA, dopamine and MPTP: contribution to the apoptotic theory in Parkinson's disease. Prog Neurobiol; p.135-72.2001. Review.

15. BROSENITSCH et al.; Expression of Phox2 transcription factors and induction of the dopaminergic phenotype in primary sensory neurons.

Mol Cell Neurosci; p.447-57, 2002. 
16. BRONSTEIS et al.; Deep brain stimulation for Parkinson disease: an expert consensus and review of key issues.;Arch Neurol; p.210.260,2011. Review.

17. CANTERAS et al.; Projections of the ventral premammillary nucleus.; J Comp Neurol; p.195-212. 1994

18. CALNE et al.; Isidiophatic parkinsonism the consequence of na event or a process? Neurology; Boston, p. 5-10. 1994

19. CARLSSON et al.; Evidence for a receptor-mediated feedback control of striatal tyrosine hydroxylase activity. J Pharm Pharmacol; p.7447. 1972.

20. CARRIVE et al.; Viscerotopic organization of neurons subserving hypotensive reactions within the midbrain periaqueductal grey: a correlative functional and anatomical study. Brain Res; p.206-15. 1972

21. CARRIVE et al.; Lidocaine blockade of amygdala output in fearconditioned rats reduces Fos expression in the ventrolateral periaqueductal gray. Neuroscience; p.1071-80.2000

22. CHAUDHURI et al.; Parkinson's disease: the non-motor issues.;Parkinsonism Relat Disord.; p. 717-23. 2011. Review.

23. CONNELLY et al.; Are there serotonergic projections from raphe and retrotrapezoid nuclei to the ventral respiratory group in the rat? NeurosciLett.; p. 34-40.1989

24. CUMMINGS et al.; Depression and Parkinson's disease: a review. Am J Psychiatry.;p. 443-54. 1992 Review.

25. DANEMAN et al.; The blood-brain barrier in health and disease. Ann Neurol.; p. 648-672. 2012

26. DAMPNEY et al.; Role of dorsolateral periaqueductal grey in the coordinated regulation of cardiovascular and respiratory function, Neurosci. Basic Clin.; p. 17-25. 2013

27. DEL-BEN et al.; Panic disorder: is the PAG involved?.;Neural Plast.; p.108-135. Review.

28. DEMPSEY et al.; Pathophysiology of sleep apnea; Physiol Rev.; p. 47-112. 2010.

29. DEUMENS et al.; Modeling Parkinson's disease in rats: an evaluation of 6-OHDA lesions of the nigrostriatal pathway.Exp Neurol.; p.30317.2002. Review.

30. DEXTER et al.; Increased nigral iron content and alterations in other metal ions occuring in brain in Parkinson's disease. J Neurochem.; p. 1830-36. 1989.

31. EZURE et al.; Synaptic connections between medullary respiratory neurons and considerations on the genesis of respiratory rhythm. ProgNeurobiol.;p.429-450.1990.

32. EZURE et al.; Brainstem and spinal projections of augmenting expiratory neurons in the rat. Neurosci Res.; p. 41-51.2003 
33. FEARNLEY et al.; Ageing and Parkinson's disease: substantia nigra regional selectivity. Brain.; p. 2283-301. 1991.

34. FEARNLEY et al.; Ageing and Parkinson's disease: substantia nigra regional selectivity. Brain.;p.2283-301. 1991.

35. FEGER et al.; Consequences of dopaminergic denervation on the metabolic activity of the cortical neurons projecting to the subthalamic nucleus in the rat.; $\mathbf{J}$ Neurosci.; p. 8762-70. 2002

36. FELDMAN et al.; Looking for inspiration: new perspectives on respiratory rhythm. Nat Rev Neurosci.; p.232-242. 2006.

37. FREUNDLIEB et al.; Dopaminergic substantia nigra neurons project topographically organized to the subventricular zone and stimulate precursor cell proliferation in aged primates.; J Neurosci.; p.2321-5. 2006.

38. FRITZSCH et al.; Fiber pathways and positional changes in efferent perikarya of 2.5- to 7-day chick embryos as revealed with Dil and dextran amines.;J Neurobiol.; p.1481-99. 1993.

39. GILMAN et al.; Obstructive leep apnea is related to a thalamic cholinergic deficit in M38SA. Neurology.; p.35-39.2003.

40. GORMAN et al.; Heart rate variability in depressive and anxiety disorders.;Am Heart J.; p.77-83. 2000. Review.

41. GUYENET et al.; Neural Control of Breathing and CO2 Homeostasis. Neuron.; p. 946-61. 2015. Review.

42. HIRSCH et al.; Iron and aluminium increase in the substantia nigra of patients with Parkinson's disease: a X-ray microanalysis. J Neurochem.; p.446-51. 1991.

43. HÖGLINGER et al.; Dopamine depletion impairs precursor cell proliferation in Parkinson disease.;Nat Neurosci.; p. 726-35. 2004.

44. HÖGLINGER et al.; A new dopaminergic nigro-olfactory projection. Acta Neuropatho.; p.333-48. 2015

45. HUCKSTEPP et al.; Role of parafacial nuclei in control of breathing in adult rats. J Neurosci..; p.1052-67. 2015.

46. HUGHES et al.; A clinicopathologic study of 100 cases of Parkinson's disease. Arch Neurol.;p. 140-8. 2003.

47. JANCZEWSKI et al.; Distinct rhythm generators for inspiration and expiration in the juvenile rat. J Physiol.; p.407-20, 2006a

48. JANCZEWSKI et al.; Novel data supporting the two respiratory rhythm oscillator hypothesis. Focus on "respiration-related rhythmic activity in the rostral medulla of newborn rats. J. Neurophysiol.; p.1-2, 2006b

49. JELLINGER et al.; Chemical evidence for 6-hydroxydopamine to be an endogenous toxic factor in the pathogenesis of Parkinson's disease.; $\mathbf{J}$ Neural Transm Suppl.; p.297-314. 1995.

50. JENNER et al.; Functional models of Parkinson's disease: a valuable tool in the development of novel therapies.;Ann Neurol. p.16-29. 2008.Review. 
51. JOEL The organization of the basal ganglia-thalamocortical circuits: open interconnected rather than closed segregated.;Neuroscience.; p.363-79.1994. Review.

52. KANG et al.; Synaptic connectivity in engineered neuronal networks. Methods Mol Biol.: p.165-73.2007.

53. KONDO et al.; Hemiparkinsonian rat models: different sensitivity of dopaminergic neurotoxins. Int. Congr. Ser.; p. 281-285.2004.

54. KORTEKAAS et al.; Blood-brain barrier dysfunction in parkinsonian midbrain in vivo.Ann Neurol.; p.176-179. 2005.

55. KLEIN et al.; False suffocation alarms, spontaneous panics, and related conditions. An integrative hypothesis. Arch Gen Psychiatry.; p.306-17. 1993.Review.

56. LABANDEIRA- GARCIA et al.; Time course of striatal changes induced by 6-hydroxydopamine lesion of the nigrostriatal pathway, as studied by combined evaluation of rotational behaviour and striatal Fos expression. Exp Brain Res.; p.69-84.1996.

57. LOPES et al.; Participation of the dorsal periaqueductal grey matter in the hypoxic ventilatory response in unanaesthetized rats. Acta Physiol.; p.528-37. 2014.

58. LOVICK et al.; Panic disorder: a malfunction of multiple transmitter control systems with the midbrain periaqueductal gray matter. Neuroscientist.; 2000

59. MAGOUN et al.; Associated Facial, Vocal and Respiratory Components of Emotional Expression: An Experimental Study. J Neurol Psychopathol.; p.241-55. 1937

60. MCDOWELL et al.; Animal models of the non-motor features of Parkinson's disease.;Neurobiol .; p.597-606. 2012 Review.

61. MENEZES et al.; Does levodopa improve swallowing dysfunction in Parkinson's disease patients?.;J Clin Pharm Ther. p.673-6.200.9

62. MENKES et al.; Subtraction of cardiopneumatic pulsations from body plethysmograph records. J Appl Physiol.1969

63. MEHANNA et al.; Respiratory problems in neurologic movement disorders. Parkinsonism RelatDisord.; p.628-38. 2010

64. MINK et al.; Fundamental Neuroscience. San Diego: Academic Press.;1999.

65. MOREIRA et al.; Central chemoreceptors and sympathetic vasomotor outflow. J. Physiol.; p.369-386, 2006.

66. NAKAMURA et al.; Central efferent pathways mediating skin coolingevoked sympathetic thermogenesis in brown adipose tissue.;Am $\mathbf{J}$ Physiol Regul Integr Comp Physiol.; p.127-36. 2007.

67. NASHOLD et al.; Sensations evoked by stimulation in the midbrain of man.; J Neurosurg.; p.14-24. 1969.

68. NARDI et al.; Panic disorder and control of breathing.;Respir Physiol Neurobiol.; p.133-43. 2009. 
69. NATTIE et al.; CO2 dialysis in one chemoreceptor site, the RTN: stimulus intensity and sensitivity in the awake rat.;Respir Physiol Neurobiol.; p.11-22. 2002

70. OBESO et al.; Pathophysiology of the basal ganglia in Parkinson's disease. Trends Neurosci. p. 8-19. 2000. Review.

71. PATTYN et al.; Expression and interactions of the two closely related homeobox genes Phox2a and Phox2b during neurogenesis. Development.; p.4065-75. 1997

72. PARKINSON.;J. An essay on the shaking palsy. $\mathbf{J}$ Neuropsychiatry.;1817.

73. PAXINOS et al.; The rat brain in stereotaxic coordinates. Academic Press.; p.17-23.1998

74. PORTER et al.; Effect of 6-hydroxydopamine and some other compounds on the concentration of norepinephrine in the hearts of mice. J PharmacolExpTher.; p.308-316. 1963.

75. PORTER et al.; The relationship between radioactivity and norepinephrine concentrations in the brains and hearts of mice following administration of labeled methyldopa or 6-hydroxydopamine. J PharmacolExpTher.; p.17-22. 1965.

76. PRENSA et al.; The nigrostriatal pathway in the rat: A single-axon study of the relationship between dorsal and ventral tier nigral neurons and the striosome/matrix striatal compartments. J Neurosci.; p.724760.2001.

77. PUTNAM et al.; Oxidative stress decreases $\mathrm{pHi}$ and $\mathrm{Na}(+) / \mathrm{H}(+)$ exchange and increases excitability of solitary complex neurons from rat brain slices.; Am J Physiol Cell Physiol.; p.940-51. 2004.

78. RAJPUT et al.; Levodopa prolongs life expectancy and is non-toxic to substantia nigra.; Parkinsonism Relat Disord.; 95-100. 2001.

79. REINER et al.; Pathway tracing using biotinylated dextran amines. $\mathbf{J}$ Neurosci Methods.; p.23-37. 2000. Review.

80. ROSIN et al.; Afferent and efferent connections of the rat retrotrapezoid nucleus. J Comp Neurol. p.64-89. 2006.

81. SATO et al.; Stimulatory effects of quinpirole hydrochloride, D2dopamine receptor agonist, at low concentrations on prolactin release in female rats in vitro. Life Sci. p.727-32. 1992.

82. SAWCHENKO et al.; Hypothalamic integration: organization of the paraventricular and supraoptic nuclei. Annu Rev Neurosci.; p.269324. 1983.

83. SCHMUED et al.; Fluoro-Gold: a new fluorescent retrograde axonal tracer with numerous unique properties. Brain Res.; p.147-54. 1986.

84. SCHIMITEL et al.; Evidence of a suffocation alarm system within the periaqueductal gray matter of the rat.;Neuroscience.; p.59-73 2011.

85. SCHULZ JB ;FALKENBURGUER .;Neuronal pathology in Parkinson's disease. Cell Tissue Res.; p. 135-147. 2004. 
86. SCHREIHOFER et al.; Identification of $\mathrm{C} 1$ presympathetic neurons in rat rostral ventrolateral medulla by juxtacellular labeling in vivo. $\mathbf{J}$ Comp Neurol. p.524-36. 1997.

87. SEWARDS et al.; Fear and power-dominance drive motivation: neural representations and pathways mediating sensory and mnemonic inputs, and outputs to premotor structures. Neurosci Biobehav Rev.; p.553-79.2002. Review.

88. SENOH et al.; Chemical, enzymatic, and metabolic studies on the mechanism of oxidation of dopamine. J Am Chem Soc. p.6236-6240. 1959.

89. SILVA J. N. et al.; Anatomical evidence of the participation of nucleus retrotrapezoid in the expiration active; Respir Physiol Neurobiol. 2016

90. SMITH J.C. et al.; Spatial and functional architecture of the mammalian brain stem respiratory network: a hierarchy of three oscillatory mechanisms. J Neurophysiol.; p.3370-3387. 2007.

91. SMITH, D.V. et al.; Excitatory and inhibitory modulation of taste responses in the hamster brainstem. Ann. N. Y. Acad. Sci., v. 855, p. 450-456, 1998.

92. SMITH, J.C. et al.; Brainstem respiratory networks: building blocks and microcircuits. Trends Neurosci.,v. 36, n. 3, p. 152-162, 2013.

93. SMITH, J.C. et al. Structural and functional architecture of respiratory networks in the mammalian brainstem. Philos Trans. R. Soc. Lond. B Biol. Sci., v. 364, n. 1529, p. 2577-2587, 2009.

94. SPILLANTINI et al.; Filamentous alpha-synuclein inclusions link multiple system atrophy with Parkinson's disease and dementia with Lewybodies. NeurosciLett.; p.205-8.2008.

95. STORNETTA et al.; Expression of Phox2b by brainstem neurons involved in chemosensory integration in the adult rat. J Neurosci.; p.10305-14. 2006.

96. SUBRAMANIAN et al.; Identification of different types of respiratory neurones in the dorsal brainstem nucleus tractus solitarius of the rat. Brain Res.; p.119-32. 2007.

97. SUBRAMANIAN et al.; The midbrain periaqueductal gray control of respiration. J Neurosci.; v.47 p.12274-83. 2008.

98. SUBRAMANIAN et al.; The nucleus retroambiguus control of respiration.;J Neurosci.; p.3824-32. 2009.

99. SUBRAMANIAN et al.; Stimulation of the midbrain periaqueductal gray modulates preinspiratory neurons in the ventrolateral medulla in the rat in vivo. J Neurophysiol.; p.3083-98. 2013

100. SUBRAMANIAN HH et al.; Motor organization of positive and negative emotional vocalization in the cat midbrain periaqueductal gray. $\mathbf{J}$ Comp Neurol.; p. 138-143.2015.

101. SEWARDS et al.; Fear and power-dominance drive motivation: neural 
representations and pathways mediating sensory and mnemonic inputs, and outputs to premotor structures. Neurosci Biobehav Rev.; p.553-79. 2002. Review.

102. SENOH et al.; Chemical, enzymatic, and metabolic studies on the mechanism of oxidation of dopamine. J Am Chem Soc. v.81 p.62366240. 1959

103. SMITH J.C. et al.; Spatial and functional architecture of the mammalian brain stem respiratory network: a hierarchy of three oscillatory mechanisms. J Neurophysiol.; v.98, p.3370-3387.2007.

104. SPILLANTINI et al.; Filamentous alpha-synuclein inclusions link multiple system atrophy with Parkinson's disease and dementia with Lewybodies. NeurosciLett.; v.251, p.205-8.

105. STORNETTA et al.; Expression of Phox $2 \mathrm{~b}$ by brainstem neurons involved in chemosensory integration in the adult rat. $\mathbf{J}$ Neurosci.; v.26, p.10305-14. 2006.

106. TAKAKURA A. C. et al.; Peripheral chemoreceptor inputs to retrotrapezoid nucleus (RTN) CO2-sensitive neurons in rats. J Physiol., v.572, p.503-523. 2006.

107. TAKAKURA A. C. et al.; Selective lesion of retrotrapezoid Phox2bexpressing neurons raises the apnoeic threshold in rats. J Physiol.; p.2975- 2991, 2008.

108. TANAKA et al.; Molecular basis of 6-hydroxydopamine-induced caspase activations due to increases in oxidative stress in the mouse striatum. Neurosci Lett.; v.410 p.85-9. 2006.

109. TILLERSON et al.; Forced nonuse in unilateral parkinsonian rats exacerbates injury. J Neurosci.v.22 p.6790-9. 2002.

110. TIVERON et al.; Molecular interaction between projection neuron precursors and invading interneurons via stromal-derived factor 1 (CXCL12)/CXCR4 signaling in the cortical subventricular zone/intermediate zone. J Neurosci.; v.26, p.13273-8. 2006.

111. TUPPY et al.; Respiratory deficits in a rat model of Parkinson's disease. Neuroscience.; v.297,p.194-204. 2015

112. TRETIAKOFF et al.; Contribution à l'étude de I'anatomiepathologiquedulocusniger de Soemmeringavecquelquesdéductionsrealtives à lapathogénie de troublesdutônus musculaire et lamaladie de Parkinson. Thése de Médecine, Paris. 1919.

113. UNGERSTEDT et al.; 6-hydroxydopamine induced degeneration of central monoamine neurons. Eur. J. Pharmacol.; v.5; p.107-110. 1968.

114. WERMUTH et al.; Mortality in patients with Parkinson's disease. ActaNeurol Scand.; v.92, p.55-58. 1995.

115. WESTON $\mathrm{M}$ et al.; Fos expression by glutamatergic neurons of the solitary tract nucleus after phenylephrine-induced hypertension in rats. 
J Comp Neurol.; v. 460, p.525-41. 2003.

116. WOLTERS et al.; Non-motor extranigral signs and symptoms in Parkinson's disease.;Parkinsonism Relat Disord.; v.15, p.6-12. 2009. Review.

117. WONG et al.; The blood-brain barrier: an engineering perspective. Front Neuroeng.; 2013

118. WEISS P et al.; Experiments on the mechanism of nerve growth. $\mathbf{J}$ Exp Zool. p.;315-95. 1913.

119. ZHANG et al.; Respiratory responses elicited by rostral versus caudal dorsal periaqueductal gray stimulation in rats. Auton Neurosci.; v.134, p.45-54.2007. 